\title{
ipen
}

INSTITUTO DE PESQUISAS ENERGÉTICAS E NUCLEARES

AUTARQUIA ASSOCIADA À UNIVERSIDADE DE SÃO PAULO

\section{IDENTIFICAÇÃO DE ASSINATURAS DE URÂNIO EM AMOSTRAS DE ESFREGAÇOS (SWIPE SAMPLES) PARA VERIFICAÇÃO DE ATIVIDADES NUCLEARES PARA FINS DE SALVAGUARDAS NUCLEARES.}

Rafael Cardoso Baptistini Pestana

Dissertação apresentada como parte dos requisitos para obtenção do Grau de Mestre em Ciências na Área de Tecnologia Nuclear - Materiais.

Orientador:

Prof. Dr. Jorge Eduardo de Souza Sarkis 


\section{AGRADECIMENTOS}

Primeiramente agradeço a minha família, pelo amor incondicional, incentivo, apoio e compreensão durante todos esses anos. Meu pai Haroldo, minha mãe Mariléa e irmão Felipe obrigado por tudo. Amo vocês!

Avó Alzira, tia Regina, tia Ivanise, tia Márcia, tio Marison e tio Fernando agradeço imensamente por fazerem parte da minha vida. Todos contribuíram de alguma forma para realização deste trabalho.

Ao Dr. Jorge Eduardo de Souza Sarkis, pela orientação, apoio, desenvolvimento profissional, assim como pelas oportunidades geradas, fruto do trabalho árduo.

Agradeço também o Dr. João Cristiano Ulrich e o Msc. Marcos A. Hortellani do LCQ, pelos treinamentos, explicações, estudos e orientação proporcionados.

À Dra. Elita Urano de Carvalho Frajndlic do Centro do Combustível Nuclear CCN, pela colaboração direta com esse trabalho, cedendo seu tempo e o espaço para a coleta das amostras.

Ao Cláudio do CCN por gentilmente colaborar com as amostragens e orientações sobre proteção radiológica.

Ao Dr. José Henrique Buchmann pelas conversas e dicas que contribuíram para o desenvolvimento do trabalho.

Ao Dr. Olívio Pereira de Oliveira Junior do Centro Tecnológico da Marinha em São Paulo - CTMSP, pelos ensinamentos e discussões sobre metrologia, assim como a contribuição nas atribuições na defesa desse trabalho.

À Dra. Roseli Fernandes Gennari do Instituto de Física da Universidade de São Paulo pela contribuição nas atribuições na defesa desse trabalho. 
Ao Dr. Cassio Hamilton Abreu-Junior do Centro de Energia Nuclear na Agricultura - CENA pelo apoio e colaboração com as análises isotópicas de urânio.

Aos amigos de laboratório Cristina, Luciana, Marin, Gustavo, Isabella, Ernesto, Cíntia, Talita e Tânia pelo companheirismo, assim como os momentos tensos e descontraídos que passamos juntos durante o período.

Agradeço imensamente os amigos da vida. Os verdadeiros que, durante a caminhada, proporcionaram momentos inesquecíveis, risadas e alegrias. Sem a felicidade da vida pessoal o êxito profissional nunca será completo.

O auxílio financeiro foi fundamental para meu sustento ao longo desses anos em São Paulo, desse modo agradeço a Comissão de Energia Nuclear - CNEN pelo apoio.

Agradeço ainda ao Instituto de Pesquisas Energéticas e Nucleares - IPEN por promover minha capacitação profissional e viabilizar esse trabalho.

À todos que contribuíram direta ou indiretamente para a realização desse trabalho, os meus sinceros agradecimentos.

\section{MUITO OBRIGADO!}




\title{
IDENTIFICAÇÃO DE ASSINATURAS DE URÂNIO EM AMOSTRAS DE ESFREGAÇOS (SWIPE SAMPLES) PARA VERIFICAÇÃO DE ATIVIDADES NUCLEARES PARA FINS DE SALVAGUARDAS NUCLEARES
}

\author{
Rafael Cardoso Baptistini Pestana
}

\section{RESUMO}

O uso das amostragens ambientais para fins de salvaguardas vêm sendo aplicadas pela Agência Internacional de Energia Atômica - AIEA desde 1996 e estão sendo rotineiramente utilizadas como uma medida de fortalecimento complementar aos procedimentos tradicionais de salvaguardas de materiais nucleares. $\mathrm{O}$ intuito é verificar se os Estados signatários aos acordos de salvaguardas não estão divergindo suas atividades nucleares pacíficas para atividades nucleares não declaradas. O presente trabalho apresenta um novo protocolo de coleta e análise de esfregaços para identificação de assinaturas nucleares que possam relacionar-se com as atividades nucleares desenvolvidas na instalação inspecionada. Neste trabalho foi utilizada como estudo de caso uma planta real de reconversão de urânio do ciclo do combustível nuclear do IPEN. A estratégia analítica proposta utiliza diferentes técnicas, como medidor de radiação alfa, MEV-EDS e ICP-MS para identificar assinaturas do urânio aderido ao esfregaço. Na análise dos esfregaços, foi possível identificar partículas de $\mathrm{UO}_{2} \mathrm{~F}_{2}$ e $\mathrm{UF}_{4}$ através da comparação morfológica e análises semi-quantitativas utilizando a técnica de MEV-EDS. Nesse trabalho, utilizaramse métodos que como resultado tem-se a composição isotópica média da amostra, onde o enriquecimento (fração atômica molar) variou de $1,453 \pm 0,023 \%$ a $18,24 \pm 0,15 \%$ no isótopo ${ }^{235} \mathrm{U}$. Através das coletas realizadas externamente, uma forma não intrusiva de amostragem, foi possível à identificação de atividades de manuseio de material enriquecido com medidas de fração atômica molar de $1,453 \pm 0,023 \%$ a $6,331 \pm 0,055 \%$ no isótopo ${ }^{235} \mathrm{U}$, bem como uso de material reprocessado, através da identificação do isótopo ${ }^{236} \mathrm{U}$. As incertezas obtidas neste trabalho para a razão $n\left({ }^{235} U\right) / n\left({ }^{238} U\right)$ variaram de $0,40 \%$ a $1,68 \%$. 


\title{
IDENTIFICATION OF URANIUM SIGNATURES IN SWIPE SAMPLES ON VERIFICATION OF NUCLEAR ACTIVITIES FOR NUCLEAR SAFEGUARDS PURPOSES
}

\author{
Rafael Cardoso Baptistini Pestana
}

\begin{abstract}
The use of environmental samplings for safeguards purposes has been applied by the International Atomic Energy Agency-IAEA since 1996 and they are routinely used as a complementary measure to strengthen the traditional nuclear safeguards procedures. The aim is verify if the signatory states to the safeguards agreements are not diverging their peaceful nuclear activities to undeclared nuclear activities. This work describes a new protocol of collect and analysis of swipe samples in order to achieve identification of nuclear signatures, which may be related to the nuclear activities developed in the inspected facility. In this work, as a case of study, a real uranium reconversion plant of the nuclear fuel cycle of IPEN was used. The strategy proposed uses different analytical techniques, such as alpha radiation meter, SEM-EDX and ICP-QMS to identify signatures of the uranium adhered to the swipe samples. In the swipe samples analysis, it was possible to identify particles of $\mathrm{UO}_{2} \mathrm{~F}_{2}$ and $\mathrm{UF}_{4}$ through the morphological comparison and semiquantitative analysis performed by SEM-EDX technique. The methods used in this work bring the average isotopic composition of the sample as a result, in which the enrichment (molar atomic fraction) ranged from $1.453 \pm 0.023 \%$ to $18.24 \pm 0.15 \%$ in the ${ }^{235} \mathrm{U}$ isotope. Through of the external collections, a non-intrusive sampling, it was possible to identify handling activities of enriched material with molar atomic fraction of $1.453 \pm 0.023 \%$ to $6.331 \pm 0.055 \%$ in the ${ }^{235} \mathrm{U}$ isotope, as well as the use of reprocessed material by means of the ${ }^{236} \mathrm{U}$ isotope identification. The uncertainties obtained in this work to the $n\left({ }^{235} U\right) / n\left({ }^{238} U\right)$ ratio varied from $0.40 \%$ to $1.68 \%$.
\end{abstract}


SUMÁRIO

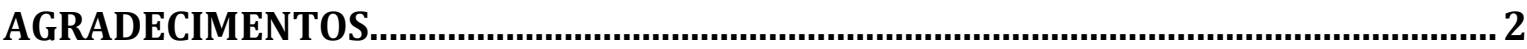

RESUMO

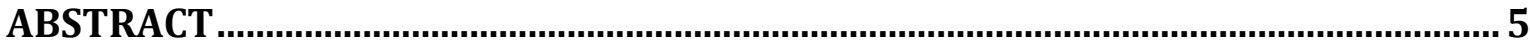

LISTA DE TABELAS

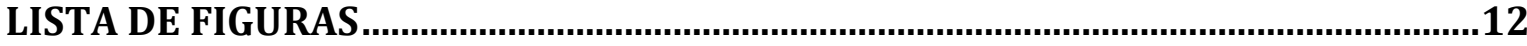

ANEXOS

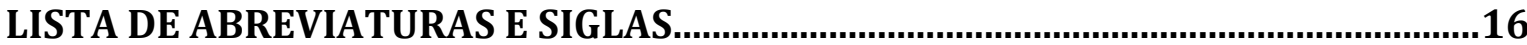

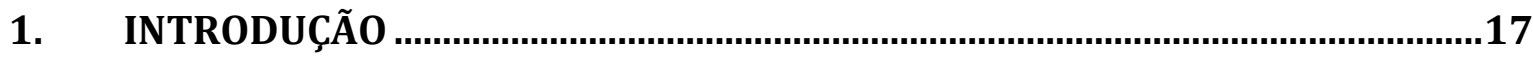

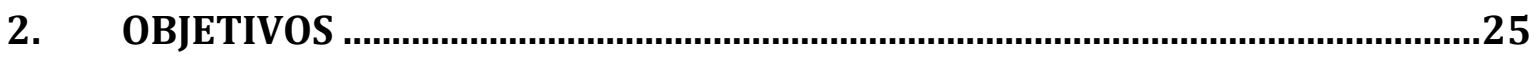

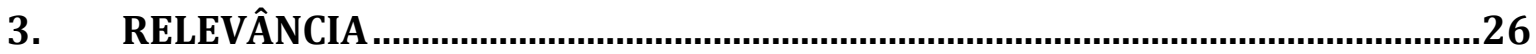

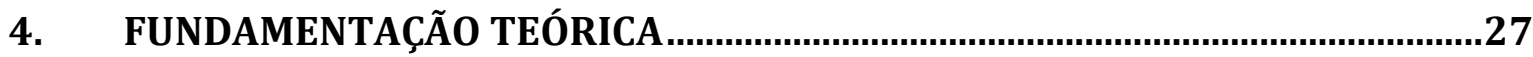

4.1. O ELEMENTO URÂNIO - PROPRIEDADES E APLICAÇÕES .............................27

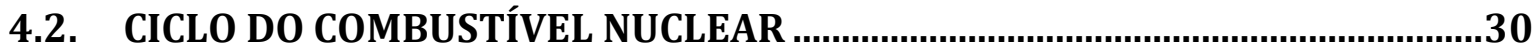

4.3. SISTEMA DE SALVAGUARDAS DO MATERIAL NUCLEAR ................................34

4.3.1. PROCEDIMENTOS DE SALVAGUARDAS ...............................................................37

4.3.2. A DESCOBERTA DA FALHA NO SISTEMA DE SALVAGUARDAS - PROGRAMA $93+239$ 
4.3.4. ESFREGAÇOS

4.4. ASSINATURAS QUE SÃO BUSCADAS EM AMOSTRAS DE ESFREGAÇOS ........46

4.5. TÉCNICAS ANALÍTICAS UTILIZADAS EM AMOSTRAS DE ESFREGAÇOS.......52

4.5.1. ATIVIDADE RADIOATIVA 55

4.5.2. MICROSCOPIA ELETRÔNICA DE VARREDURA 55

4.5.3. ESPECTROMETRIA DE MASSAS .61

4.5.3.1. HISTÓRICO .61

4.5.3.2. O EQUIPAMENTO. .63

4.5.3.3. ESPECTRÔMETRO DE MASSAS COM FONTE DE PLASMA INDUZIDO ICP-MS 64

4.6. ESTIMATIVA DAS INCERTEZAS ASSOCIADAS AOS PROCEDIMENTOS DE MEDIÇÃo . .66

5. DESENVOLVIMENTO EXPERIMENTAL .70

5.1. TRATAMENTO DOS DADOS .70

5.1.1. ATIVIDADE RADIOATIVA . .70

5.1.2. RAZÕES ISOTÓPICAS DE URÂNIO .71

5.1.3. PORCENTAGEM ATÔMICA DOS ISÓTOPOS DE URÂNIO 71

5.1.4. DISCRIMINAÇÃO DE MASSA.

5.2. EQUIPAMENTOS 
5.3. MATERIAIS DE LABORATÓRIO .75

5.4. REAGENTES, PADRÕES E MATERIAIS DE REFERÊNCIA .75

5.5. ÁREA DE AMOSTRAGEM .76

5.6. ESTRATÉGIA ANALÍTICA .78

5.6.1. ANÁLISE MICROSCÓPICA .79

5.6.2. ANÁLISE ISOTÓPICA. .79

5.6.2.1. LIXIVIAÇÃO ASSISTIDA POR ULTRASSOM (LIX/US) .80

5.6.2.2. DIGESTÃO TOTAL (DT) .80

6. RESULTADOS E DISCUSSÃO .83

6.1. ATIVIDADE .83

6.2. ANÁLISE MICROSCÓPICA POR MEV-EDS .85

6.2.1. ANÁLISE MORFOLÓGICA POR MEV. .87

6.2.2. ANÁLISE QUÍMICA PELA TÉCNICA DE EDS 91

6.3. ANÁLISE ISOTÓPICA. 94

6.3.1. DESENVOLVIMENTO DO MÉTODO DE LIX/US 96

7. CONCLUSÕES 103

ANEXO 1: CÁlCULOS PARA A ESTIMATIVA DAS INCERTEZAS ASSOCIADAS ÀS DETERMINAÇÕES DE RAZÕES ISOTÓPICAS DE URÂNIO 105 
ANEXO 3: BASE DE DADOS: MICROGRAFIAS DE DIFERENTES COMPOSTOS DE

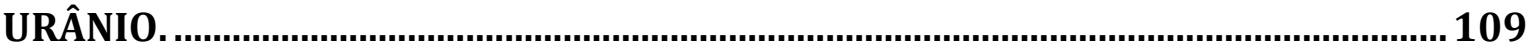

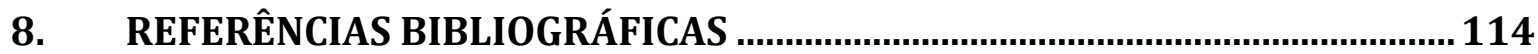




\section{LISTA DE TABELAS}

TABELA 1: Propriedades físicas do elemento urânio

TABELA 2: Distribuição das reservas mundiais de urânio, expressas em toneladas de $\mathrm{U}_{3} \mathrm{O}_{8}$ e U.

TABELA 3: Possíveis compostos associados com as etapas do CCN.

TABELA 4: Classificação do urânio em relação a fração mássica no isótopo ${ }^{235} \mathrm{U}$ (OLIVEIRA JUNIOR, 2006; ITV, 2010)

TABELA 5: Técnicas analíticas utilizadas em amostras de esfregaços para obter informações com fins de salvaguardas nucleares.

TABELA 6: Valores de atividade medida, atividade empírica e quantidade estimada de urânio presente em cada amostra com suas respectivas incertezas expandidas com nível de confiança de $95,45 \%$.

TABELA 7: Métodos que serão aplicados nas amostras coletadas no CCR. .85

TABELA 8: Área aproximada das partículas de urânio encontradas na amostra 16 referentes a FIGURA 32.

TABELA 9: Área aproximada das partículas de urânio encontradas nas amostras 3 e 6 referentes a FIGURA 35.

TABELA 10: Resultados de \% atômica obtidos pela análise semi-quantitativa por EDS para os padrões $\mathrm{UF}_{4} \mathrm{CEA}$ e $\mathrm{U}_{3} \mathrm{Si}_{2} \mathrm{IPEN}$

TABELA 11: Resultados de \% atômica obtidos pela análise semi-quantitativa de EDS para duas partículas (a) e (b) (FIGURA 32) encontradas na amostra 16, assim como para o padrão de $\mathrm{UF}_{4} \mathrm{CEA}$.

TABELA 12: Condições otimizadas de operação e parâmetros de aquisição para análises isotópicas no ICP-QMS.

TABELA 13: Erro relativo e porcentagem das incertezas expandidas para razões isotópicas do MRC NBL U200. Dados para solução de concentração de $10 \mu \mathrm{g} / \mathrm{kg}$ de urânio. Valores de incertezas expandidas com nível de confiança de 95,45\%. .95

TABELA 14: Valores do fator de discriminação de massas obtidos para razões isotópicas de urânio para o MRC NBL U200. Incertezas apresentadas como incertezas padrão.

TABELA 15: Comparação de resultados de fração mássica referente ao isótopo ${ }^{235} U$ para amostra simulada de esfregaço, amostra de combustível nuclear e valor especificado. Valores de incertezas expandidas com nível de confiança de 95,45\% 
TABELA 16: Valores das razões isotópicas de urânio para as amostras utilizadas para comparação entre os métodos de digestão total (DT) e método da lixiviação assistida por ultrassom (Lix/Us). Valores de incertezas expandidas com nível de confiança de 95,45\%.

.98

TABELA 17: Comparação das incertezas expandidas percentuais $(\% \mathrm{U})$ obtidas para razão $n\left({ }^{235} U\right) / n\left({ }^{238} U\right)$ em diferentes estudos em esfregaços.

TABELA 18: Valores obtidos de Branco, Limite de Detecção (LD) e de Quantificação (LQ) encontrados para o método de Lix/Us. 100

TABELA 19: Valores das razões isotópicas e incertezas expandidas para amostras submetidas ao processo de Lix/Us. Valores de incertezas expandidas com nível de confiança de $95,45 \%$.

TABELA 20: Valores de fração atômica molar em relação ao isótopo ${ }^{235} \mathrm{U}$ para as amostras utilizadas no trabalho. Valores de incertezas expandidas com nível de confiança de $95,45 \%$. 


\section{LISTA DE FIGURAS}

FIGURA 1: Alguns processos de fissão do ${ }^{235} \mathrm{U}$ que ocorrem através de uma reação de fissão em cadeia (SCHMITZ, 2012).

FIGURA 2: Conjunto de plantas de processamento do urânio, chamado de ciclo do combustível nuclear. Adaptado: BALDWIN, 2006. 30

FIGURA 3: Uma das rotas frequentemente utilizada na produção do combustível nuclear a base de $\mathrm{UO}_{2}$. 31

FIGURA 4: Tríade que formam o regime de não proliferação nuclear. 35

FIGURA 5: Fluxograma dos procedimentos de um sistema de salvaguardas aplicados pela

FIGURA 6: Evolução dos acordos de salvaguardas e Protocolo Adicional no período entre 2007 e 2012. Fonte: AIEA, 2011 e AIEAb, 2012. 39

FIGURA 7: Coleta de amostras pela técnica esfregaços

FIGURA 8: Diferenças morfológicas de compostos de $\mathrm{UF}_{4}$ produzidos por duas rotas químicas diferentes. (a) $\left(\mathrm{HF}_{2}\right)^{-}$e (b) $\mathrm{SnCl}_{2}$ (SALIBA-SILVA, 2011).

FIGURA 9: Micrografias obtidas por MEV de diuranato de amônia $\left(\mathrm{NH}_{4} \mathrm{U}_{2} \mathrm{O}_{7}\right)$ produzidos em diferentes condições. (a) com amônia aquosa, (a1) magnificação de 1000X (a2) 10.000X (a3) 100.000X (b) com amônia gasosa, (b1) magnificação de 1000X (b2) 10.000X (b3) 100.000X (MANNA, 2012).

FIGURA 10: Partículas esféricas de $\mathrm{UO}_{2} \mathrm{~F}_{2}$ (a) e aglomerados esféricos de $\mathrm{UO}_{2} \mathrm{~F}_{2}$ que podem ser encontrados em amostras de esfregaço provenientes da reação de hidrólise do $\mathrm{UF}_{6}(\mathrm{STEBELKOV}, 2010)$.

FIGURA 11: Análise de elementos de terras raras para dois compostos de $\mathrm{U}_{3} \mathrm{O}_{8}$ de diferentes procedências. Valores em ng/g (ROSA, 2011).

FIGURA 12: Componentes básicos de um MEV (NAU, 2013).

FIGURA 13: Diferentes tipos eventos que podem ser gerados na interação do feixe de elétrons com a amostra (MALISKA, 2013). .58

FIGURA 14: Diferenças nas micrografias obtidas por MEV devido ao uso de detectores de elétrons secundários (a) e de retroespalhados (b) em uma partícula de zircônio encontrada numa folha de árvore próxima a instalação nuclear do IPEN.

FIGURA 15: Espectro típico de uma partícula de resíduo de disparo de arma de fogo GSR, onde pode-se observar os raios-X característicos e contínuos. 60 
FIGURA 16: Processos de transições eletrônicas que envolvem as emissões de raios-X (MALISKA, 2013)

FIGURA 17: Tudo de descarga de Goldstein para geração de íons positivamente carregados (BECKER, 2007). 61

FIGURA 18: Espectrômetro de parábola construído por Thomson (KSHITIJ, 2013)........62

FIGURA 19: Diagrama esquemático de um espectrômetro de massas

FIGURA 20: Componentes de um Espectrômetro de Massas com Fonte de Plasma Induzido (AGILENT, 2013).

FIGURA 21: Filtro quadrupolar de massas

FIGURA 22: Diagrama de causa e efeito (Ishikawa): Fontes das incertezas associadas na determinação das razões isotópicas de urânio. Detalhamento na sessão de 5.1. Tratamento dos dados. 68

FIGURA 23: Fluxograma de uma das rotas de produção do combustível nuclear utilizado no reator IEA-R1 formado pela liga metálica de siliceto de urânio e alumínio. .77 FIGURA 24: Mapa dos pontos de coleta dos esfregaços nas dependências da instalação de reconversão de urânio do CCR utilizada como estudo de caso. Onde A: Escritórios; B: Usina de Produção do $\mathrm{UF}_{4}$; C: Sala de transferência do $\mathrm{UF}_{6}$; D: Laboratório de recuperação do $\mathrm{UF}_{4} ; \mathrm{E}$ : Depósito. .78

FIGURA 25: Amostra real de esfregaço coletada na planta de reconversão do CCR .78 FIGURA 26: Estratégia analítica aplicada nos esfregaços para Sequência de ensaios realizados para caracterização das amostras de esfregaço. .79 FIGURA 27: Diferentes métodos aplicados nas amostras para verificar a eficiência do método de Lix/Us como forma de extração de urânio dos esfregaços. 80 FIGURA 28: Sequência utilizada no procedimento de DT . 81 FIGURA 29: Fluxograma do processo envolvido na separação cromatográfica do urânio em meio clorídrico em resina aniônica forte. 82

FIGURA 30: Micrografia obtida pela técnica de MEV para a amostra 3 utilizando uma magnificação de 300X. A partícula em destaque no centro da imagem é uma partícula de zircônio. .86

FIGURA 31: Micrografias obtidas de partículas de urânio encontradas nos esfregaços: Diferenças do uso do detector SE (a) e (c) e BSE (b) e (d). Partículas (a) e (b) são provenientes da amostra 6 (externa), sendo as (c) e (d) amostras coletadas em uma tubulação de saída de ar, localizada externamente a instalação (amostra 3). Imagens obtidas pelo equipamento Philips XL-30. 
FIGURA 32: Micrografias de partículas de urânio encontradas na amostra 16. .88

FIGURA 33: Características morfológicas de $\mathrm{UF}_{4}$ produzido (a) via $\mathrm{HF}_{2}^{-}$e (b) possível partícula de $\mathrm{UF}_{4}$ produzido pela mesma rota.

FIGURA 34: Partícula esférica de $\mathrm{UO}_{2} \mathrm{~F}_{2}$ (área de $13 \mu \mathrm{m}^{2}$ ) encontrada na amostra 3. Uso do detector BSE, com uma magnificação de 2500x (a), onde facilita encontrar partículas de urânio e (b) com o uso de detector SE e magnificação de 10000x, onde privilegia as características superficiais do material.

FIGURA 35: Micrografias das amostras de esfregaços coletadas externamente (amostra 3 (a) e (b) e amostra 6 - (c) e (d)) a instalação de reconversão.

FIGURA 36: Espectro de EDS da partícula de urânio encontrada na amostra 16 - FIGURA 32 (a).

FIGURA 37: Mapa químico de uma partícula de urânio encontrada na amostra 16. 93

FIGURA 38: Valores do fmd para as razões isotópicas de urânio para MRC NBL U200. 96 FIGURA 39: Resultados de fração mássica no isótopo ${ }^{235} \mathrm{U}$ para amostra de esfregaço simulada, amostra de combustível nuclear e valores alvos.

FIGURA 40: Valores da razão isotópica $n\left({ }^{235} U\right) / n\left({ }^{238} U\right)$ para as amostras submetidas aos dois diferentes métodos a fim de verificar suas equivalências. A linha tracejada é o valor da razão $n\left({ }^{235} U\right) / n\left({ }^{238} U\right)$ para o MRC NBL U200.

FIGURA 41: Fluxograma das incertezas associadas ao processo de medição e correção das razões isotópicas de urânio.

FIGURA 42: Micrografias de compostos de urânio. Superior: Acetato de uranila $\left(\mathrm{CH}_{3} \mathrm{COO}\right)_{2} \mathrm{UO}_{2}$; Inferior: Tricarbonato de amônio e uranila $\mathrm{UO}_{2}\left(\mathrm{CO}_{3}\right)_{3}\left(\mathrm{NH}_{4}\right)_{4}$. Sequências com magnificações de 100x, 500x e 1500x.

FIGURA 43: Micrografias de compostos de urânio. Superior: Dióxido de urânio $\mathrm{UO}_{2}$; Inferior: Octóxido de triurânio $\mathrm{U}_{3} \mathrm{O}_{8}$. Sequências com magnificações de 100x, 500x e 1500x. 110

FIGURA 44: Micrografias de compostos de urânio. Superior: Siliceto de urânio $\mathrm{U}_{3} \mathrm{Si}_{2}$; Inferior: Urânio metálico $U^{\circ}$. Sequências com magnificações de 100x, 500x e 1500x. ...111 FIGURA 45: Micrografias de compostos de urânio. Superior: Nitrato de uranila $\mathrm{UO}_{2}\left(\mathrm{NO}_{3}\right)_{2}$; Inferior: Diuranato de amônio $\mathrm{NH}_{4} \mathrm{U}_{2} \mathrm{O}_{7}$. Sequências com magnificações de 100x, 500x e 1500x.

FIGURA 46: Micrografias de compostos de urânio. Superior: UF 4 Sequências com magnificações de 1500x, 3000x e 5000x. 


\begin{abstract}
ANEXOS
ANEXO 1: Cálculos para a estimativa das incertezas associadas às determinações de

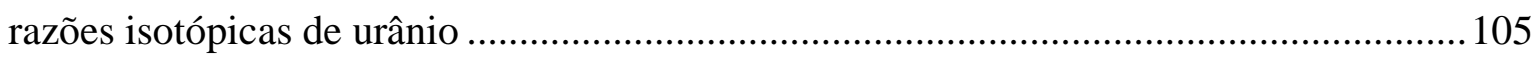

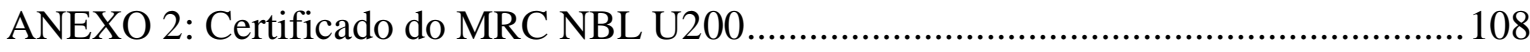

ANEXO 3: Base de dados: Micrografias de diferentes compostos de urânio. ................... 109
\end{abstract}




\section{LISTA DE ABREVIATURAS E SIGLAS}

ABACC - Agência Brasileiro-Argentina de Contabilidade e Controle de Materiais Nucleares

ACA - Associação de Controle de Armas

AIEA - Agência Internacional de Energia Atômica

BSE - Elétrons Retroespalhados

CCN - Ciclo do Combustível Nuclear

CCR - Centro do Combustível e Recuperação

CF - Discriminação de Massas por Unidade de Massa Atômica

CQMA - Centro de Química e Meio Ambiente

CNEN - Comissão Nacional de Energia Nuclear

CCTBO - Comprehensive Nuclear-Test-Ban Treaty Organization

DT - Digestão Total

EDS - Sistema de Energia Dispersiva

Fmd - Fator de Discriminação de Massa

ICP-MS - Espectrometria de Massas com Fonte de Plasma Induzido

INFCIRC - Informativo Circular

IPEN - Instituto de Pesquisas Energéticas e Nucleares

LCQ - Laboratório de Caracterização Química e Isotópica

Lix/Us - Lixiviação Assistida por Ultrassom

MEV/EDS - Microscopia Eletrônica de Varredura com Sistema de Energia Dispersiva

MRC - Material de Referência Certificado

NBL - New Brunswick Laboratory

NEA - Agência de Energia Nuclear

SE - Elétrons Secundários

TNP - Tratado de Não Proliferação Nuclear 


\section{INTRODUÇÃO}

Quando foi o primeiro passo dado em direção ao que mais tarde viria a ser chamado de energia nuclear e seu uso? Diversos experimentos contribuíram para a descoberta do átomo, suas partículas constituintes passando pelas reações nucleares de fissão, até a descoberta da possibilidade de utilizar a energia gerada por estas reações.

Em 6 de janeiro de 1939 não seria uma má escolha. Nessa data os físicos alemães Otto Hahn e Fritz Strassmann publicaram, na revista Naturwissenschaften, a descoberta de um novo tipo de reação nuclear, a de fissão (JONTER, 2008; NODE, 2013).

No experimento, eles haviam bombardeado um átomo de urânio e conseguiram com sucesso dividi-lo em dois elementos mais leves. Logo em seguida, os austríacos Lise Meitner e Otto Frisch demonstraram experimentalmente que essa fissão gerava uma grande quantidade de energia, e que seria possível explorá-la. Estas descobertas deixaram a comunidade científica mais otimista em relação a um mundo onde a questão energética poderia vir a ser solucionada (JONTER, 2008; THINKQUEST, 2013).

No entanto, para líderes políticos de países como Alemanha, Inglaterra, EUA e União Soviética não foi o uso civil da energia nuclear que despertara interesse. O mundo estava à beira de uma guerra, que se tornou um fato em setembro 1939, e foi, portanto, as possibilidades militares da energia nuclear que induziam líderes políticos à desempenhar um papel ativo no desenvolvimento da tecnologia nuclear (JONTER, 2008).

Durante a Segunda Guerra Mundial, as informações estavam fluindo para os serviços de inteligência das grandes potências sobre as tentativas dos outros países na aquisição de materiais nucleares e sobre seus planos para produzir armamento nuclear. Isso ocasionou uma corrida entre as grandes potências para determinar quem iria se tornar o primeiro país a desenvolver uma arma nuclear.

Os primeiros cientistas dos EUA a se conscientizarem deste perigo foram os físicos húngaros, refugiados da Europa, Leo Szilard, Eugene Wigner e Edward Teller. Para eles, não existiam dúvidas de que a Alemanha iria dobrar seus esforços para desenvolver a arma nuclear. Então os cientistas convenceram o físico Albert Einstein a assinar uma carta que tinham escrito para o presidente Franklin Roosevelt (RHODES, 1995; GLOBO, 2013).

$\begin{array}{ccc}1789 & 1896 & 1939 \\ \begin{array}{c}\text { Descoberta do } \\ \text { urânio }\end{array} & \begin{array}{l}\text { Descoberta da } \\ \text { radioatividade }\end{array} & \text { Descoberta da } \\ \text { fissão }\end{array}$


Como consequência, o físico encaminhou a carta em 02 de agosto de 1939 ao presidente dos EUA, Franklin D. Roosevelt, onde afirmou que a Alemanha iniciado experimentos voltados para a produção de urânio altamente enriquecido para o desenvolvimento de armas nucleares. Em sua carta, o físico aconselhou Roosevelt a comprometer recursos para desenvolver armas nucleares antes que a Alemanha fosse capaz de ter êxito em fazê-la (GROUFF, 1967; JONTER, 2008; CHARNYSH, 2013).

Num trecho da carta de Albert Einstein relatava que:

"Em um trabalho recente de E. Fermi e L. Szilard leva-me à esperança de que o elemento urânio pode ser transformado em uma nova e importante fonte de energia em um futuro imediato. Certos aspectos dessa situação parecem exigir vigilância (...). Creio ser meu dever trazer à sua atenção aos seguintes fatos e recomendações: (...) através do trabalho de Joliot na França bem como o de Fermi e Szilard na América-pode ser possível desencadear reações nucleares em cadeia numa grande massa de urânio, através das quais seriam produzidas enormes quantidades de energia (...). Este novo fenômeno conduziria também à construção de bombas extremamente poderosas (...). Contudo, tive o conhecimento do que a Alemanha suspendeu efetivamente a venda de urânio das minas da

Checoslováquia de que se apoderou. O fato de ter tomado esta ação tão rapidamente talvez deva ser entendido tendo em conta que o filho do subsecretário de Estado alemão está ligado ao Instituto Kaiser Wilhelm, em Berlim, onde alguns dos trabalhos americanos sobre o urânio estão sendo repetidos" (MORAES, 2009)

Esse documento mostrava com ênfase o perigo de uma arma de enorme poder destrutivo que Alemanha poderia estar desenvolvendo. Tais suspeitas foram levantadas a partir das pesquisas sobre urânio já em curso, e que Hitler contava com grande acesso à comunidade científica, através de seu subsecretário de Estado, pai do conhecido físico Carl Von Weiszächer, que se ocupava do assunto no Instituto Kaiser Wilhelm, assim como a suspensão da venda de urânio por parte dos alemães (MORAES, 2009).

$\begin{array}{cc}1939 & 1939 \\ \begin{array}{c}\text { Carta de Albert } \\ \text { Einstein }\end{array} & \text { Início II Guerra } \\ \text { Mundial }\end{array}$


Deste modo, Roosevelt decidiu imediatamente criar o Comitê de Pesquisa de Defesa Nacional (National Defense Research Comittee - NDRC) para comandar o Projeto Manhattan, no qual disponibilizou verbas para universidades americanas para o desenvolvimento de pesquisa em urânio. Assim o pedido de Albert Einstein fora acatado (GROUFF, 1967).

O nome Projeto Manhattan foi atribuído, pelo Corpo de Engenheiros do Departamento de Guerra, às atividades científicas que tiveram como objetivo a utilização da tecnologia nuclear para fins militares em território norte americano, sendo a meta principal a produção de armamento nuclear (RODDEN, 1950).

Ainda, no início da Segunda Guerra Mundial, o Almirante Isoroku Yamamoto, comandante da frota japonesa, elaborou um plano para imobilizar uma das frotas dos EUA com um ataque surpresa à base militar de Pearl Harbor, situada no pacífico, tendo o ataque ocorrido em 7 de dezembro de 1941. Tal evento contribuiria na decisão futura dos EUA em utilizar o armamento nuclear sobre território japonês (DD, 1991).

Após um ano do ataque à base, os cientistas ${ }^{1}$ do Projeto Manhattan ainda não tinham resolvido o problema da reação em cadeia; a produção de ${ }^{235} \mathrm{U}$ ainda era insuficiente e o plutônio que estava sendo produzido no cíclotron de Berkeley não passava de alguns microgramas, o que levou os cientistas a sugerirem um sistema para a produção de plutônio em larga escala, surgindo a ideia do reator nuclear (LLBL, 2003; JONTER, 2008).

Dessa maneira, em 7 de novembro de 1942 iniciou-se a construção do primeiro reator nuclear da história. Chamado de Chicago Pile - CP-1, o reator que utilizava urânio natural e grafite como moderador, foi construído sob o estádio de futebol da Universidade de Chicago, durante o Projeto Manhattan, e gerou a primeira reação em cadeia autossustentada no dia 2 de dezembro de 1942 (GROUFF, 1967).

Ao mesmo tempo, a fim de dificultar o progresso de programas nucleares de outras nações como a Alemanha e União Soviética, tanto a Inglaterra como os EUA realizaram pesquisas secretas de reservas de urânio no mundo, com intuito de garantir o controle sobre estes materiais.

$\begin{array}{ccc}1941 & 1942 & 1942 \\ \text { Ataque Pearl Harbor } & \text { Projeto Manhattan } & 1^{\circ} \text { Reator Nuclear (CP1) }\end{array}$

\footnotetext{
${ }^{1}$ Os cientistas responsáveis pelo Projeto Manhattan eram: Robert Oppenheimer, David Bohm, Leo Szilard, Eugene Wigner, Otto Frisch, Rudolf Peierls, Felix Bloch, Niels Bohr, Emilio Segre, James Franck, Enrico Fermi, Klaus Fuchs e Edward Teller.
} 
Logo, em junho de 1944, os EUA e a Inglaterra entraram em um acordo, o Combined Development Trust, com a intenção de ganhar o controle sobre as reservas mundiais de urânio. O objetivo mais importante era obter influência sobre o maior depósito de urânio do mundo, situado no Congo Belga, sendo alcançado em 1944-45, quando um acordo secreto foi firmado com o governo belga no exílio sobre a exploração comercial das reservas de urânio no país. Este acordo de cooperação, assim, resultou às duas nações o controle de mais de 97\% da produção total de urânio da época (JONTER, 2008).

Paralelamente, em 25 de abril de 1945, o secretário de Guerra dos EUA, Henry Stimson comunicou ao então presidente $\operatorname{Truman}^{2}$ que:

"O controle de armas nucleares, sem dúvida será a questão de maior dificuldade e que envolverá inspeções minuciosas e rigorosos controles internos como nunca visto antes" (FISCHER, 1997).

Após os cientistas do Projeto Manhattan terem dominado o processo de enriquecimento de urânio, por meio da técnica de difusão gasosa, assim como a produção de plutônio em larga escala, os EUA estavam aptos a construir armamento nuclear para ser utilizado na guerra.

Desse modo, frutos do projeto Manhattan, surgiram três eventos importantes da história nuclear, sendo eles:

i. 16 de julho 1945 - No deserto de Alamogordo, no estado de Novo México, o Exército dos EUA realizou o primeiro teste da história de detonação de um dispositivo nuclear. Evento conhecido como Trinity Test a arma nuclear, chamada de Gadget, era de plutônio e desencadeou uma explosão de 18,6 kton ${ }^{3}$. O objetivo do teste era confirmar que a montagem do dispositivo de implosão juntamente com um núcleo de plutônio poderia desencadear uma reação nuclear em cadeia (RHODES, 1995; AHF, 2013; DW, 2013).

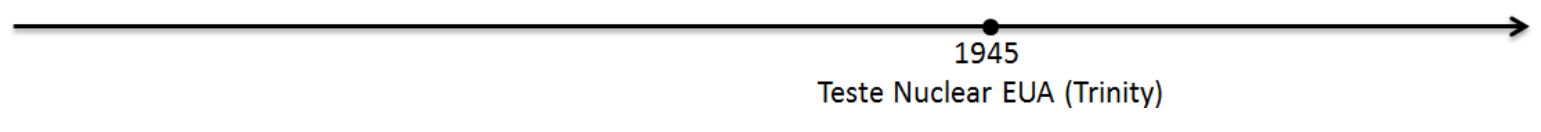

\footnotetext{
${ }^{2}$ O presidente Roosevelt morreu no dia 12 de abril de 1954, assim, Harry S. Truman foi nomeado presidente dos EUA.

${ }^{3}$ Um kton (quiloton) equivale a mil toneladas de TNT (Trinitrotolueno, um explosivo comumente conhecido) (DW, 2013)
} 
ii. Com o sucesso de Trinity Test, a primeira arma nuclear utilizada em guerra foi lançada, no dia 6 de agosto de 1945, pelo bombardeiro B29, batizado como Enola Gay da Força Aérea dos EUA sobre a cidade japonesa Hiroshima. Chamada de Little boy, era uma bomba de urânio altamente enriquecido, contendo $64 \mathrm{~kg}$ de ${ }^{235} \mathrm{U}$, gerando uma explosão de 12,5 kton (GROUFF, 1967; RHODES, 1995; JONTER, 2008).

iii. Três dias após Hiroshima, a segunda arma nuclear, dessa vez de plutônio $(6,2 \mathrm{~kg}$ de plutônio, gerando 22 kton), denominada Fat Man foi lançada sobre Nagasaki. Um consenso sobre o número de japoneses mortos não existe. Estima-se que houveram mais de 250 mil mortos e foi deixada uma terrível herança radiológica a população japonesa (GROUFF, 1967; RHODES, 1995; JONTER, 2008; UNIFICADO, 2013).

Como consequência direta às explosões, em 15 de agosto de 1945 o Japão se rende, em 2 de setembro de 1945, pondo fim à Segunda Guerra Mundial.

Ainda no mesmo ano, iniciou-se a guerra fria, que foi uma disputa estratégica entre o capitalismo americano e o socialismo soviético. Desencadeada com o objetivo destas nações em ampliar suas áreas de influência no mundo, foi um conflito (não armado) de ordem política, militar, tecnológica, econômica e ideológica, se estendendo até a extinção da União Soviética em 1991.

Durante este período, a União Soviética e Inglaterra realizaram, com sucesso, seus primeiros testes nucleares nos anos de 1949 e 1952, respectivamente. Como consequência houve um medo crescente de que mais países pudessem desenvolver armas nucleares e colocar o mundo em perigo (JONTER, 2008, CTBTO, 2013).

Nesse cenário, em 8 de dezembro de 1953, o então presidente dos EUA, Dwight D. Eisenhower, propôs na Assembleia Geral das Nações Unidas a criação de uma organização para promover o uso pacífico da energia nuclear e garantir que essa tecnologia não serviria a qualquer propósito militar, desencorajando o uso para este fim (FISCHER, 1997).

\begin{tabular}{cccc}
\hline $\begin{array}{c}\text { Ataque Hiroshima e } \\
\text { Nagasaki }\end{array}$ & Fim II Guerra Mundial & 1945 & 1949 \\
Início Guerra Fria & Teste Nuclear - URSS & Teste Nuclear - UK
\end{tabular}


$\mathrm{Na}$ ocasião o presidente declarou que:

"Os EUA asseguram diante dos senhores, e, portanto diante do mundo, sua determinação em ajudar a resolver o temível dilema atômico - devotar seu coração e sua mente inteiros a encontrar a maneira pela qual a miraculosa inventividade do homem não seja dedicada à sua morte, mas consagrada à sua vida" (OPERAMUNDI, 2013).

Como consequência direta do programa Átomos para a $\mathrm{Paz}^{4}$, a proposta de Eisenhower levou, em 1957, à criação da Agência Internacional de Energia Atômica AIEA, ajudando a moldar a cooperação internacional do uso civil da tecnologia nuclear. (FISCHER, 1997; KHATER, 2005).

O Artigo III do estatuto da AIEA descreve:

"A Agência procurará acelerar e ampliar a contribuição da energia atômica para paz, saúde e prosperidade mundial. Também deve assegurar, na medida do que é capaz, que a assistência fornecida por ela, ou a seu pedido, ou sob sua supervisão, ou controle, que qualquer atividade nuclear não seja usada de tal forma a promover qualquer objetivo militar" (AIEAa, 2013)

Para tal, foi criado o sistema de salvaguardas nucleares da AIEA, que teve como base legal, o primeiro acordo de salvaguardas aprovado pelo Conselho de Governadores da AIEA o INFCIRC $5 / 26$ de 30 de março de 1961, que sete anos mais tarde foi aperfeiçoado tornando o INFCIRC/66.

Nesta época, países como França e China, realizaram testes nucleares em 1960 e 1964, respectivamente. A partir de então, o aumento de países que tinham e poderiam obter armamento nuclear era considerável para uma preocupação de segurança mundial (CTBTO, 2013).

$\begin{array}{ccccc}1953 & 1957 & 1960 & 1961 & 1964 \\ \text { Átomos para Paz } & \text { Criação AIEA } & \text { Teste Nuclear } & \text { INFCIRC/26 } & \text { Teste Nuclear } \\ & & \text { China } & \end{array}$

\footnotetext{
${ }^{4}$ Foi a primeira iniciativa de políticas de desenvolvimento da tecnologia nuclear voltada exclusivamente para fins pacíficos.

${ }^{5}$ INFCIRC $=$ Informativo Circular
} 
A dificuldade de contensão do uso militar se encontrava no fato de que o acordo de salvaguarda vigente ${ }^{6}$ tinha como objetivo apenas o controle de materiais nucleares declarados pelas nações, não sendo suficiente para evitar o uso militar da tecnologia nuclear. Dessa necessidade foi criado o tratado de Não Proliferação de Armas Nucleares $\mathrm{TNP}^{7}$ (FISCHER, 1997).

Porém, mesmo após o desenvolvimento do TNP foram realizados diversos testes nucleares por países como a Índia - 1974 e 1998, Paquistão - 1998 e pela Coréia do Norte - 2006 e 2013. Atualmente, segundo a CTBTO - Comprehensive Nuclear-Test-Ban Treaty Organization foram realizados aproximadamente 2053 testes nucleares em todo o mundo, sendo mais da metade (1032) realizada pelos EUA (CTBTO, 2013).

Neste contexto, quanto pode e deve os países confiarem uns nos outros? O prérequisito para a cooperação internacional é que as partes interessadas realmente possam confiar e cumprirem aquilo que se comprometeram. Essa ideia é bem abordada no primeiro princípio do direito romano - Pactos devem ser respeitados (Pacta sunt servanda) (JONTER, 2008).

Até o início da década de 90, apenas as declarações feitas pelos responsáveis das instalações nucleares eram verificadas. A garantia da ausência de material nuclear não declarado não fazia parte dos relatórios dos inspetores de salvaguardas.

Com o fim da União Soviética houve um colapso no sistema de controle de materiais nucleares naquele país, e, como consequência, no início da década de 90 foram observados na Europa os primeiros casos de tráfico ilícito de materiais nucleares. Na mesma época foi descoberto o programa nuclear clandestino iraquiano, pela AIEA. Fatos como estes, despertaram nas autoridades mundiais um sinal de alerta sobre a necessidade de elevar o nível de confiabilidade, controle e detecção de atividades não declaradas em Estados sob salvaguardas (STURM, 2010).

$\begin{array}{lccccc}1968 & 1970 & 1972 & 1974 & 1991 & 1991 \\ \text { INFCIRC/66 } & \text { TNP } & \text { INFCIRC/153 } & \text { Teste Nuclear Índia } & \text { Final da Guerra Fria } & \text { Descoberta de } \\ \text { INFCIRC/140 } & & & \begin{array}{c}\text { programa nuclear } \\ \text { clandestino Iraque }\end{array}\end{array}$

\footnotetext{
${ }^{6}$ INFCIRC/66

7 TNP = INFCIRC/140 de 22 de abril de 1970
} 
Assim, foi desenvolvido o Programa 93+2, criando um sistema íntegro de verificação e detecção, através de novos procedimentos adotados em salvaguardas, subsidiados por tratados e acordos internacionais, como, Tratado Abrangente de Salvaguardas - INFCIRC/153, bem como o Protocolo Adicional - INFCIRC/540.

Uma das melhorias do sistema foi a implementação de amostragens ambientais como ferramenta complementar na identificação de atividades nucleares não declaradas em Estados signatários.

\begin{tabular}{ccccc}
\hline 1995 & 1997 & 1998 & 2006 & 2013 \\
$\begin{array}{c}\text { Programa 93+2 é } \\
\text { aprovado pela IAEA }\end{array}$ & $\begin{array}{c}\text { Protocolo Adicional } \\
\text { INFCIRC/540 }\end{array}$ & $\begin{array}{c}\text { Teste Nuclear } \\
\text { Índia e Paquistão }\end{array}$ & $\begin{array}{c}\text { Teste Nuclear } \\
\text { Coreia do Norte Coreia do Norte }\end{array}$
\end{tabular}




\section{OBJETIVOS}

\section{Gerais}

O objetivo deste trabalho consiste em trazer uma contribuição às atividades de salvaguardas nucleares no país. Dessa forma será proposto uma nova estratégia analítica, utilizando técnicas destrutivas e não destrutivas, a fim de obter a maior quantidade de informação presentes em amostras de esfregaços, relacionando-as com as atividades nucleares desenvolvidas na instalação estudada.

\section{Específicos}

Os objetivos específicos são:

○ Desenvolver procedimento de pré-análise de esfregaços por meio da medida de radiação alfa;

- Desenvolver uma metodologia baseada na técnica MEV-EDS para identificação dos compostos de urânio nos esfregaços;

o Desenvolver uma nova metodologia de extração de urânio presente nos esfregaços baseada na lixiviação assistida por ultrassom;

○ Identificar assinaturas do urânio em amostras reais de esfregaços que possam exibir um quadro geral das atividades que são desenvolvidos numa planta de reconversão de urânio do IPEN/CNEN;

- Avaliar aspectos metrológicos das incertezas associadas às medidas de razão isotópica de urânio. 


\section{RELEVÂNCIA}

Ao longo dos anos, AIEA junto com seus Estados membros firmaram acordos de salvaguardas para minimizar qualquer diversão ou uso fora do controle regulatório de materiais nucleares, garantindo somente o uso pacífico desses materiais.

Até 31 de dezembro de 2012, a AIEA tinha acordos de salvaguardas em vigor com 179 membros e com Taiwan, China, sendo mais de 1200 instalações nucleares em todo o mundo sob salvaguardas, e, como consequência, são analisadas cerca de mil amostras anualmente (IAEA).

Frente à grande demanda de análises de esfregaços, assim como a necessidade de obter o maior número de informações possíveis de cada amostra, esforços estão sendo aplicados em diversos laboratórios do mundo com o intuito de conseguir suprir tais necessidades.

O presente trabalho traz uma contribuição inédita aos procedimentos de salvaguardas propondo um protocolo rápido e robusto para coleta e análise de esfregaços. A metodologia desenvolvida permite a obtenção de informações relacionadas a características físicas, químicas e isotópicas do material manipulado na instalação como também indícios da sua rota de produção. 


\section{FUNDAMENTAÇÃO TEÓRICA}

\subsection{O elemento urânio - propriedades e aplicações}

O elemento químico de número atômico 92, pertencente à família dos actinídeos, foi nomeado urânio, que na mitologia romana significa ' Pai dos Céus', em homenagem à descoberta do planeta Uranus (OLIVEIRA JUNIOR 2006; HAMMOND, 2012).

O urânio foi descoberto pelo químico alemão Martin Heinrich Klaproth quando ele tentava extrair um estranho metal associado a uma amostra de mineral chamada de Pechblenda. A comunicação dessa importante descoberta foi realizada em 24 de setembro de 1789 na Academia de Ciências de Berlim (OLIVEIRA JUNIOR, 2006).

Porém, Klaproth havia isolado o composto dióxido de urânio $\left(\mathrm{UO}_{2}\right)$, sendo o urânio metálico $\left(\mathrm{U}^{\circ}\right)$ isolado apenas em 1841 por Peligot (HAMMOND, 2012).

A descoberta da natureza radioativa do urânio somente foi realizada 55 anos depois por Henri Becquerel, e através de uma de suas alunas, Marie Curie, que o novo fenômeno foi atribuído como radioatividade (OLIVEIRA JUNIOR 2006).

Urânio não é um elemento raro, sendo mais abundante que elementos como mercúrio, antimônio, prata e cádmio e tão abundante quanto arsênio e molibdênio. Ocorre naturalmente no meio ambiente assim como nos seres vivos. No corpo humano existem, em média, cerca de $90 \mathrm{mg}$ de urânio, proveniente de ingestão de doses normais de água, alimentos e ar, sendo aproximadamente $66 \%$ encontrado no esqueleto, $16 \%$ no fígado, $8 \%$ nos rins e 10\% em outros tecidos (WHO, 2001; BETTI, 2003; HAMMOND, 2012).

O urânio está presente no meio ambiente em concentrações aproximadas de 1-5 mg $\mathrm{kg}^{-1}$ na crosta terrestre, $3 \mathrm{mg} \mathrm{L}^{-1}$ na água do mar e 2,5 $\mathrm{ng} \mathrm{m}^{-3}$ no ar (NCRP, 1999; PARRISHA, 2008; HANDLEY-SIDHU, 2010).

Existem diversos minerais e rochas que apresentam urânio em sua composição, dentre os mais importantes, a destacar, a Pechblenda, Carnotita e Uraninita (HAMMOND, 2012).

A Pechblenda, com uma mistura de $\mathrm{U}_{3} \mathrm{O}_{8}$ e $\mathrm{UO}_{2}$, é de origem ígnea e contém uma vasta quantidade de outros elementos, entretanto a Carnotita é um mineral de origem sedimentar e contém elementos como vanádio, potássio e urânio em proporções representados pela fórmula química $\mathrm{K}_{2}\left(\mathrm{UO}_{2}\right)_{2}\left(\mathrm{VO}_{4}\right)_{2} \cdot 3 \mathrm{H}_{2} \mathrm{O}$ (RODDEN, 1964).

O urânio pode ser encontrado na natureza como uma mistura de três isótopos, o ${ }^{234} \mathrm{U},{ }^{235} \mathrm{U}$ e ${ }^{238} \mathrm{U}$ no qual estão presentes em frações mássicas de $0,0054 \pm 0,0005 \%$; $0,7204 \pm 0,0006 \%$ e $99,2742 \pm 0,0010 \%$, respectivamente. Entretanto, existem outros 20 
isótopos que podem ser obtidos artificialmente em reatores, sendo todos os isótopos do urânio radioativos (HAMMOND, 2012).

Um grama de urânio natural tem uma atividade específica de $0,68 \mu \mathrm{Ci}$, sendo aproximadamente $49 \%$ da atividade atribuível ao isótopo ${ }^{234} \mathrm{U}, 2 \%$ ao ${ }^{235} \mathrm{U}$ e $49 \%$ ao ${ }^{238} \mathrm{U}$ (ATSDR, 2013).

Na TABELA 1 estão apresentadas outras propriedades físicas do urânio (DOE, 2001; DE LAETER, 2003; HAMMOND, 2012).

TABELA 1: Propriedades físicas do elemento urânio

\begin{tabular}{l|cc}
\hline Propriedade & Valor & Unidade \\
\hline Número atômico & 92 & - \\
Massa atômica & $238.02891(3)$ & u.m.a. ${ }^{\mathbf{1}}$ \\
Ponto de fusão & 1135 & ${ }^{\circ} \mathrm{C}$ \\
Ponto de ebulição & 4131 & ${ }^{\circ} \mathrm{C}$ \\
Densidade & 18,9 & g.cm ${ }^{-3}$ \\
Massa atômica ${ }^{234} \mathrm{U}$ & $234.0409447(22)$ & u.m.a. ${ }^{\mathbf{1}}$ \\
Massa atômica ${ }^{235} \mathrm{U}$ & $235.0439222(21)$ & u.m.a. ${ }^{\mathbf{1}}$ \\
Massa atômica ${ }^{238} \mathrm{U}$ & $238.0507835(22)$ & u.m.a. ${ }^{\mathbf{1}}$ \\
Valência & $+2,+3,+4,+5$, ou +6 & - \\
Meia vida ${ }^{234} \mathrm{U}$ & $2,454(6) \times 10^{5}$ & Anos \\
Meia vida ${ }^{235} \mathrm{U}$ & $7,037(11) \times 10^{8}$ & Anos \\
Meia vida ${ }^{238} \mathrm{U}$ & $4,468(5) \times 10^{9}$ & Anos \\
Configuração eletrônica & {$[R n] 7 \mathrm{~s}^{2} 5 \mathrm{f}^{4}$} & - \\
Atividade específica ${ }^{234} \mathrm{U}$ & $6,2432 \times 10^{-3}$ & $\mathrm{Ci} / \mathrm{g}$ \\
Atividade específica ${ }^{235} \mathrm{U}$ & $2,1621 \times 10^{-6}$ & $\mathrm{Ci} / \mathrm{g}$ \\
Atividade específica ${ }^{238} \mathrm{U}$ & $3,3513 \times 10^{-7}$ & $\mathrm{Ci} / \mathrm{g}$ \\
\hline u.m.a. é abreviação de unidade de massa atômica. &
\end{tabular}

OBS: Valores entre parênteses estão relacionados com os valores da incerteza de medição.

Atualmente o uso mais explorado do urânio é através da característica do seu isótopo ${ }^{235} \mathrm{U}$ de fissionar-se e também pela capacidade de sustentar uma reação em cadeia de fissão, gerando grande quantidade de energia térmica. 
O isótopo físsil do urânio é o ${ }^{235} \mathrm{U}^{8}$, podendo fissionar-se, por nêutrons térmicos, de 53 maneiras diferentes, segundo o princípio de conservação de energia. A FIGURA 1 apresenta uma reação de fissão em cadeia para o isótopo ${ }^{235} \mathrm{U}$ (TERREMOTO, 2004; SCHMITZ, 2012; UFSM, 2013).

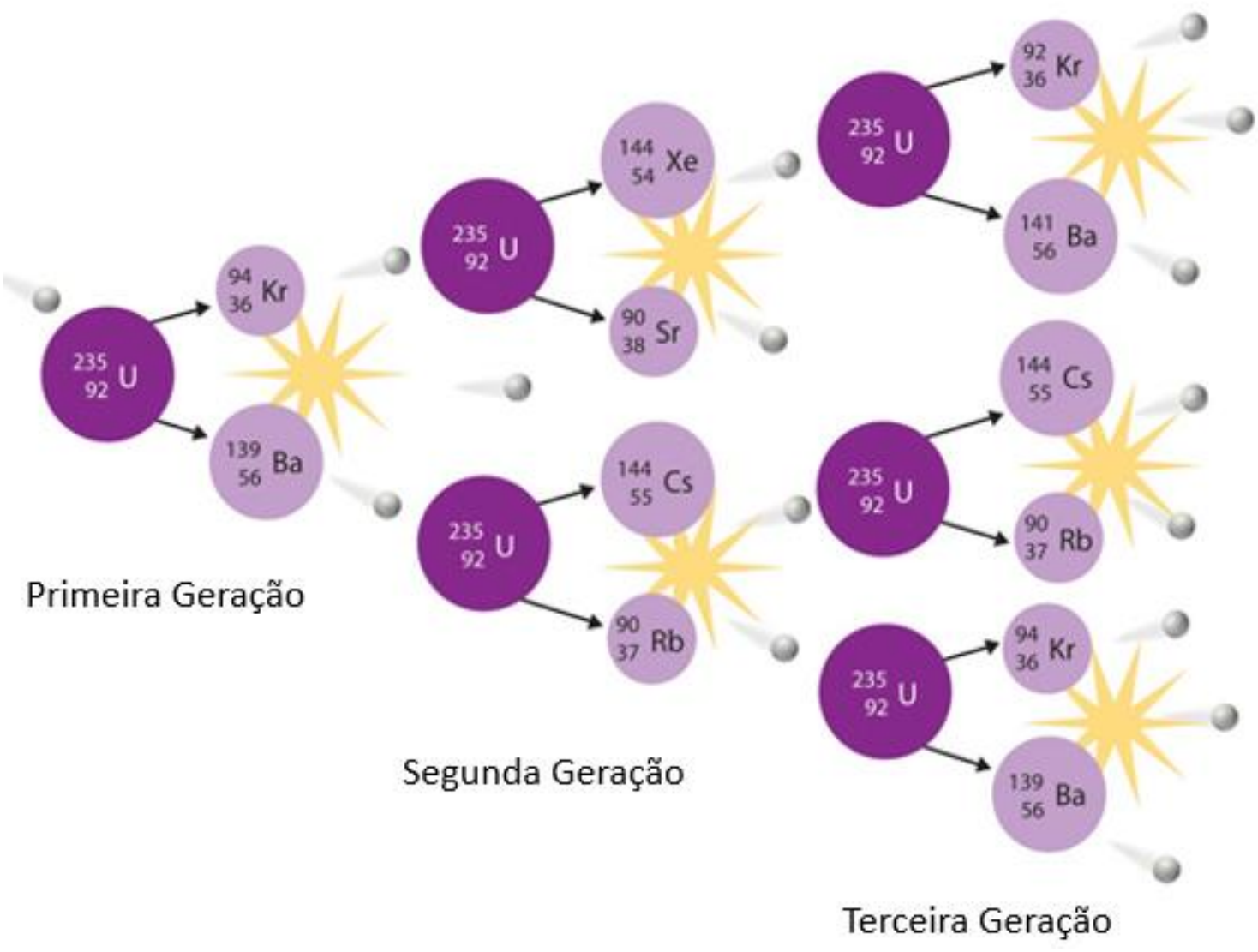

FIGURA 1: Alguns processos de fissão do ${ }^{235} \mathrm{U}$ que ocorrem através de uma reação de fissão em cadeia (SCHMITZ, 2012).

Considerando a enorme quantidade de energia gerada em um evento de fissão ${ }^{9}$, o rendimento energético de $1 \mathrm{~g}$ de ${ }^{235} \mathrm{U}$ fornece 80 milhões de $\mathrm{kJ}$ em comparação aos $16 \mathrm{~kJ}$ gerado por $1 \mathrm{~g}$ TNT. Desse modo um processo de fissão nuclear libera uma quantidade de energia 5 milhões de vezes maior que TNT.

Sendo assim, atualmente, o uso mais importante do urânio é como material físsil em combustível nuclear para centrais térmicas, chamadas de reatores nucleares, comumente utilizados para geração de energia elétrica ou como propulsores navais em

\footnotetext{
${ }^{8} \mathrm{O}$ isótopo ${ }^{233} \mathrm{U}$ também é físsil, porém não comumente utilizado.

${ }^{9}$ Uma fissão do isótopo ${ }^{235} \mathrm{U}$ gera cerca de $200 \mathrm{MeV}$, comparada com alguns MeV para outras reações nucleares e alguns eV para as reações químicas (TERREMOTO, 2004).
} 
reatores de potência, ou para estudo de irradiação de materiais e/ou produção de radiofármacos em reatores de pesquisa (TERREMOTO, 2004; ACA, 2013).

Segundo dados da NEA e AIEA, existem no mundo 440 reatores de potência em funcionamento, sendo 64 em construção e 247 reatores de pesquisa em operação (AIEAb, 2012; AIEAd, 2013; NEA, 2013).

\subsection{Ciclo do combustível nuclear}

Para que o urânio seja passível de ser utilizado em reatores, há a necessidade de transformar a rocha que contêm urânio em um composto com composição química definida e com baixos níveis de impurezas, atingindo o chamado 'grau nuclear'. Para tal o urânio necessita passar por processos químicos e físicos que, neste contexto, são chamados de Ciclo do Combustível Nuclear - CCN.

Desse modo, o CCN se refere a todas as atividades relacionadas com a produção e uso de material físsil, que, segundo Aquino 2008, pode ser entendido como um conjunto de plantas de processamento químico do urânio onde se desenvolvem diversas operações unitárias, que direta ou indiretamente promovem diferentes graus de purificação, segundo condições físico-químicas muito bem controladas.

O conjunto de etapas do CCN está representado na FIGURA 2.

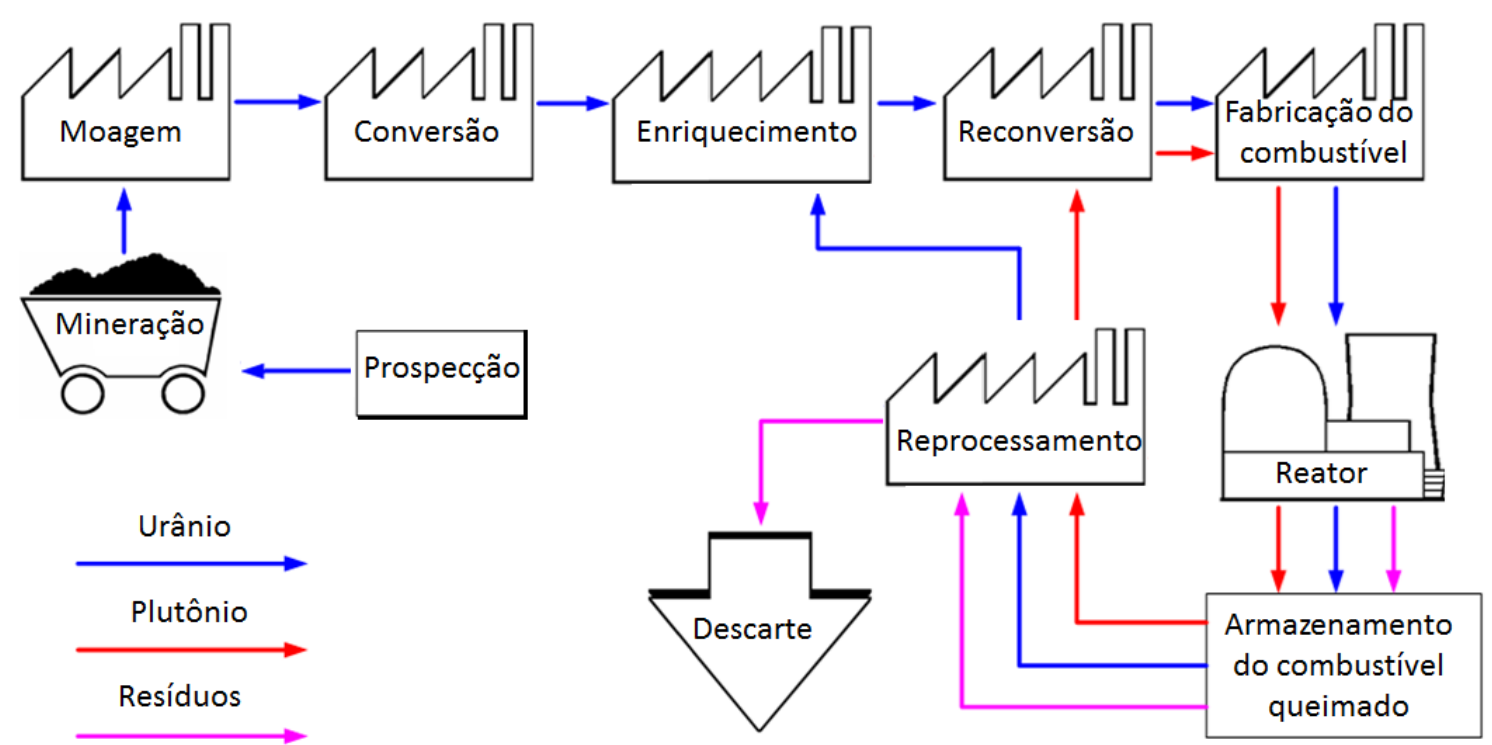

FIGURA 2: Conjunto de plantas de processamento do urânio, chamado de ciclo do combustível nuclear. Adaptado: BALDWIN, 2006. 
Na FIGURA 3 está apresentada uma das rotas químicas comumente utilizadas nos processos desenvolvidos no CCN para a fabricação de combustível nuclear enriquecido a base de $\mathrm{UO}_{2}$.

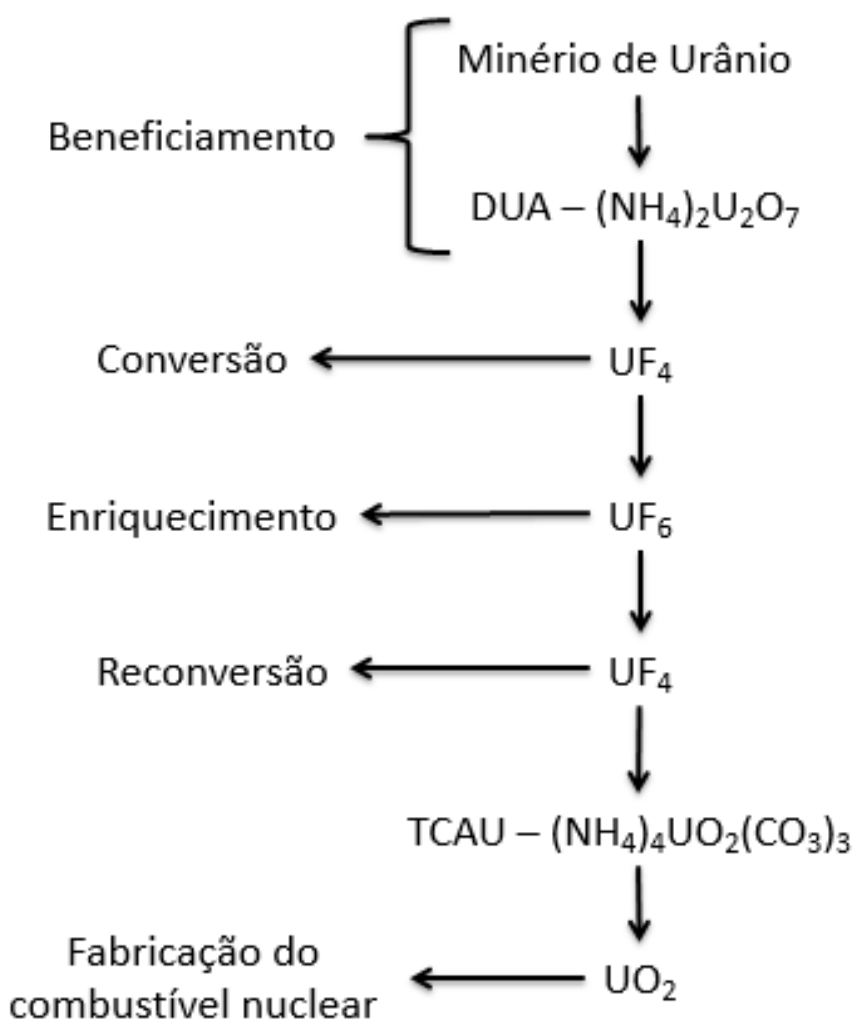

FIGURA 3: Uma das rotas frequentemente utilizada na produção do combustível nuclear a base de $\mathrm{UO}_{2}$.

Conforme mostrado na FIGURA 2, o CCN pode ser dividido em:

- Prospecção

O CCN se inicia na sondagem de jazidas de urânio e sua avaliação econômica, etapa chamada de prospecção da área a ser explorada. Atualmente com 25 a $30 \%$ do território brasileiro prospectado, as reservas geológicas expressas em $\mathrm{U}_{3} \mathrm{O}_{8}$ somam aproximadamente 310 mil toneladas, sendo a sexta maior reserva de minério de urânio do mundo, segundo a TABELA 2 (CNEN 2010; INB 2013). 
TABELA 2: Distribuição das reservas mundiais de urânio, expressas em toneladas de $\mathrm{U}_{3} \mathrm{O}_{8}$ e U.

\begin{tabular}{l|cc}
\hline \multicolumn{1}{c|}{ País } & $\boldsymbol{t} \boldsymbol{U}_{3} \boldsymbol{O}_{\boldsymbol{8}}$ & $\boldsymbol{t} \boldsymbol{U}$ \\
\hline \multirow{2}{*}{ Austrália } & $<\mathrm{US} \$ 130 / \mathrm{kg} \mathrm{U}$ & $<\mathrm{US} \$ 130 / \mathrm{kg} \mathrm{U}$ \\
Cazaquistão & 1.462 .000 & 1.243 .000 \\
Rússia & 961.000 & 817.000 \\
África do Sul & 641.000 & 546.000 \\
Canadá & 512.000 & 435.000 \\
EUA & 497.000 & 423.000 \\
Brasil & 399.000 & 342.000 \\
\hline
\end{tabular}

Fonte: Indústrias Nucleares do Brasil (INB, 2013).

- Mineração e beneficiamento

Os processos industriais se iniciam nas etapas de mineração e beneficiamento. Entende-se como beneficiamento do urânio as etapas de tratamento do minério que envolve processos como britagem, lixiviação, extrações e a produção do concentrado de urânio, chamado diuranato de amônio, DUA, ou popularmente de torta amarela - yellow cake (AQUINO, 2008).

- Conversão

Nesta etapa é produzido o hexafluoreto de urânio, $\mathrm{UF}_{6}$, (único composto gasoso estável de urânio) utilizado na tecnologia de enriquecimento por processos de gás dinâmico.

- Enriquecimento isotópico do urânio

O processo de enriquecimento isotópico do urânio é necessário para a fabricação do combustível nuclear para a maioria dos reatores e para a fabricação de armas nucleares.

$\mathrm{O}$ enriquecimento consiste em aumentar a fração mássica do isótopo físsil ${ }^{235} \mathrm{U}$ que é de apenas $0,71 \%$ no urânio natural, para 2 a 5\%, viabilizando seu uso como combustível em alguns reatores de potência.

Este valor, entretanto, pode ser elevado a $20 \%$ para reatores de pesquisas, ou chegando a patamares acima de 90\%, utilizados em reatores HTGR, High Temperature 
Gas Reactor, assim como na fabricação de armas nucleares (TERREMOTO, 2004; MEDALIA, 2010).

$\mathrm{Na}$ tecnologia de enriquecimento de urânio são conhecidos processos de gás dinâmico (difusão gasosa e ultracentrifugação) além de processos físicos (eletromagnetismo ou ionização por laser). Atualmente os dois principais processos adotados para a realização do enriquecimento isotópico do urânio são a difusão gasosa e a ultracentrifugação (DONOHUE, 2003; USNRC, 2013).

- Reconversão

$\mathrm{O} \mathrm{UF}_{6}$ não é apropriado para fabricação do combustível nuclear, havendo necessidade de uma transformação, denominada reconversão, para uma forma física mais adequada, entre as mais comuns pastilhas de $\mathrm{UO}_{2}, \mathrm{U}_{3} \mathrm{O}_{8}$ e $\mathrm{MOX}$ (Mixed Oxide Fuel), composto e $\mathrm{UO}_{2}$ e $\mathrm{PuO}_{2}$, além de ligas a base de silício $\left(\mathrm{U}_{3} \mathrm{Si}_{2}\right)$ e molibdênio (U-Mo) (AQUINO, 2008; SALIBA-SILVA, 2008; AREGBE, 2009).

- Fabricação do combustível nuclear e sua utilização

Nesta etapa é feita a montagem do elemento combustível, que consiste em um conjunto de varetas combustíveis, onde internamente é selado o material físsil desejado. Os elementos combustíveis podem ser utilizados em reatores de potência, entre os mais comuns o PWR - Pressurized Water Reactor e o BWR - Boiling Water Reactor, assim como em reatores de pesquisa, por exemplo, o tipo piscina chamados de MTR - Materials Testing Reactor (TERREMOTO, 2004).

- Reprocessamento

O combustível queimado pode ser reaproveitado após o apropriado tempo de resfriamento. A maioria dos processos na etapa de reprocessamento é baseada na extração líquido-líquido para a separação do urânio, plutônio e outros produtos de transmutação como amerício e cúrio, além dos produtos de fissão, sendo o mais utilizado o processo PUREX $^{10}$ (AREGBE, 2009).

Os processos de extração e separação têm como finalidade aproveitar o urânio remanescente assim como o plutônio formado (para fabricação de combustíveis MOX) dos

${ }^{10}$ É um acrônimo para a Plutonium URanium EXtraction. Processo desenvolvido durante o Projeto Manhattan. 
combustíveis queimados, para serem reutilizados nas etapas de enriquecimento e conversão, respectivamente.

Como desfecho final do ciclo, os rejeitos formados, durantes as etapas do processamento do urânio, são tratados e os resíduos finais com níveis ambientais de radioatividade são descartados ao meio ambiente e os que contêm atividade são devidamente estocados em locais apropriados.

Todo material físsil apresenta um potencial energético dual, isto quer dizer que, a energia liberada pelas reações em cadeia de fissão, tanto pode ser utilizada para geração de energia elétrica e outras formas pacíficas, quanto para o uso ilícito.

Tendo em foco a não proliferação nuclear, os processos tecnológicos, dentro do CCN, para produzir material físsil para fins pacíficos ou não, são essencialmente similares, consequentemente, o processo de enriquecimento bem como a etapa de reprocessamento, que são consideradas as fases mais sensíveis dentro CCN, devem apresentar um sistema de verificação e controle mais rigoroso por parte da AIEA (DOUCET, 2011).

Consequentemente, o conhecimento técnico dos processos envolvidos no $\mathrm{CCN}$ é de suma importância para o inspetor de salvaguardas, visto que, é onde irá extrair subsídios para conduzir a inspeção a pontos estratégicos e críticos de cada etapa, com o intuito de verificar se as atividades nucleares estão sendo conduzidas de forma pacífica e declaradas.

\subsection{Sistema de salvaguardas do material nuclear}

A história da utilização da energia nuclear tem como início também a história do sistema de salvaguardas do material nuclear. Desde os primórdios da era nuclear, rapidamente foi reconhecido que a utilização dessa tecnologia exige a necessidade de um controle rigoroso (FISCHER, 1999).

Para tal foi criado um sistema de contensão, verificação e controle que são baseados no uso integrado dos acordos de salvaguarda, controle de exportações e proteção física formando os pilares do regime de não proliferação nuclear, conforme a FIGURA 4. 


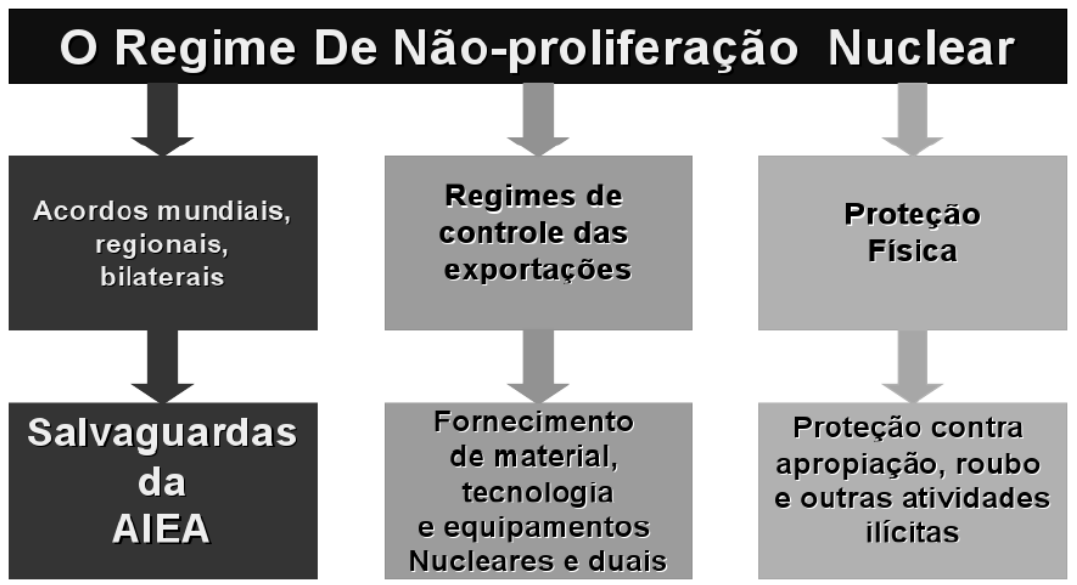

FIGURA 4: Tríade que formam o regime de não proliferação nuclear.

A proteção física está relacionada com a proteção contra roubo, sabotagem, apropriação de qualquer material ou tecnologia que esteja relacionado com o CCN. Ferramentas como: sistema de vigilância, monitoração remota, sensores de movimento bem como controle de acesso são utilizadas (RICHTER, 2008; FUNK, 2013).

O controle de exportações está relacionado com o comércio e fornecimento de qualquer material, tecnologia ou equipamentos nucleares que são negociados entre países e que devem seguir tratados específicos.

A salvaguarda do material nuclear é uma das atividades mais importantes inserida no universo do regime de não proliferação nuclear. São medidas destinadas ao controle e proteção do material nuclear e estão sendo aplicadas junto aos países signatários através de organizações internacionais, como AIEA, EURATOM ${ }^{11}$ e ABACC ${ }^{12}$.

A base legal para a atuação dessas organizações provém de acordos internacionais ${ }^{13}$ assinados entre os Estados membros e a própria agência que estabeleceram os direitos e obrigações das partes interessadas, no qual constitui o sistema de salvaguardas.

O sistema de salvaguardas tem como objetivo, detectar a tempo, desvios de quantidades significativas de material nuclear de atividades nucleares pacíficas (dentro do regime regulatório) para a fabricação de armas nucleares ou outros dispositivos nucleares (parte II, parágrafo 28, INFCIRC/153), garantindo a comunidade internacional que os Estados signatários estão cumprindo com seus compromissos de utilizar a tecnologia nuclear apenas para fins pacíficos (AIEA, 1972; DONOHUE, 1998; AIEAb, 2013).

\footnotetext{
${ }^{11}$ EURATOM - European Atomic Energy Community - Comunidade Europeia de Energia Atômica

12 ABACC - Agência Brasileiro-Argentina de Contabilidade e Controle de Materiais Nucleares

13 Dentre os acordos de salvaguardas destacam-se os: INFCIRC/26, INFCIRC/66/rev2, INFCIRC/140, INFCIRC/153, INFCIRC/435 e INFCIRC/540.
} 
No Brasil, o uso pacífico da tecnologia nuclear é garantido pela Constituição Nacional, sob Art. XXIII (a) onde menciona:

“(...) Toda atividade nuclear em território nacional somente será admitida para fins pacíficos e mediante aprovação do Congresso Nacional " (CONSTITUIÇÃO DA REPÚBLICA FEDERATIVA DO BRASIL, 2010).

A Comissão Nacional de Energia Nuclear - CNEN é uma autarquia federal vinculada ao Ministério de Ciência e Tecnologia responsável pelas salvaguardas do material nuclear no Brasil. Suas atribuições legais são: executar ações de pesquisa, desenvolvimento, regulamentação, fiscalização e licenciamento na área nuclear em território nacional (CNEN, 2011; CNEN, 2013a).

No período das décadas de 80 e 90, intensas negociações foram realizadas entre Brasil e Argentina no âmbito nuclear. No dia 18 de julho de 1991, em Guadalajara, foi assinando o acordo mútuo do uso exclusivamente pacífico da energia nuclear (Acordo Bilateral) no qual, entre outras providências, foi criada a ABACC (ABACC, 2013a).

$\mathrm{A} \mathrm{AB} A C \mathrm{C}$ tem compromisso de garantir, à Argentina, ao Brasil e à comunidade internacional, que todas as atividades nucleares, dentro de seus territórios, sejam utilizadas com fins exclusivamente pacíficos, fornecendo transparência sobre seus programas nucleares, criando um ambiente de confiança mútua e colaborando, construtivamente, com as políticas de não proliferação nuclear que ambos os países aderiram no âmbito internacional (ABACC, 2013b).

Um dos principais acordos nucleares onde o Brasil é signatário é o Quadripartite de 13 de dezembro de 1991. Por meio desse acordo o Brasil, Argentina, ABACC e a AIEA assinaram para aplicação de salvaguardas em território brasileiro e argentino sob supervisão de ambas as agências. Acordo no qual é baseado no INFCIRC/435 e entrou em vigor no dia 4 de março de 1994 (AIEA, 1994).

Mesmo o Brasil sendo um Estado membro da AIEA desde 29 de julho de 1957, foi somente assinar o TNP, de 1970, no ano de 1998 no governo de Fernando Henrique Cardoso (AIEA, 2012). 


\subsubsection{Procedimentos de salvaguardas}

Os procedimentos de salvaguardas aplicados pela AIEA são baseados na contabilização, controle, contenção, vigilância e verificação dos materiais nucleares declarados pela instalação (KHATER, 2005).

Estes procedimentos de salvaguardas, isto é, as medidas técnicas implementadas, são decorrente do tipo de acordo em vigor que o Estado tem com a AIEA (AIEAb, 2013).

No geral eles incluem:

i. Verificações das informações geradas pelo Estado;

ii. Verificação do projeto da instalação nuclear;

iii. Manutenção e fiscalização de registros contábeis dos materiais nucleares;

iv. Medidas de confinamento e vigilância dos mesmos;

v. Relatórios contendo informações sobre as inspeções conduzidas por inspetores da AIEA;

vi. Amostragens ambientais, como parte integrante do Protocolo Adicional INFCIRC/540.

Para que o sistema seja eficiente são necessárias ações conjuntas entre os responsáveis pela instalação nuclear, autoridades Nacionais e a AIEA (HOOPER 1999; MCCLAIN, 2005).

Após o estabelecimento do acordo, o processo de salvaguarda é iniciado pelo Estado enviando à AIEA um relatório completo contendo informações sobre quais materiais nucleares dispõe, a quantidade e composição precisa desses materiais (dados contábeis), quais as instalações que os contêm e as atividades que são desenvolvidas nas mesmas.

Assim, a AIEA envia inspetores para verificar se as informações geradas pelos Estados estão de acordo com aquelas encontradas. Os inspetores aplicam as medidas técnicas acordadas e conduzem à AIEA informações relevantes como desfecho da avaliação deste processo.

A FIGURA 5 apresenta os procedimentos que incluem um sistema de salvaguarda e a relação entre o Estado signatário e a AIEA. 
O programa de salvaguardas

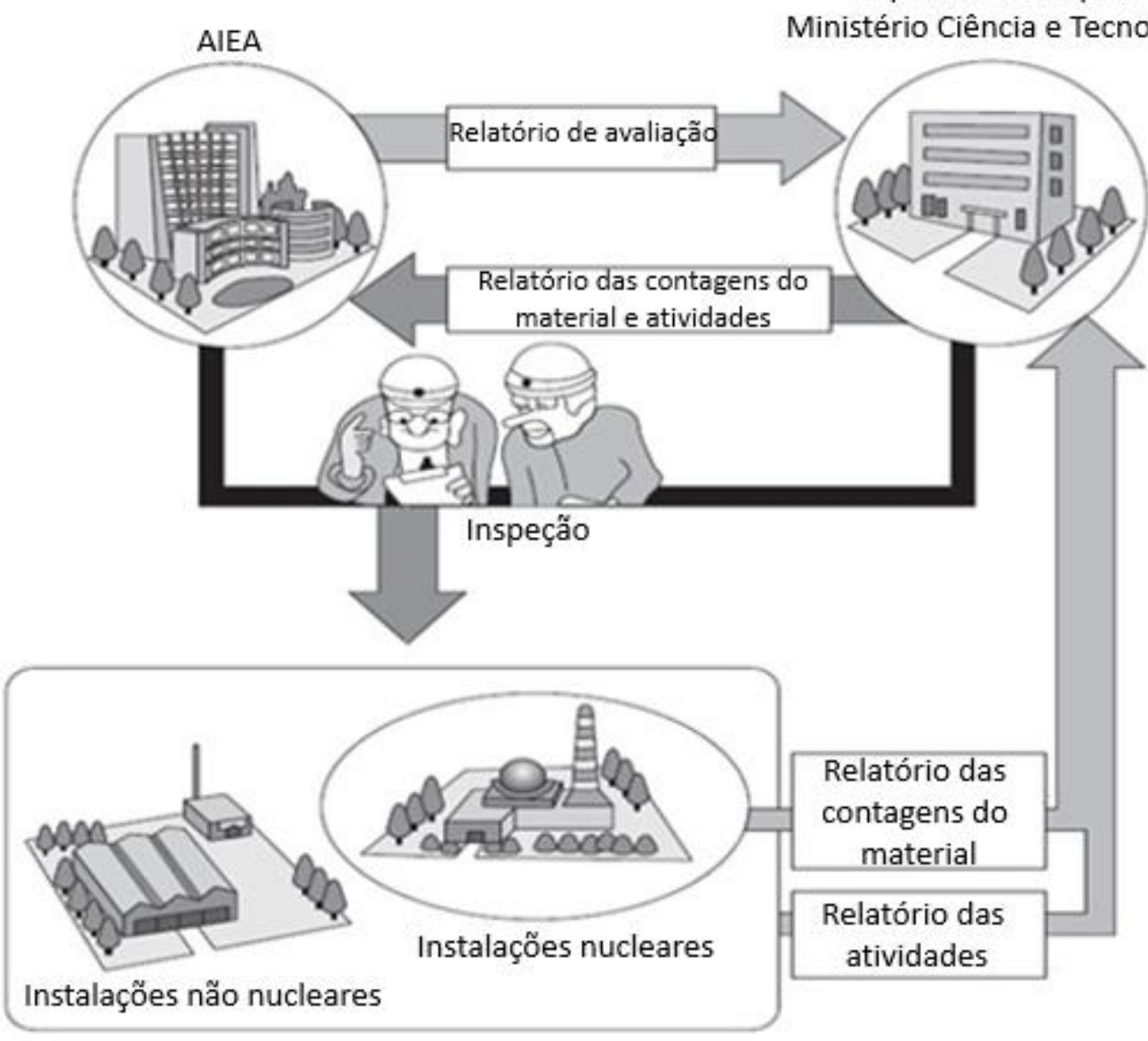

Sistema de salvaguardas

Supervisionado pelo

Ministério Ciência e Tecnologia

FIGURA 5: Fluxograma dos procedimentos de um sistema de salvaguardas aplicados pela AIEA (FEPC, 2002).

Segundo a AIEA, existem mais de 1200 instalações em todo o mundo que estão sob salvaguardas e no ano de 2012 foram aplicadas inspeções em 179 Estados membros. Desse total 119 Estados tinham em vigor acordos de salvaguardas com a adição do Protocolo Adicional (vide item 4.3.2.) e os 60 Estados restantes apenas acordos de salvaguardas sem o Protocolo Adicional dentre eles o Brasil (AIEAb, 2012).

A FIGURA 6 apresenta a evolução dos acordos de salvaguardas em Estados membros do ano de 2007 a 2012. 


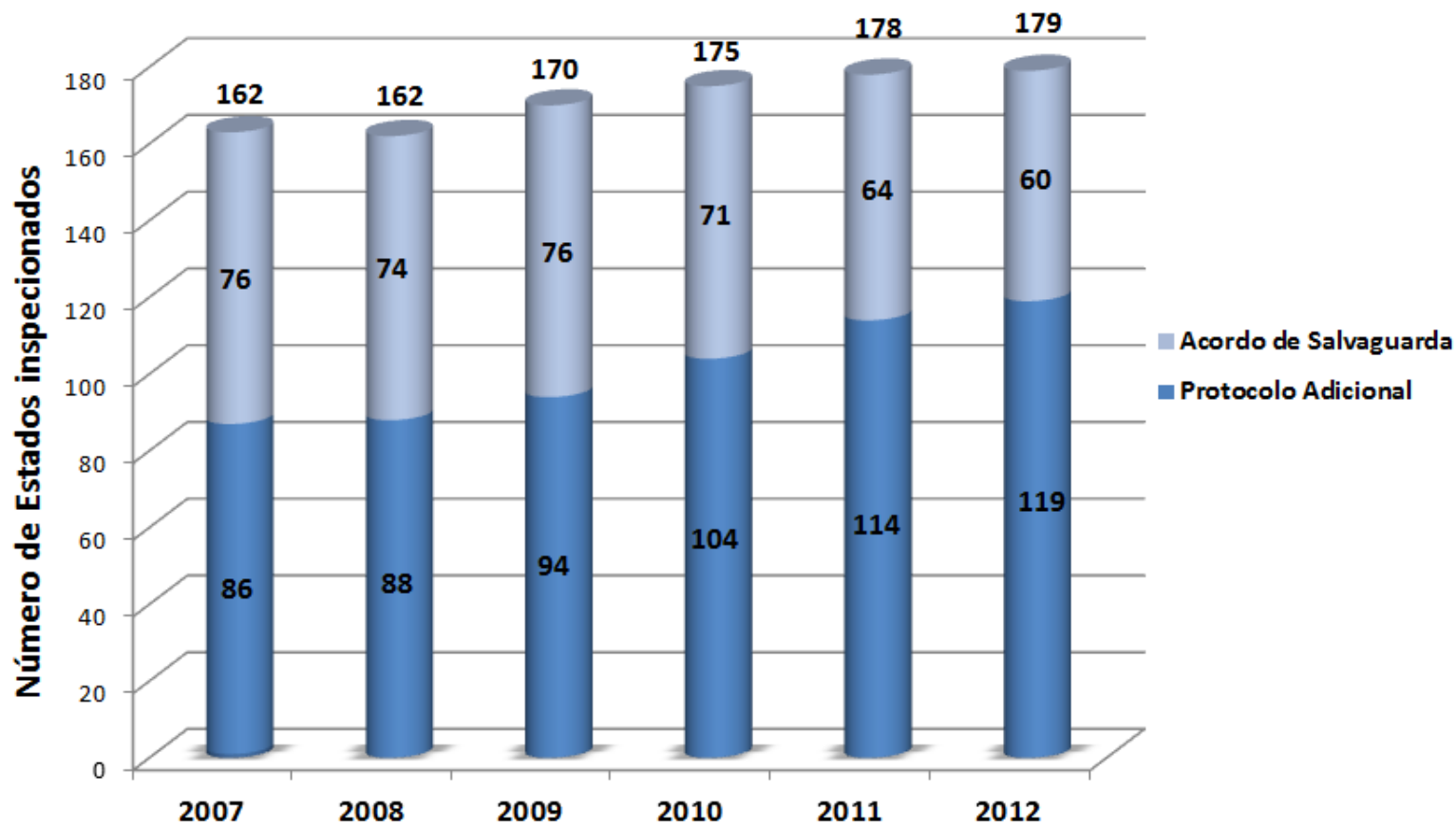

FIGURA 6: Evolução dos acordos de salvaguardas e Protocolo Adicional no período entre 2007 e 2012. Fonte: AIEA, 2011 e AIEAb, 2012.

\subsubsection{A descoberta da falha no sistema de salvaguardas - Programa 93+2}

Segundo Donohue e Moyland, o divisor de águas do sistema de salvaguardas ocorreu através de uma série de acontecimentos envolvendo atividades nucleares fora de regulamentação ao $\mathrm{TNP}^{14}$, em países como Iraque e Coréia do Norte, mesmo que ambos já eram, na época, signatários e, portanto, tinham o compromisso de utilizar a tecnologia nuclear apenas para fins pacíficos (MOYLAND, 1997; DONOHUE, 1998).

Logo após o Iraque invadir o Kuwait, na guerra do Golfo de 1991, a AIEA descobriu durante inspeções realizadas sob o Conselho de Segurança das Organizações das Nações Unidas - ONU, que o Iraque buscava caminhos para desenvolver, através de um programa nuclear clandestino, armas nucleares em instalações declaradas e muitas outras não declaradas (MOYLAND, 1997; BERRIMAN, 2004).

Foram encontradas instalações com equipamentos capazes de fazer separação isotópica eletromagnética de urânio, bem como ultracentrífugas a gás para seu enriquecimento isotópico, além de plantas de reprocessamento especializada em separação de plutônio dos combustíveis já irradiados (MOYLAND, 1997).

14 Tratado de não proliferação nuclear - INFCIRC/140 de 1970. 
De modo semelhante ao caso Iraquiano, em 1992 quando a AIEA foi verificar as informações iniciais geradas pela Coréia do Norte sobre seus materiais e instalações nucleares, ficou evidenciado incompatibilidades entre tais declarações e as atividades encontradas pelos inspetores (MOYLAND, 1997).

As análises das amostras de esfregaços coletadas em glove-box apontaram que a Coréia do Norte havia processado combustíveis nucleares além dos declarados. Imagens de satélites feitas pelos EUA indicaram também, que haviam instalações nucleares subterrâneas não declaradas em território norte-coreano (MOYLAND, 1997).

Assim, até então, o sistema de salvaguarda vigente ${ }^{15}$ não era suficientemente capaz de detectar programas nucleares paralelos (clandestinos), mesmo dentro de Estados onde já eram desenvolvidas inspeções de salvaguardas. Desse modo o pilar central do regime de não proliferação nuclear entraria ameaçado em entrar em colapso (FISCHER, 1999; DONOHUE, 2003).

Dessa forma, a comunidade internacional concordou que o sistema de salvaguardas da AIEA teria a necessidade de ser fortalecido, assim como sua capacidade em detectar atividades nucleares não declaradas, reestabelecendo, dessa forma, sua credibilidade (SCHRIEFER, 1996; DONOHUE, 1998; HOOPER 2003).

Desse modo, o Conselho dos Governadores da AIEA, requisitou ao SAGSI Standing Advisory Group on Safeguards Implementation, grupo da AIEA formado por especialistas em salvaguardas, que apresentasse novas medidas de fortalecimento ao sistema. Assim foi desenvolvido o Programa 93+2, que ampliaria os poderes das AIEA em fiscalizar e controlar melhor suas atribuições legais (DONOHUE, 1998; HOOPER 2003).

O Programa 93+2 foi criado em 1993 e após dois anos de discussões, com a revisão do TNP e extensão de convenções, foi estabelecido seu início.

Segundo Schriefer, 1996 e Donohue, 1998 o desenvolvimento do Programa teve como pressuposto e objetivo único aumentar o nível mundial de segurança nuclear em relação ao uso não declarado de atividades nucleares.

A nova prática incluiu atividades relacionadas à ampliação do acesso à informação por parte da AIEA, através de medidas tais como (SCHRIEFER, 1996):

i. Amostragens ambientais;

ii. Uso de inspeções não anunciadas;

${ }^{15}$ INFCIRC/153 
iii. Extensão do acesso físico aos inspetores da AIEA às instalações nucleares e não nucleares;

iv. Providenciar informações sobre qualquer instalação, como parte das obrigações do Estado signatário;

v. Uso de sistemas de monitoração remota;

vi. Informações sobre pesquisas e desenvolvimento da área nuclear;

vii. Informações sobre minas de urânio e tório;

viii. Maior cooperação com os Sistemas Estaduais de Contabilidade e Controle de Materiais Nucleares (SSACs).

Os novos direitos de acesso também se estendem às instalações, empresas e instituições de pesquisa que não utilizam ou possuem qualquer material nuclear, mas que estão relacionadas de alguma forma com o ciclo do combustível nuclear e suas tecnologias. Isto implica que o sistema de salvaguarda não é mais meramente relacionado com a presença de material nuclear (HOOPER 2003).

Porém, o acordo de salvaguarda vigente fornecia a base legal apenas para a aplicação das salvaguardas em locais declarados. Desse modo, com as novas medidas foi necessária a negociação de um acordo complementar ao INFCIRC/153, onde ratificasse a implementação das melhorias desenvolvidas durante o Programa 93+2, acordo no qual foi chamado de Protocolo Adicional - INFCIRC/540 (FISCHER, 1999).

De acordo com o Protocolo Adicional o Estado signatário tem que declarar seu passado, presente e intenção das suas atividades nucleares, incluindo descrição de todas as instalações, condições das atividades, acrescentando suas pesquisas e desenvolvimento no âmbito nuclear (FISCHER, 1999; HOOPER 2003).

Durante o Programa também foi desenvolvido o chamado Modelo Físico - The Physical Model. Foi um projeto para identificar, descrever e caracterizar os vários componentes do $\mathrm{CCN}$, fornecendo uma ferramenta técnica no auxílio na identificação de programas de produção de materiais para armas e outros dispositivos nucleares (LIU, 2007).

Sendo assim, com todo o sistema de salvaguardas reformulado, as garantias apresentaram-se robustas, tornando a AIEA capaz de detectar atividades nucleares não declaradas em estágios iniciais, em Estados que haviam assumido compromissos de utilizar a tecnologia nuclear somente para fins pacíficos. 


\subsubsection{Amostras ambientais}

Uma das principais medidas de fortalecimento proposta no Programa $93+2$ foi a implementação das amostragens ambientais no sistema de salvaguardas. O poder dessas amostragens foi demonstrado, durante o programa, através de uma série de ensaios de campo, conduzidos dentro e em torno de doze instalações nucleares em onze Estados membros. A conclusão geral obtida foi que, através das análises das amostras, foram adquiridas assinaturas nucleares proveniente dos locais coletados (DONOHUE, 1998).

Sendo assim, com o sucesso dos ensaios, em janeiro de 1996, o conselho de Governadores da AIEA tomou a decisão de implantar as amostragens ambientais como parte das rotinas nas inspeções, marcando, com o Protocolo Adicional, o início legal dessas amostragens como uma nova medida de fortalecimento no sistema de salvaguardas (DONOHUE, 1998; KUHN, 2001; DONOHUE 2002).

A utilização das amostras ambientais é baseada no princípio que toda manipulação de material nuclear, não importa o quão selado e estanque é a instalação, emite pequenas quantidades desse material processado, em forma de partículas ou aerossóis ao meio ambiente (TAMBORINI, 1998; KUHN, 2001; ALDAVE, 2002; KIPS, 2009; STURM, 2010).

Este material pode-se depositar em equipamentos e superfícies dentro das instalações, assim como pode ser transportado para fora depositando-se sobre vegetações, solo ou ser conduzido por sistemas de água em torno das instalações nucleares.

Essas partículas emitidas são difíceis de serem totalmente removidas do ambiente, com o intuito de tornar a área inspecionada limpa, como uma forma de esconder as atividades nucleares desenvolvidas (RANEBO, 2009).

Esse material carrega uma impressão nuclear, chamada de assinatura, finger-print, relacionada com os processos e atividades desenvolvidas nas instalações, trazendo indicativos do processo que as derivam (TAMBORINI, 1998; KUHN, 2001; KIPS, 2009; STURM, 2010).

Antes, as amostragens ambientais eram realizadas em instalações de enriquecimento e locais onde se manipulavam combustíveis já irradiados, chamadas de células quentes, hot cells, atualmente, com o Protocolo Adicional, os locais se estenderam para o chamado áreas amplas, wide-area (DONOHUE, 1998).

$\mathrm{O}$ termo wide-area tem sido utilizado para designar locais além daqueles a que os inspetores tinham acesso para inspeções, mas em regiões de centenas e milhares de $\mathrm{km}$ 
quadrados ao redor das instalações. Incluindo também, locais sem estoque de materiais nucleares, onde há operações de mineração e descarte de matérias nucleares (KUHN, 2001; KALINOWSKI, 2009).

As amostras ambientais têm sido coletadas em um meio amostral diversificado, como, ar, água, sedimento, vegetação, solo, biota, filtros de ar, assim como amostras de esfregaços (DONOHUE, 2002; AIEA, 2002).

Um dos primeiros trabalhos encontrados na literatura internacional utilizando amostras ambientais para identificação de assinaturas nucleares foi de Buchmann, utilizando como bioindicadores agulhas de pinheiros coletadas em pontos próximos a duas instalações nucleares (IPEN e o Centro Tecnológico da Marinha em São Paulo - CTMSP). No trabalho foi possível identificar assinaturas de elementos como cobalto e níquel (presentes em altas porcentagens em alguns tipos de aço maraging utilizados em ultracentrífugas de enriquecimento isotópico), lantânio e cério (manipulado em grandes quantidades em instalações de purificação de zircônio), samário e cobalto (suas ligas são largamente utilizadas em magnetos de alta performance, sendo importantes constituintes de ultracentrífugas), tório que é um elemento típico encontrado em plantas do $\mathrm{CCN}$, além de valor de 0,0092 para a razão $n\left({ }^{235} U\right) / n\left({ }^{238} U\right)$ com uma incerteza expandida de 2,2\% (BUCHMANN, 2003 e 2006).

\subsubsection{Esfregaços}

Dentre as amostras ambientais, as amostragens por esfregaços, conhecidas como swipe samples tornaram-se uma das ferramentas mais importantes nas inspeções conduzidas pela AIEA para certificar que atividades nucleares clandestinas não estão sendo ignoradas (SZÉLES, 2010).

A coleta das amostras pela técnica esfregaços consiste em esfregar em uma superfície um pedaço de tecido com o intuito de remover partículas de materiais nucleares ali depositados (KRAIEM, 2011).

Essa coleta pode ser realizada em qualquer lugar dentro e fora da instalação, mas ocorre, preferencialmente, em áreas de trabalho como, paredes, pisos, capelas, glove-box, assim como em sistemas de exaustão, onde existe a maior probabilidade de encontrar partículas de materiais nucleares (MARIN, 2013).

Embora o conceito seja simples, os procedimentos utilizados para a coleta dos esfregaços podem, na prática, variar de forma considerável. Um método padrão ou técnica 
para a coleta dos esfregaços não existe, uma vez que os tecidos são flexíveis e permite coletas em lugares de difícil acesso, podendo ser utilizado em qualquer tipo de superfície (EPA, 2011).

Os esfregaços segundo Donohue, 1988, apresentam vantagens frente às outras amostragens ambientais, pelo fato de conter muito pouco urânio nos tecidos, diminuindo assim a possibilidade de urânio antropogênico mascarar o urânio proveniente da instalação, como pode ocorrer, por exemplo, em amostras de solo.

É importante notar que a coleta de amostras ambientais é um processo dinâmico. A amostragem realizada representa os vestígios em um local particular no espaço e no tempo. Existe também, a possibilidade de encontrar vestígios de atividades passadas, que ocorrem por acumulação ao longo do tempo ou devido à mistura e ressuspensão. Isto é mais comum quando a coleta de amostras é realizada perto de locais onde emissões de particulados são frequentes (KALINOWSKI, 2009).

A FIGURA 7 apresenta uma coleta real de esfregaços realizada no presente trabalho nas imediações do Centro do Combustível Nuclear do IPEN.

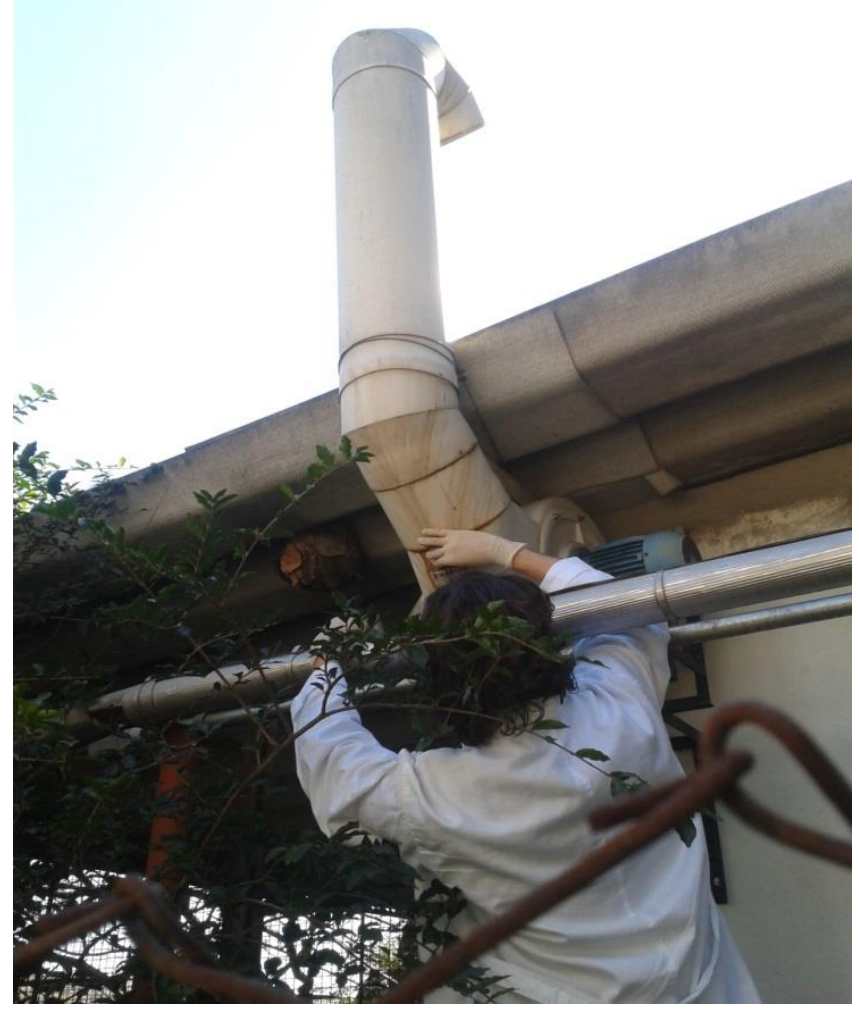

FIGURA 7: Coleta de amostras pela técnica esfregaços 
Em 1996, também durante o Programa 93+2, a AIEA montou em Seibersdorf na Áustria, o Laboratório Analítico de Salvaguardas, Safeguards Analytical Laboratory SAL, classe 100, que é responsável pela preparação de material, triagem, distribuição e análises das amostras ambientais (DONOHUE, 1998).

Em seguida, a AIEA iniciou a criação da Rede de Laboratórios Analíticos, Network of Analytical Laboratories - NWAL, para análises das amostras ambientais e que atualmente dispõe de 20 laboratórios credenciados distribuídos pelos Estados membros, sendo um localizado no Rio de Janeiro, o Laboratório de Espectrometria de Massas do Instituto de Radioproteção e Dosimetria IRD/CNEN (AIEA, 2007; IRD 2013).

Segundo dados da AIEA, são analisados pelo NWAL cerca de 800 amostras de esfregaços a cada ano (AIEAc, 2013).

$\mathrm{Na}$ literatura existem alguns trabalhos com análise de esfregaço. A destacar:

Zhang, 2007 utilizou um MEV-EDS para identificar partículas de urânio em amostras simuladas de esfregaço. Com a ajuda de um micro-manipulador acoplado transferiu estas partículas para filmes de silício para serem dissolvidas em meio nítrico para posterior análise isotópica em um HR-ICP-MS. Para partículas entre 0,5 e 3,9 $\mu \mathrm{m}$ a razão $n\left({ }^{235} U\right) / n\left({ }^{238} U\right)$ foi determinada com sucesso com desvio-padrão relativo de $4,2 \%$. A partir dos resultados, o autor considera a metodologia proposta como uma alternativa para análise de partículas individuais para fins de salvaguardas.

Godoy, do IRD, publicou estudos sobre a análise de razão isotópica e concentração de plutônio e urânio em amostras de esfregaços e de solo para fins de salvaguardas nucleares. A técnica analítica utilizada foi um ICP-QMS com nebulizador ultrassônico. Como metodologia foi utilizada extração cromatográfica com resina Teva e Dowex 1x8. Incertezas expandidas de 0,4 a $1,6 \%$ foram relatadas pela autora para a razão $n\left({ }^{235} U\right) / n\left({ }^{238} U\right)$. A autora conseguiu níveis de precisão e acurácia requeridos pela AIEA para acreditação ao NWAL (GODOY, 2007 e 2009).

Szeles, 2010, utilizou para digestão dos esfregaços um sistema de micro-ondas e para separação cromatográfica a resina TRU. A análise dos isótopos de urânio e plutônio foi realizada utilizando um ICP-SF-MS. O método foi testado em amostras reais de esfregaços coletadas em uma instalação nuclear na Hungria. Incertezas expandidas de 3,8 a $6,2 \%$ foram relatadas pela autora para a razão $n\left({ }^{235} U\right) / n\left({ }^{238} U\right)$. Os resultados obtidos para o trabalho, segundo o autor, estão em boa concordância com os requeridos pelo NWAL.

Lee, 2011, aplicou um método de separação cromatográfica utilizando resina Uteva em meio nítrico, conseguindo níveis de recuperação de $94 \pm 7 \%$ e $95 \pm 5 \%$ para plutônio e 
urânio, respectivamente. $\mathrm{O}$ autor também faz um estudo sobre a utilização de $\mathrm{H}_{2} \mathrm{O}_{2}$ nas etapas de oxirredução preliminares à separação química. $\mathrm{O}$ método se mostrou efetivo para análises dos radionuclídeos em níveis de picogramas em amostras de esfregaços utilizando diluição isotópica e análise por TIMS.

Marin, 2013 utilizou a técnica de laser ablation ICP-MS para analisar razões isotópicas de urânio diretamente em amostras reais de esfregaços coletadas em uma planta de reconversão do Centro do Combustível Nuclear - IPEN. O autor encontrou razões $n\left({ }^{235} U\right) / n\left({ }^{238} U\right)$ variando de $0,023 \pm 0,007$ a $0,211 \pm 0,034$, obtendo incertezas expandidas de $3,5 \%$ a $29,8 \%$ para a mesma razão.

\subsection{Assinaturas que são buscadas em amostras de esfregaços}

Desde que as amostras ambientais estão sendo aplicadas como parte das inspeções de salvaguardas, a simples presença de urânio não é totalmente esclarecedora.

Nesses casos, informações mais específicas são necessárias para caracterizar a amostra, a fim de associá-la a uma atividade nuclear. O desafio está em extrair a maior quantidade de informações dessas amostras, para obter a mais completa imagem das atividades desenvolvidas na instalação inspecionada (MAYER, 2008; AXELSSON, 2009; POINTURIER, 2010).

Essas informações são chamadas de assinaturas, fingerprint, e são definidas como um conjunto de características específicas de um dado material que permitam a sua distinção, identificação de sua origem ou mesmo o estabelecimento do período no qual foi produzido. Elas incluem características químicas, físicas, elementares e isotópicas (AIEA, 2006).

Assinaturas químicas estão relacionadas com a forma química do material, por exemplo, diferentes compostos de urânio: $\mathrm{UO}_{2}, \mathrm{U}_{3} \mathrm{O}_{8}, \mathrm{UO}_{3}, \mathrm{U}^{\circ}, \mathrm{UF}_{4}, \mathrm{U}_{3} \mathrm{Si}_{2}$, no qual estão vinculadas com as etapas do $\mathrm{CCN}$, assim como associações com componentes orgânicos (Tributilfosfato - TBP, Tenoiltrifluoroacetona - TTA, Querosene) que podem ser indicativos de plantas de reprocessamento (AIEA, 2006).

Na TABELA 3 são apresentados diferentes compostos de urânio que podem ser encontrados em instalações de cada etapa do CCN. 
TABELA 3: Possíveis compostos associados com as etapas do CCN.

\begin{tabular}{l|c}
\hline \multicolumn{1}{c|}{ Processos de Produção } & Compostos encontrados \\
\hline Deposição geológica & Rochas contendo U e Th \\
Mineração e beneficiamento & $\mathrm{UO}_{2}\left(\mathrm{CO}_{3}\right)_{3}\left(\mathrm{NH}_{4}\right)_{4}, \mathrm{NH}_{4} \mathrm{U}_{2} \mathrm{O}_{7}, \mathrm{Na}_{2} \mathrm{U}_{2} \mathrm{O}_{3}, \mathrm{UO}_{2} \mathrm{SO}_{4}, \mathrm{UO}_{3}$ \\
Conversão & $\mathrm{UF}_{6}, \mathrm{UO}_{2} \mathrm{~F}_{2}, \mathrm{UF}_{4}, \mathrm{UO}_{2}, \mathrm{U}_{3} \mathrm{O}_{8}, \mathrm{U}^{\circ}, \mathrm{UO}_{2}\left(\mathrm{CO}_{3}\right)_{3}\left(\mathrm{NH}_{4}\right)_{4}$ \\
Enriquecimento isotópico & $\mathrm{UF}_{6}$ \\
Fabricação do combustível & $\mathrm{UO}_{2}, \mathrm{U}_{3} \mathrm{O}_{8}, \mathrm{U}_{3} \mathrm{Si}_{2}, \mathrm{U}-\mathrm{Mo}, \mathrm{PuO}_{2}+\mathrm{UO}_{2}(\mathrm{MOX}), \mathrm{ThO}_{2}$ \\
Reprocessamento & $\mathrm{Pu}, \mathrm{U}, \mathrm{Terras} \mathrm{Raras}(\mathrm{TR})$, Produtos de fissão (PF) \\
Descarte e armazenamento & $\mathrm{U}, \mathrm{TR}, \mathrm{PF}$ \\
\hline
\end{tabular}

Fonte: AQUINO, 2008; AIEAa, 2012.

As assinaturas físicas estão relacionadas com a utilização, manipulação ou mesmo com processos metalúrgicos de produção do material. Características como morfologia, textura, formato e distribuição das partículas, podem trazer indícios de qual é o composto de urânio, da rota de produção, equipamentos utilizados, bem como a qualidade da tecnologia utilizada (AIEA, 2006; DONOHUE, 2008).

Na FIGURA 8 são apresentadas diferenças morfológicas de compostos de tetrafluoreto de urânio, $\mathrm{UF}_{4}$, produzidos por rotas químicas diferentes.
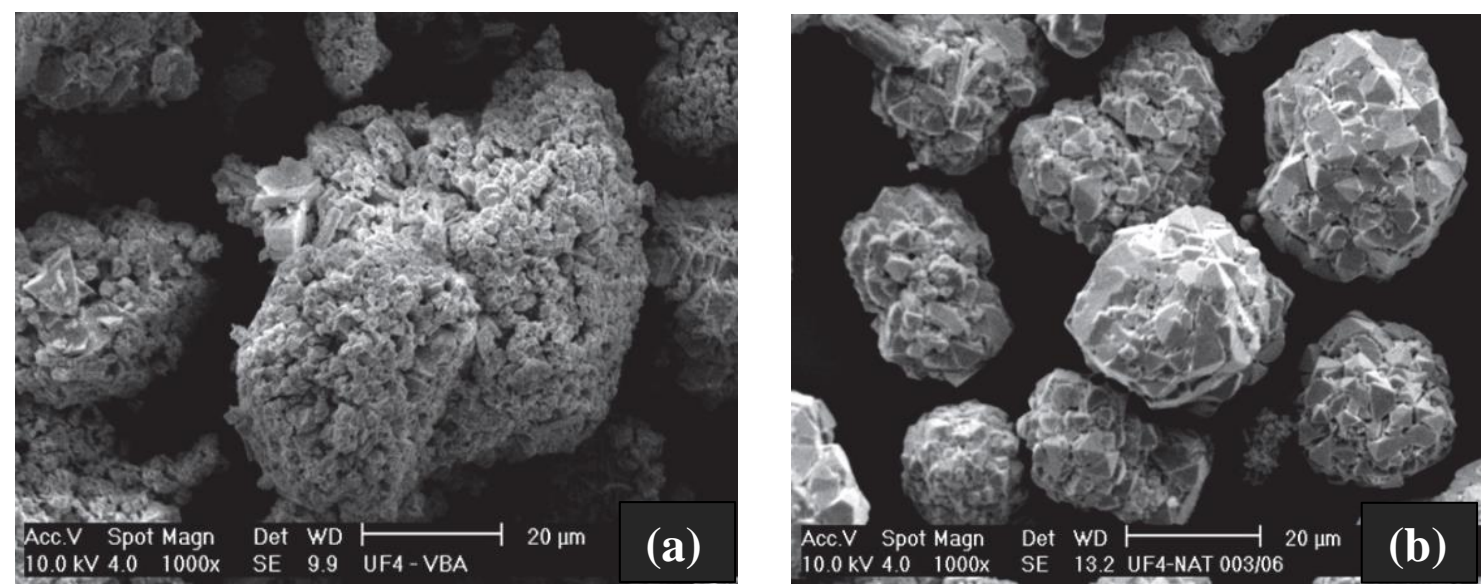

FIGURA 8: Diferenças morfológicas de compostos de $\mathrm{UF}_{4}$ produzidos por duas rotas químicas diferentes. (a) $\left(\mathrm{HF}_{2}\right)^{-}$e (b) $\mathrm{SnCl}_{2}$ (SALIBA-SILVA, 2011).

Através da FIGURA 8 percebe-se diferenças evidentes nas características morfológicas das partículas. A partícula (a) apresenta superfície porosa enquanto a partícula (b) é poligonal e de granulometria menor. 
A FIGURA 9 apresenta diferenças morfológicas de compostos de diuranato de amônia, $\mathrm{NH}_{4} \mathrm{U}_{2} \mathrm{O}_{7}$, produzidos em diferentes condições.

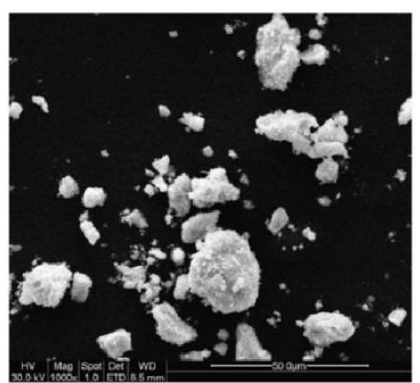

(a1)

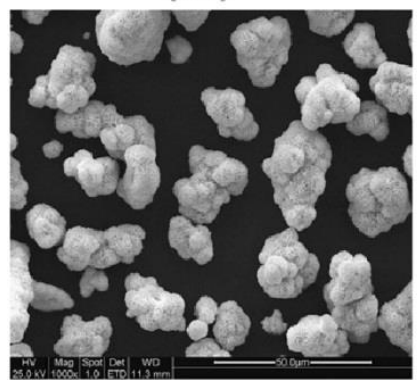

(b1)

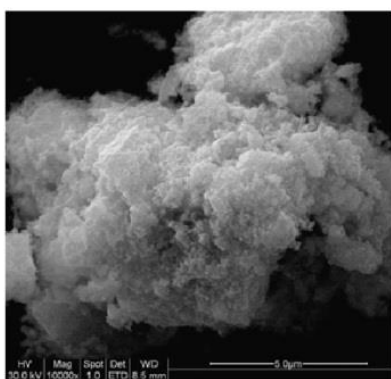

(a2)

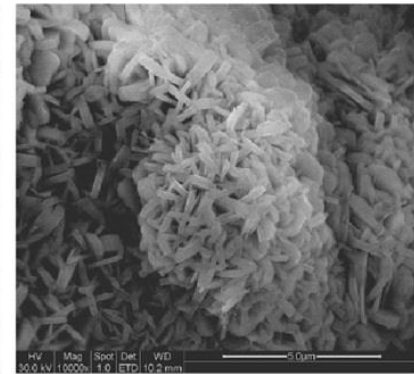

(b2)

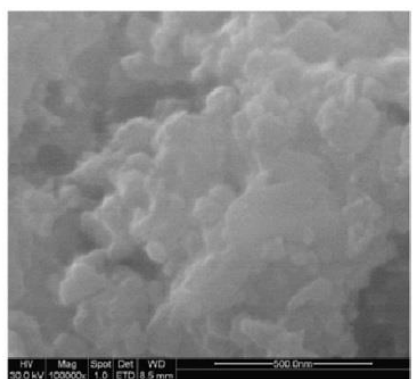

(a3)

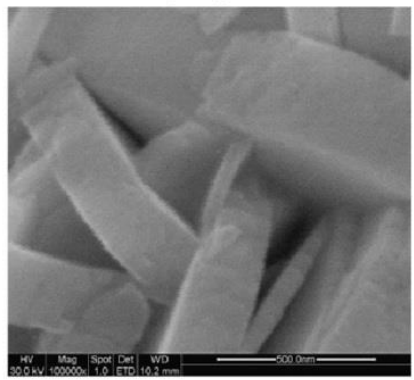

(b3)

FIGURA 9: Micrografias obtidas por MEV de diuranato de amônia $\left(\mathrm{NH}_{4} \mathrm{U}_{2} \mathrm{O}_{7}\right)$ produzidos em diferentes condições. (a) com amônia aquosa, (a1) magnificação de 1000X (a2) 10.000X (a3) 100.000X (b) com amônia gasosa, (b1) magnificação de 1000X (b2) 10.000X (b3) 100.000X (MANNA, 2012).

Partículas esféricas ou aglomerados esféricos de urânio (FIGURA 10) podem ser formados a partir da reação de hidrólise do $\mathrm{UF}_{6}$ na presença de umidade atmosférica, formando $\mathrm{UO}_{2} \mathrm{~F}_{2}$, segundo a reação 1 (KIPS, 2007; AREGBE, 2008).

$$
\mathrm{UF}_{6}+2 \mathrm{H}_{2} \mathrm{O} \rightarrow \mathrm{UO}_{2} \mathrm{~F}_{2}+4 \mathrm{HF}
$$



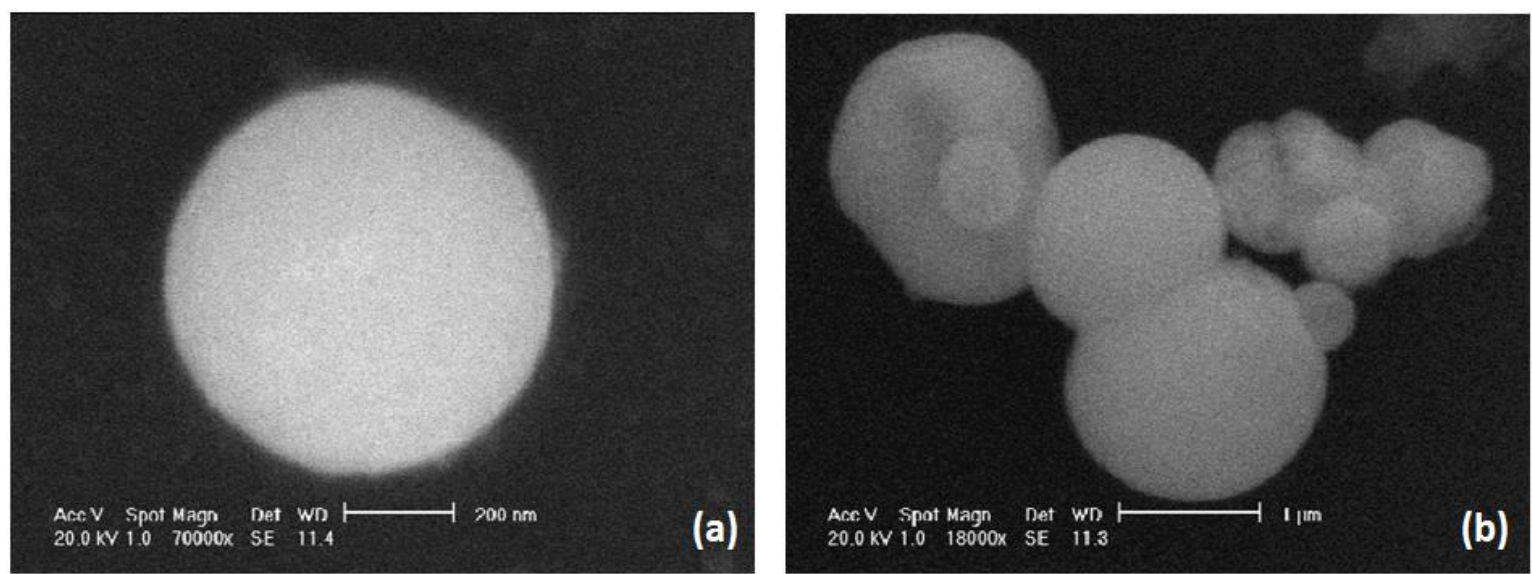

FIGURA 10: Partículas esféricas de $\mathrm{UO}_{2} \mathrm{~F}_{2}$ (a) e aglomerados esféricos de $\mathrm{UO}_{2} \mathrm{~F}_{2}$ que podem ser encontrados em amostras de esfregaço provenientes da reação de hidrólise do $\mathrm{UF}_{6}(\mathrm{STEBELKOV}, 2010)$.

A identificação desse tipo de partícula é uma evidencia de manipulação de $\mathrm{UF}_{6}$, assim, a probabilidade de encontrar partículas esféricas são maiores em instalações de enriquecimento, conversão e reconversão (STEBELKOV, 2010).

As assinaturas elementares incluem determinações dos elementos majoritários, minoritários e traços. Os majoritários podem definir a identidade e origem do material, utilizando terras raras (FIGURA 11) e impurezas, e os minoritários como Er, Gd (venenos queimáveis) e $\mathrm{Ga}$ (estabilizador de $\mathrm{Pu}$ metálico) podem relacionar-se com a função do material. Elementos traços podem ser indicativos de processo, como $\mathrm{Fe}, \mathrm{Cr}$ (resíduos de ferramentas de aço inoxidável) (AIEA, 2006).

Rosa, 2011, determinou elementos de terras raras para diferentes compostos de urânio. Na FIGURA 11 pode-se perceber as diferenças encontradas para os elementos praseodímio, cério, lantânio e ítrio em compostos de $\mathrm{U}_{3} \mathrm{O}_{8}$ de diferentes procedências. 


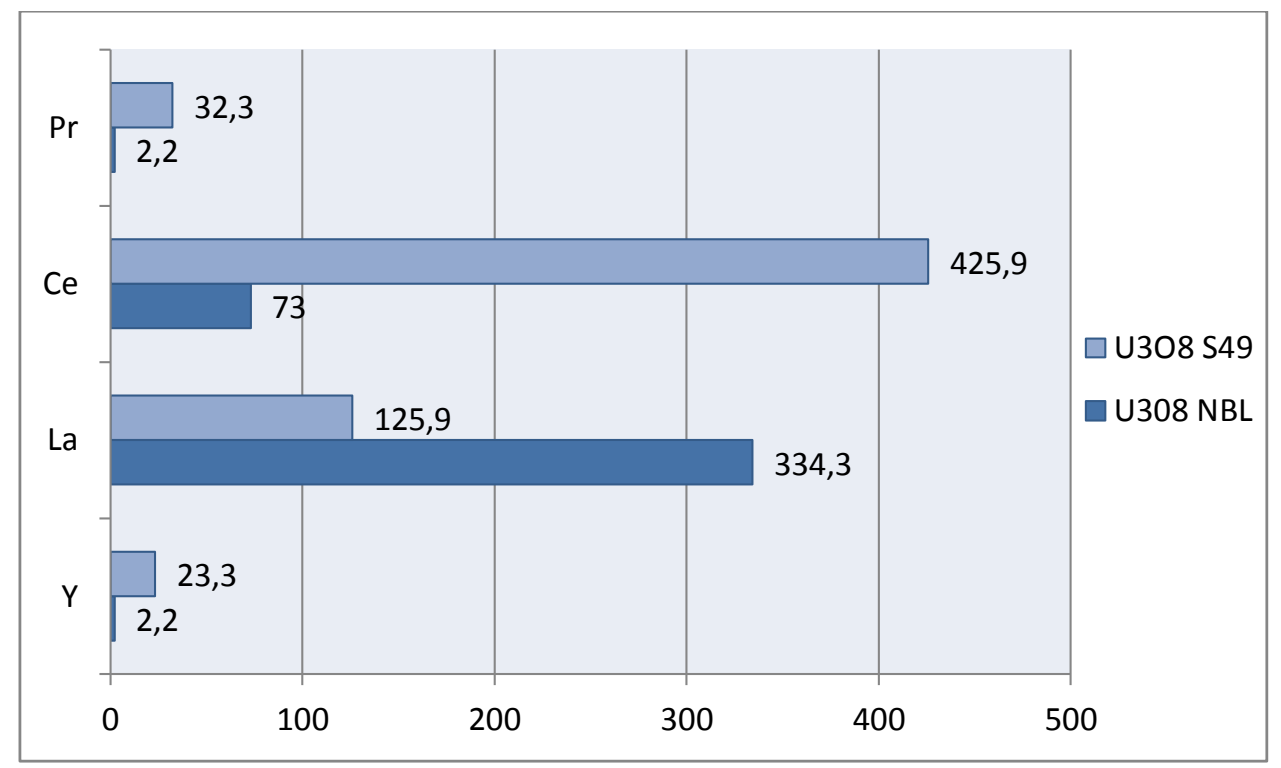

FIGURA 11: Análise de elementos de terras raras para dois compostos de $\mathrm{U}_{3} \mathrm{O}_{8}$ de diferentes procedências. Valores em ng/g (ROSA, 2011).

As características isotópicas incluem detecção de isótopos de urânio, produtos de fissão e isótopos provenientes de transmutações nucleares, no qual podem trazer informações quanto ao histórico de operação do reator utilizado. Produtos de decaimento também são importantes na determinação da idade do material, isto é, o tempo da ultima separação química que o material foi submetido (AIEA, 2006).

No âmbito das salvaguardas os isótopos de urânio de maior interesse são: o isótopo físsil artificial ${ }^{233} \mathrm{U}$, que é produzido em reatores regeneradores ${ }^{16}$, através da reação ${ }^{232} \mathrm{Th}$ $(\mathrm{n}, \Upsilon){ }^{233} \mathrm{U}$ (Reação 2), o ${ }^{235} \mathrm{U}$, assim como o ${ }^{236} \mathrm{U}$.

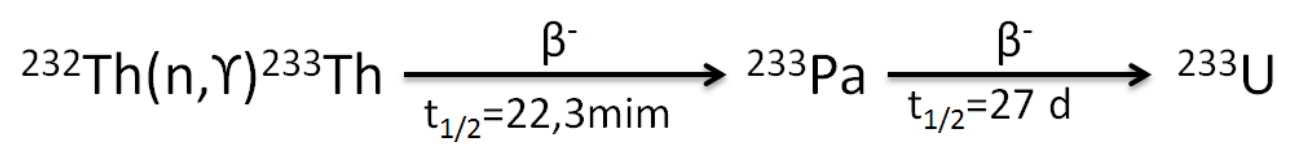

O isótopo ${ }^{235} \mathrm{U}$ é o indicador do enriquecimento da amostra, quando expresso em função da razão $n\left({ }^{235} U\right) / n\left({ }^{238} U\right)$, ou mais comumente utilizado na forma de fração mássica. A

TABELA 4 apresenta a classificação do urânio em relação aos níveis de enriquecimento, em relação a fração mássica no isótopo ${ }^{235} \mathrm{U}$.

\footnotetext{
${ }^{16}$ FBR - Fast Breeder Reactor ou TBR - Thermal Breeder Reactor.
} 
TABELA 4: Classificação do urânio em relação a fração mássica no isótopo ${ }^{235} \mathrm{U}$ (OLIVEIRA JUNIOR, 2006; ITV, 2010)

\begin{tabular}{l|cccc}
\hline & Empobrecido & Natural & LEU & HEU \\
\hline Fração mássica ${ }^{235} \mathbf{U}$ & $<0,71 \%$ & $=0,71 \%$ & $0,71 \%<\mathrm{X} \leq 20 \%$ & $>20 \%$ \\
\hline
\end{tabular}

O uso de urânio empobrecido ${ }^{17}$ também é controlado e sua existência pode ser um indício de plantas de enriquecimento isotópico de urânio, pois é um subproduto do processo, sendo também utilizado na fabricação do isótopo ${ }^{239} \mathrm{Pu}$ (BETTI, 2003; DONOHUE, 2003; MCCLAIN, 2005; BUCHMANN, 2006; LLOYD, 2009).

$\mathrm{O}$ isótopo artificial ${ }^{236} \mathrm{U}$ é produzido nos reatores por meio da reação ${ }^{235} \mathrm{U}(\mathrm{n}, \Upsilon)$ ${ }^{236} \mathrm{U}$ (Reação 3), permanecendo como indicador inequívoco de que o material foi irradiado, ou o material foi contaminado por urânio irradiado ou é proveniente de uma unidade de reprocessamento (MAYER, 2008; OLIVEIRA JUNIOR, 2006; REDERMEIER, 2009).

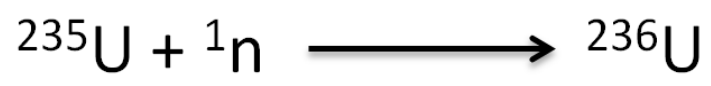

Reação 3

Se plutônio é encontrado na amostra, sua origem pode ser atribuída de três formas distintas: a amostra pode ser oriunda de um tipo de combustível nuclear, chamado de MOX, composto por $\mathrm{UO}_{2}$ e $\mathrm{PuO}_{2}$ e utilizado em alguns reatores nucleares regeneradores, poder ser proveniente de combustível nuclear já irradiado, através da formação em reações de transmutação, ou ainda proveniente de unidades de reprocessamento.

$\mathrm{O}{ }^{238} \mathrm{Pu}$ é produzido em reatores regeneradores a partir de reações $(n, \Upsilon)$ e decaimentos $\beta^{-}$, iniciado pelo ${ }^{236} \mathrm{U}$, segundo a Reação 4 (WILSON, 1996).

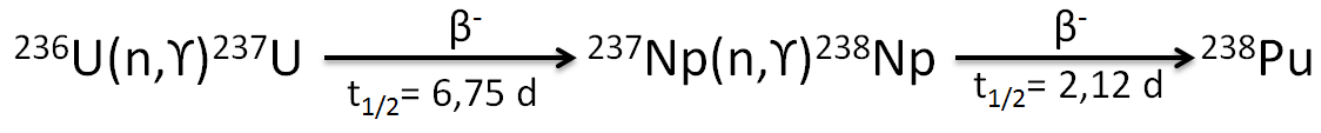

${ }^{17} \mathrm{O}$ urânio empobrecido pode ser utilizado em armamento militar, munições e blindagens, por apresentar densidade elevada (BETTI, 2003). 
$\mathrm{O}{ }^{239} \mathrm{Pu}$ é produzido a partir da reação ${ }^{238} \mathrm{U}(\mathrm{n}, \Upsilon){ }^{239} \mathrm{Pu}$ em reatores regeneradores, através da captura radiativa de um nêutron pelo ${ }^{238} \mathrm{U}$, segundo Reação 5 (REDERMEIER, 2009; TERREMOTO, 2004).

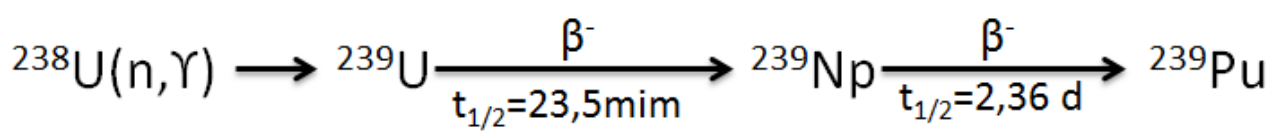

Reação 5

Os outros isótopos ${ }^{240} \mathrm{Pu},{ }^{241} \mathrm{Pu}$ e o ${ }^{242} \mathrm{Pu}$ são produzido da mesma forma que o ${ }^{239} \mathrm{Pu}$ através da captura radioativa de nêutrons (WILSON,1996)

\subsection{Técnicas analíticas utilizadas em amostras de esfregaços}

No âmbito das salvaguardas, os esfregaços podem ser analisados por diferentes técnicas que possam identificar assinaturas com o intuito de ajudar a AIEA a verificar se as atividades nucleares desenvolvidas não estão sendo divergidas para atividades ilícitas.

Existem técnicas que durante a análise conservam a amostra, chamadas de técnicas não destrutivas e outras que são chamadas de técnicas destrutivas que consomem a amostra durante a análise.

As análises dos esfregaços são divididas em:

i. Análise com digestão total, chamada de bulk analysis é quando todo o esfregaço é consumido na etapa de digestão. São análises onde se obtêm como resultado a composição isotópica média de todas as partículas encontradas no esfregaço (STURM, 2010).

ii. Análise individual de partículas, chamada de particle analysis, envolve a medição de cada partícula individualmente obtendo informação característica da partícula analisada.

As técnicas mais utilizadas nas análises dos esfregaços estão dispostas na TABELA 5. 
TABELA 5: Técnicas analíticas utilizadas em amostras de esfregaços para obter informações com fins de salvaguardas nucleares.

\begin{tabular}{|c|c|c|}
\hline Técnica & Medida & Informação \\
\hline TEM-EDS $*$ B & $\mathrm{U}, \mathrm{Pu}$ e elementos associados & Morfologia, processo de produção, análise semi-quantitativa, tipo de material \\
\hline $\mathrm{ICP}-\mathrm{MS}^{* * \mathrm{~A}}$ & $\begin{array}{c}\text { Razões e concentrações de U e Pu e } \\
\text { impurezas }\end{array}$ & Composição isotópica, impurezas, enriquecimento, idade, localização geográfica, \\
\hline TIMS $* * A$ & $\begin{array}{c}\text { Razões e concentrações de U e Pu e } \\
\text { impurezas }\end{array}$ & Composição isotópica, impurezas, enriquecimento, idade, localização geográfica, \\
\hline FT-TIMS $* *$ B & $\begin{array}{c}\text { Razões e concentrações de U e Pu e } \\
\text { impurezas }\end{array}$ & Composição isotópica, impurezas, enriquecimento, idade, localização geográfica, \\
\hline HRGS* & U, Pu, Am e Produtos de Fissão & Composição isotópica, tempo de resfriamento e queima de combustíveis \\
\hline $\mathrm{XRF}^{*}$ & Concentração de U e Pu; U/Pu & Composição química \\
\hline MRS $* \mathrm{~B}$ & $\mathrm{U}, \mathrm{Pu}$ e elementos associados & Composição química \\
\hline
\end{tabular}

*Técnica não destrutiva; **Técnica destrutiva; ${ }^{\mathrm{A}}$ Análise com digestão total; ${ }^{\mathrm{B}}$ Análise individual de partícula. 
MEV-EDS = Microscopia eletrônica de varredura com espectroscopia por dispersão de energia; TEM-EDS = Microscopia eletrônica de transmissão com espectroscopia por dispersão de energia; ICP-MS = Espectrometria de massas com fonte de plasma induzido; LA-ICP-MS = Sistema de ablação a laser conectado com espectrômetro de massas com fonte plasma induzido; TIMS = Espectrometria de massas por termo ionização; FT-TIMS = análises de traços de fissão por Espectrometria de massas por termo ionização; SIMS = Espectrometria de massas de íons secundários; AS = Espectrometria alfa; HRGS = Espectrometria gama de alta resolução; XRF = Fluorescência de raios$\mathrm{x} ; \mathrm{MRS}=$ espectroscopia micro raman. 
No contexto desse trabalho foram utilizadas as técnicas: contador de radiação alfa, microscopia eletrônica de varredura com espectroscopia de dispersão de energia - MEVEDS e espectrometria de massas com fonte de plasma induzido - ICP-QMS, que serão discutidas com detalhes a seguir.

\subsubsection{Atividade radioativa}

Toda a vida no planeta Terra desenvolveu-se na presença de radiação proveniente das reações nucleares que ocorrem no Sol e/ou através de materiais radioativos naturais como minérios de tório e urânio (AIEA, 2004).

O fenômeno radioativo dos materiais se deve ao fato de um núcleo muito energético, por ter excesso de partículas ou de carga, tende a estabilizar-se através de emissões espontâneas na forma de partículas (alfa $-\alpha$ ou beta $-\beta$ ) e/ou energia $(\Upsilon)$, fenômeno conhecido como desintegração radioativa ou decaimento radioativo (OKUNO, 2010; CNENb, 2013).

A taxa de decaimento (emissões $\alpha, \beta$ ou $\Upsilon$ ), que é o número de decaimentos por unidade de tempo, é definida como atividade radioativa e pode ser medida, por exemplo, através de um detector Geiger-Müller (OKUNO, 2010).

O elemento urânio emite principalmente partículas alfa e é frequentemente caracterizado durante as etapas do $\mathrm{CCN}$, em amostras biológicas para controle de trabalhadores que manipulam urânio, bem como em amostras ambientais para verificação das atividades desenvolvidas nas instalações inspecionadas.

Essa caracterização é normalmente realizada com medições de atividades por espectrometria alfa, medindo-se a quantidade de urânio total, assim como medições de razões isotópicas por espectrometria de massas fornecendo o nível de enriquecimento (RUCKER, 1998).

\subsubsection{Microscopia eletrônica de varredura}

A microscopia eletrônica de varredura - MEV é uma técnica versátil, geralmente utilizada para observações de amostras espessas, ou seja, que não são transparentes a elétrons. Ela permite a aquisição de informações superficiais, estruturais, morfológicas e composicional podendo ser utilizada em diferentes tipos de materiais (KESTENBACK, 1989). 
A técnica apresenta características como:

$\checkmark$ Magnificações de até 900000 X;

$\checkmark$ Resolução nanométrica;

$\checkmark$ Análise qualitativa rápida (1 minuto)

$\checkmark$ Análise semi-quantitativa;

$\checkmark$ Mapeamento químico;

$\checkmark$ Imagem com impressão tridimensional;

$\checkmark$ Identificação de características morfológicas e topográficas.

O princípio do funcionamento do MEV consiste na detecção da radiação emitida através da interação do feixe de elétrons com o material, gerando imagens e fornecendo informações úteis sobre a amostra.

Os elétrons que irão interagir com a amostra é proveniente de um filamento capilar de tungstênio contido no eletrodo negativo, chamado de canhão de elétrons (DEGEO, 2013).

Variando a diferença de potencial aplicada entre o canhão de elétrons e o eletrodo positivo, altera-se a aceleração, consequentemente, a energia dos elétrons emitidos no feixe em direção à amostra (DEGEO, 2013).

O diâmetro do feixe de elétrons produzidos não permite que sejam adquiridas imagens nítidas com alta magnificação, sendo necessário o uso de lentes magnéticas para colimar e, assim, focalizar o feixe. A correção do percurso do feixe é realizada por lentes que os alinham em direção à abertura da lente objetiva. A objetiva ajusta o foco do feixe de elétrons antes do mesmo atingir a amostra a ser analisada (WILLIAMS, 2009).

A FIGURA 12 mostra os componentes básicos de um MEV. 


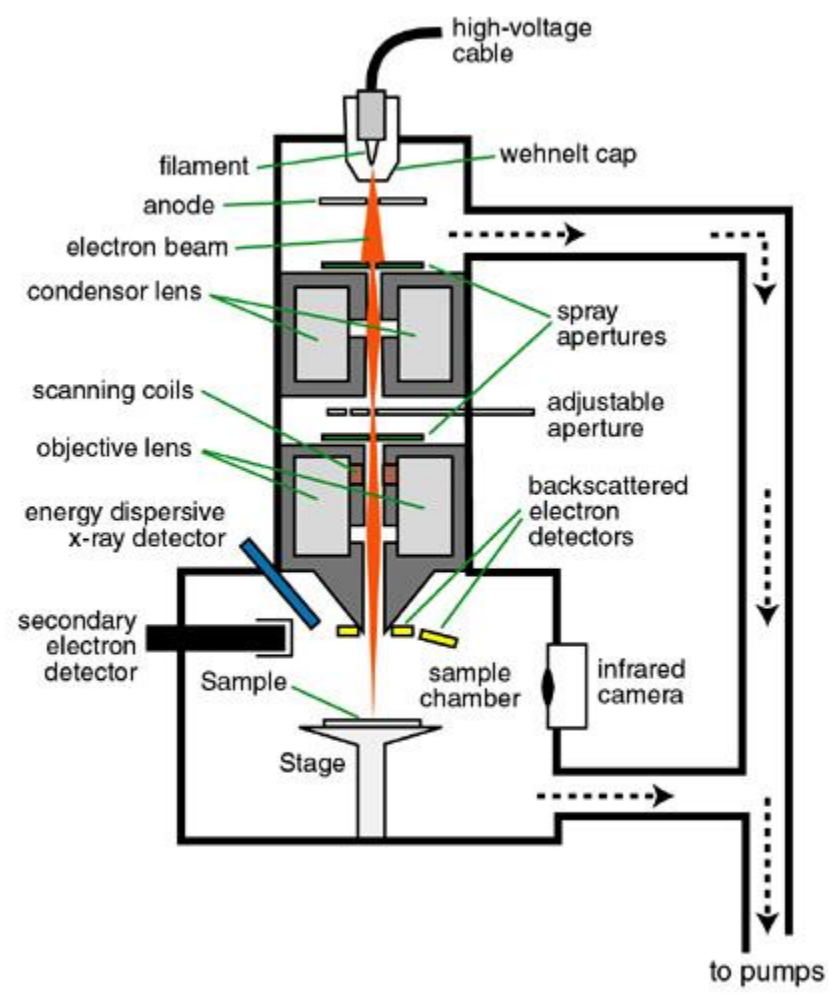

FIGURA 12: Componentes básicos de um MEV (NAU, 2013).

Após o ajuste, o feixe de elétrons interage com a superfície da amostra gerado uma grande quantidade de sinais (eventos) devido ao espalhamento elástico e inelástico dos elétrons, dentre os quais pode-se destacar os elétrons retroespalhados, secundários e raiosX característicos (CARTER, 2009).

A FIGURA 13 apresenta alguns fenômenos que podem ocorrer na interação do feixe de elétrons com a amostra. 


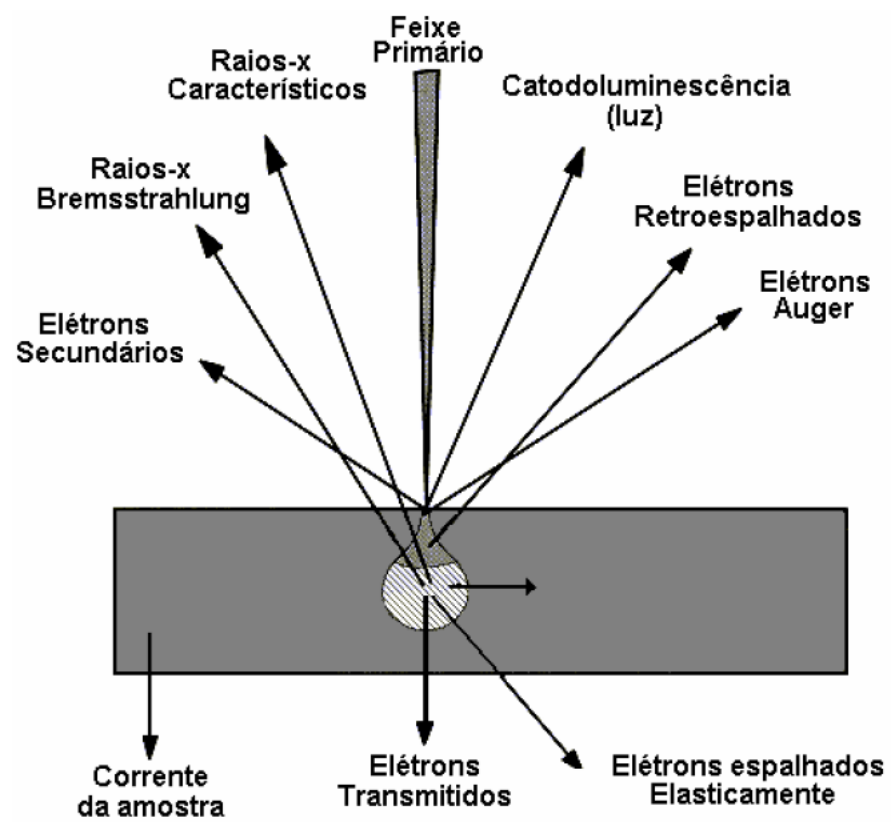

FIGURA 13: Diferentes tipos eventos que podem ser gerados na interação do feixe de elétrons com a amostra (MALISKA, 2013).

Os sinais de maior interesse para a formação das imagens são os elétrons secundários e os retroespalhados. À medida que o feixe de elétrons vai varrendo a amostra estes sinais vão sofrendo modificações de acordo com as variações da superfície.

Os elétrons secundários fornecem imagens topográficas da amostra e são os responsáveis pela obtenção das imagens de alta resolução, já os retroespalhados fornecem imagens característica da variação de composição encontrada na amostra.

Elétrons secundários são elétrons de baixa energia (inferior a $50 \mathrm{eV}$ ) que são ejetados dos átomos da amostra devido a interações inelásticas dos elétrons energéticos do feixe primário com elétrons pouco energéticos da banda de condução nos metais ou de valência nos semicondutores (KESTENBACK, 1989; MALISKA, 2013).

O retroespalhamento ocorre quando o feixe de elétrons penetra na nuvem eletrônica do átomo e sofre atração Coulombiana pelo núcleo, resultando em um espalhamento elástico com ângulos superiores a $90^{\circ}$. Esse efeito aumenta conforme se eleva o número atômico (Z) dos átomos presentes na amostra (WILLIAMS, 2009).

O sinal de elétrons retroespalhados resultante das interações que ocorreram mais para o interior da amostra são provenientes da região do volume de interação com maior diâmetro do que o diâmetro do feixe primário. Portanto a resolução da imagem gerada por esses elétrons é pior do que a resolução da imagem correspondente dos elétrons secundários (MALISKA, 2013). 
Na FIGURA 14 é demonstrada a diferença encontrada em imagens adquiridas utilizando detectores de elétrons secundários - SE (a) e retroespalhados - BSE (b).

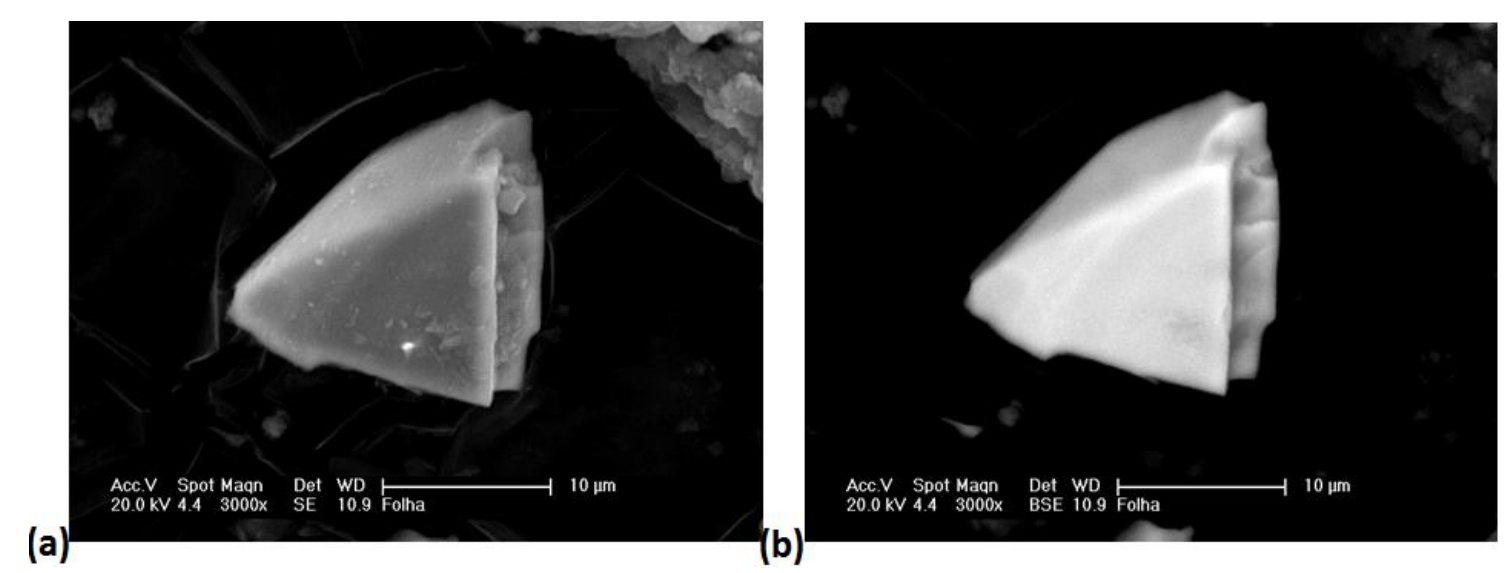

FIGURA 14: Diferenças nas micrografias obtidas por MEV devido ao uso de detectores de elétrons secundários (a) e de retroespalhados (b) em uma partícula de zircônio encontrada numa folha de árvore próxima a instalação nuclear do IPEN.

Como pode ser observado na FIGURA 14, com uso de detector de SE as características superficiais das partículas são mais bem detalhadas, enquanto que com o uso BSE partículas com número atômico elevado $(\mathrm{Zr}, \mathrm{Z}=40)$ destacam-se.

Para a determinação qualitativa e semi-quantitativa da composição de uma região da amostra (microanálise) são utilizados os raios-X emitidos através da interação inelástica do feixe de elétrons com a amostra.

Durante a interação, os raios-X podem ser gerados de duas maneiras:

$\checkmark$ Excitação de raios-X Bremsstrahlung ou raios-X contínuos;

$\checkmark$ Ionização de camadas internas, dando origem a emissão dos raios-X característicos.

Estas radiações dão origem a dois diferentes componentes do espectro de raios-X: um componente característico, que identifica o átomo ou átomos presentes no volume de interação, e o componente contínuo, não específico e que forma o background, conforme apresentado na FIGURA 15 (MALISKA, 2013). 


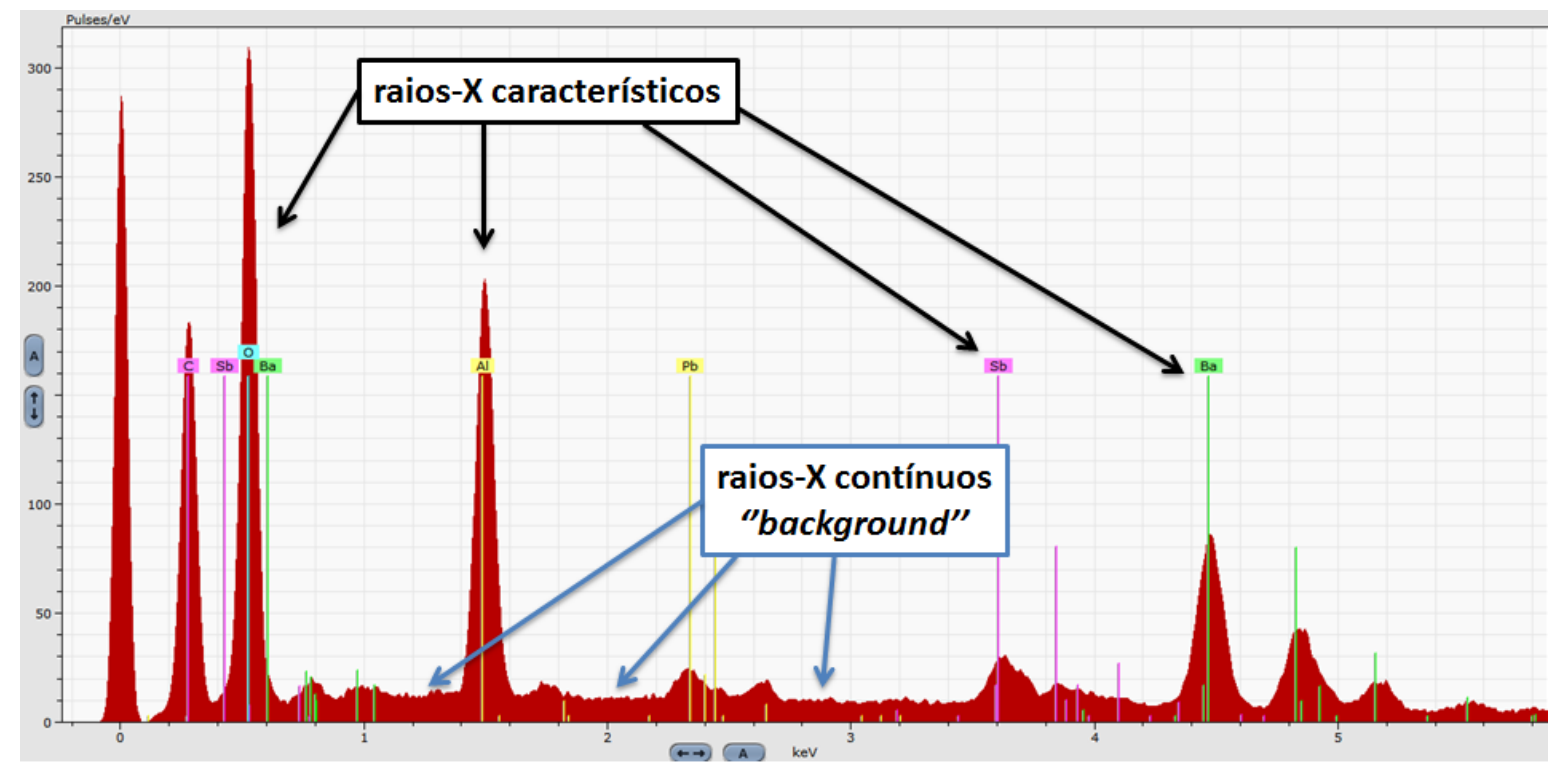

FIGURA 15: Espectro típico de uma partícula de resíduo de disparo de arma de fogo -

GSR, onde pode-se observar os raios-X característicos e contínuos.

O processo de emissão de raios-X característico é proveniente de uma transição eletrônica onde a diferença de energia é expressa como um fóton de radiação eletromagnética com energia específica do elemento, identificando-o (FIGURA 16).

Essa energia específica é tabelada e disponível em gráficos ou em base de dados dos computadores dos MEV.

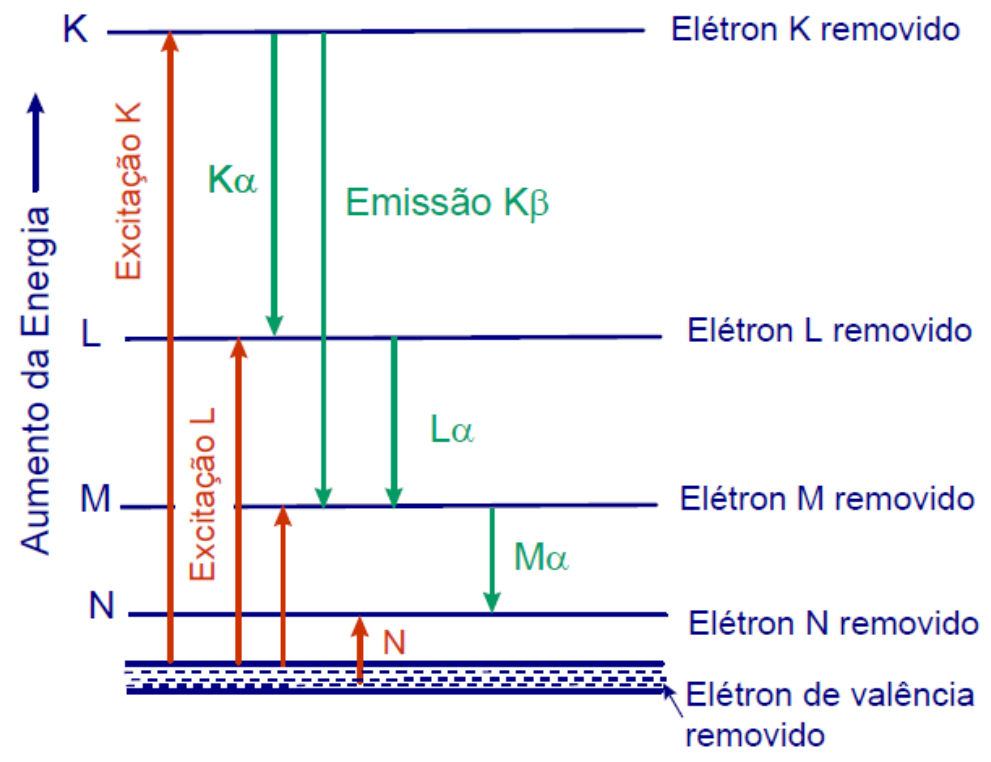

FIGURA 16: Processos de transições eletrônicas que envolvem as emissões de raios-X (MALISKA, 2013). 
A identificação dessas radiações (elétrons secundários, retroespalhados e raios-X) quando captadas corretamente por detectores específicos irão fornecer características sobre a amostra, podendo identificar informações quanto à topografia da superfície, composição química, assim como características morfológicas, caracterizando o material em questão.

\subsubsection{Espectrometria de massas}

\subsubsection{Histórico}

A técnica de espectrometria de massas tem mais de 120 anos e produziu resultados relevantes no desenvolvimento da física atômica. O rápido desenvolvimento da física nuclear, em particular, seria impensável sem a aplicação de métodos de espectrometria de massas, no qual contribuiu na evidência da hipótese da estrutura atômica da matéria (BECKER, 2007).

Atualmente a espectrometria de massas é uma das técnicas mais importante que fornece contribuições para diferentes áreas da ciência, especialmente nas ambientais, de materiais, nucleares, geociência, petroquímica, forense, análises clínicas e metrologia.

Os espectrômetros de massas atuais são consequências do experimento realizado por Eugene Goldstein, em 1886, onde descobriu a formação de íons carregados positivamente em um tubo de descarga, FIGURA 17. Tal descoberta foi utilizada em experimentos posteriores de Thomson e Aston (OUTREACHa, 2013; SHARMA, 2013).

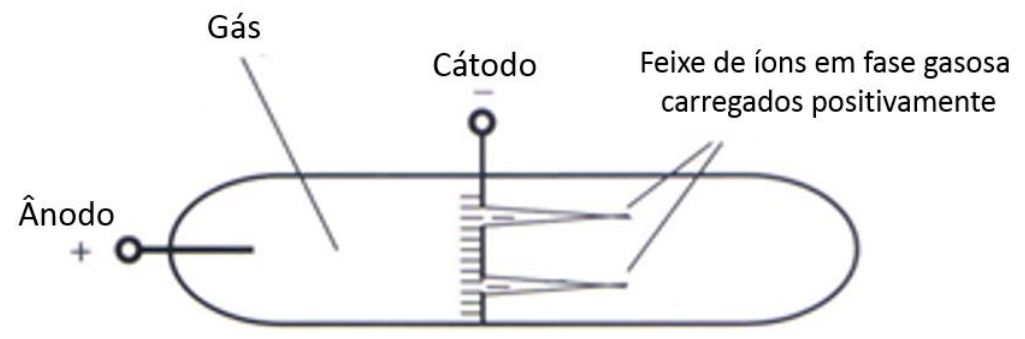

FIGURA 17: Tudo de descarga de Goldstein para geração de íons positivamente carregados (BECKER, 2007).

O verdadeiro desenvolvimento da espectrometria de massas nos leva a 1910, quando Joseph John Thomson (Laboratórios Cavendish, Universidade de Cambridge, Inglaterra) com seu espectrômetro de massas de parábola (FIGURA 18), descobriu que o neônio consistia de dois diferentes isótopos com massas de 20 e 22 (com abundâncias de 
91 e $9 \%$ respectivamente). Assim, foram descobertos isótopos de um mesmo elemento com o mesmo comportamento químico, porém com diferentes massas, conectando a história dos isótopos com a espectroscopia de massas (VEGA-BUSTILLOS, 2003; SARKIS, 2005; AUDI, 2006; OLIVEIRA JUNIOR, 2006; OUTREACHb, 2013).

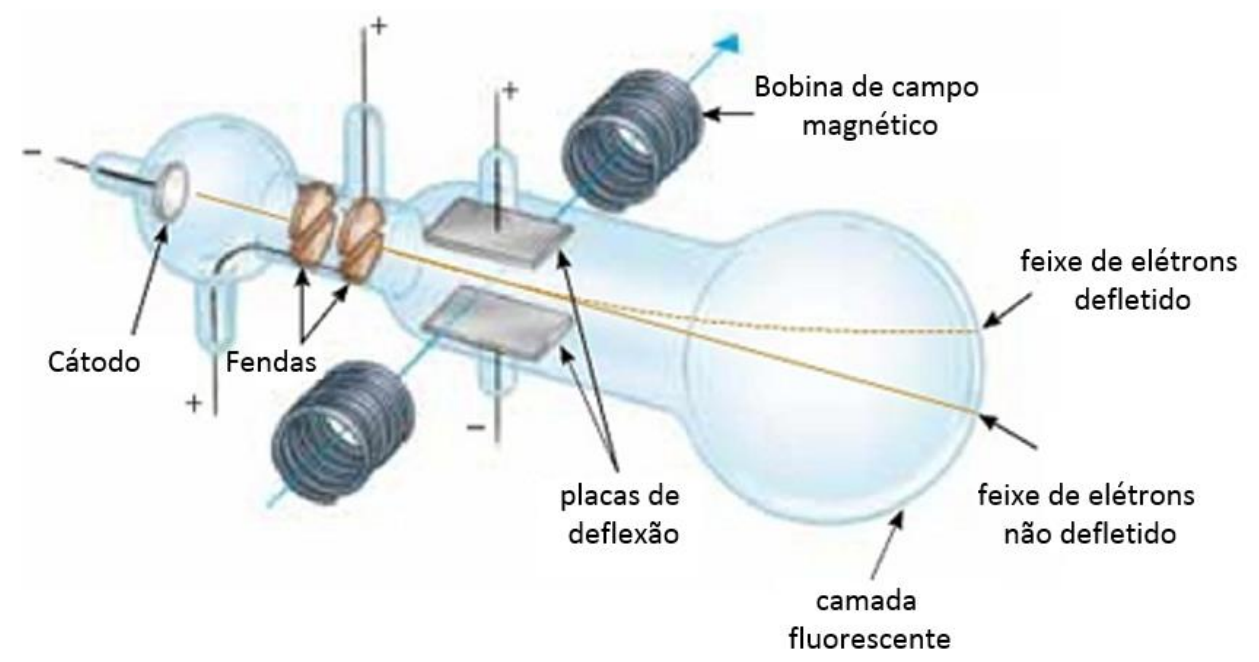

FIGURA 18: Espectrômetro de parábola construído por Thomson (KSHITIJ, 2013).

Poucos anos mais tarde, o assistente de Thomson, Francis William Aston descobriu outro isótopo menos abundante $(0,3 \%)$ do neônio com massa igual a 21 . Durante a sua carreira, Aston descobriu 212 dos 287 isótopos naturais, se tornando conhecido como o pai da espectrometria de massas (BECKER, 2002; SARKIS, 2005; AUDI, 2006).

A partir desse desenvolvimento inicial, a evolução da técnica de espectrometria de massas esteve marcada por desenvolvimentos tecnológicos que acabaram por criar uma ordem complexa de instrumentos.

Novas tecnologias de alto vácuo, transmissão, focalização e detecção de íons, assim como avanços na informática, tem permitido o aperfeiçoamento de equipamentos cada vez mais sensíveis (podendo alcançar níveis de detecção para elementos mais pesados como plutônio na ordem de alguns pg. $\mathrm{kg}^{-1}$ ), flexíveis (permitindo o acoplamento com técnicas distintas); robustos (capazes de analisar diferentes matrizes com a mesma eficiência) e com alto desempenho analítico (um grande número de amostras sequencialmente) (SARKIS, 2005).

Devido à grande diversidade de aplicações da espectrometria de massas, nenhum instrumento é adequado em todas as instâncias. Como consequência, podem-se encontrar numerosas descrições de diferentes fontes de íons, analisadores de massas e detectores de 
íons, por exemplo; aplicações criadas no intuito de alcançar a maior abrangência possível dessa importante técnica (ROSA, 2011).

\subsubsection{2. $O$ equipamento}

Espectrômetros de massas são instrumentos que utilizam o movimento de íons em um campo elétrico, magnético ou em ambos simultaneamente de modo classificá-los de acordo com sua relação massa-carga (m/q) (SARKIS, 2005).

Pode-se definir sinteticamente o espectrômetro de massa como um instrumento que tem recursos para produzir, acelerar, transmitir, separar, coletar e medir íons, de tal forma que a razão das correntes iônicas medidas é proporcional à fração molar dos isótopos presentes na amostra (OLIVEIRA JUNIOR, 2006).

Para tal, os componentes básicos (FIGURA 19) de todos os espectrômetros de massas são:

$\checkmark$ Sistema de introdução de amostras;

$\checkmark$ Fonte de ionização;

$\checkmark$ Lentes de focalização;

$\checkmark$ Analisador de massas;

$\checkmark$ Sistema de detecção;

$\checkmark$ Sistema de alto vácuo,

$\checkmark$ Sistema de controle e aquisição dos dados.

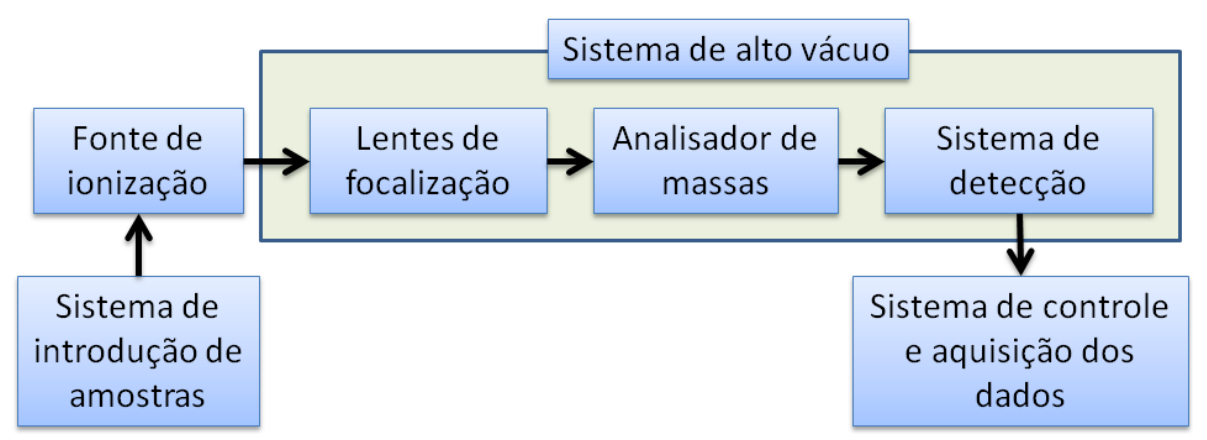

FIGURA 19: Diagrama esquemático de um espectrômetro de massas 


\subsubsection{Espectrômetro de massas com fonte de plasma induzido - ICP-MS}

Dentre os mais importantes espectrômetros está o ICP-MS, que vem sendo a técnica analítica mais empregada para análise inorgânica devido as suas qualidades, tais como:

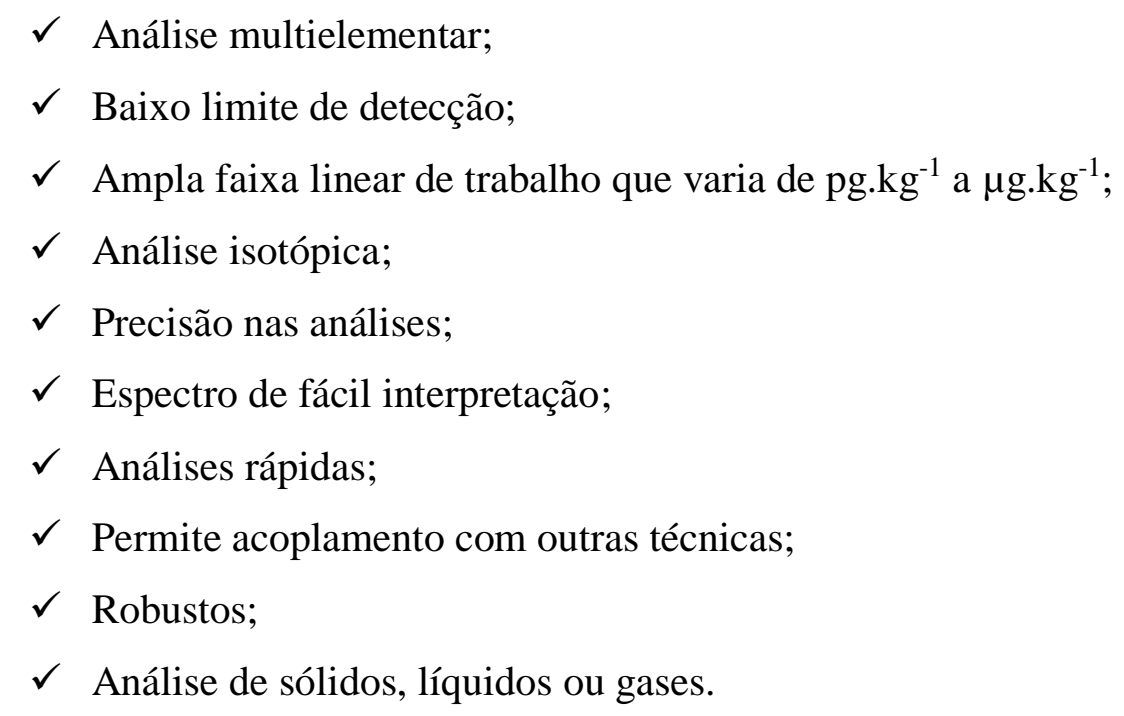

O desenvolvimento da técnica de ICP-MS teve início devido à procura de uma técnica substituta a técnica de espectrometria de emissão óptica com fonte de plasma indutivamente acoplada, ICPOES (BUCHMANN, 2000).

Além do ICPOES apresentar sérios problemas de interferentes espectrais começava-se a sentir a necessidade de atingir limites de detecção ainda menores do que aqueles alcançados pelo ICPOES (ROWLEY, 2000; SARKIS, 2005).

Desse modo, nos primeiros anos da década de 70, alguns grupos de pesquisadores de países como EUA, Inglaterra e Canadá, desenvolveram os primeiros ICP-MS acoplando a eficiência de ionização por fonte de plasma com a espectrometria de massas, obtendo equipamentos sensíveis e precisos (SARKIS, 2005).

O princípio de funcionamento de um ICP-MS consiste na introdução da amostra na forma de um aerossol finalmente disperso em um plasma de argônio a temperatura de aproximadamente $8000 \mathrm{~K}$. No transcurso pelo plasma a amostra passa por processos de desolvatação, vaporização, atomização, excitação e finalmente a ionização.

Os íons formados no plasma são extraídos através de uma interface e acelerados na direção do analisador de massas, onde cada íon é discriminado de acordo com a sua relação m/q, FIGURA 20 (SARKIS, 2005; SKOOG, 2006). 


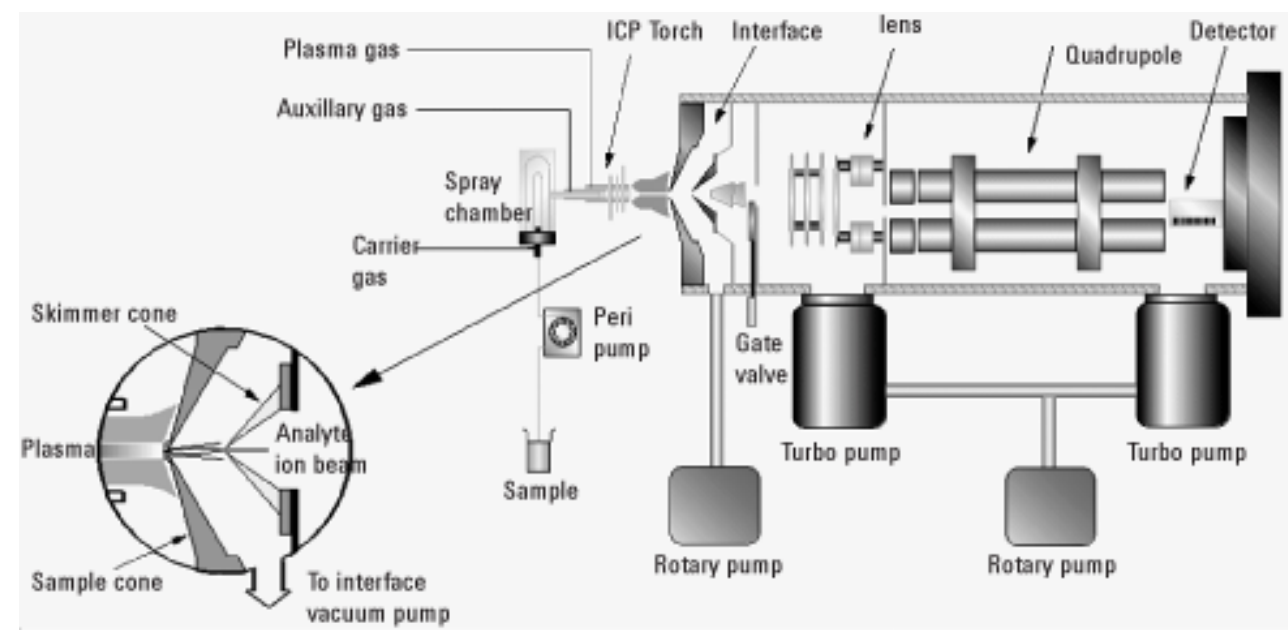

FIGURA 20: Componentes de um Espectrômetro de Massas com Fonte de Plasma Induzido (AGILENT, 2013).

Os ICP-MS são classificados segundo o seu analisador de massas. Existem atualmente, entre os mais comuns, os analisadores quadrupolos, setor magnético, tempo de voo e captura de íons (MONTASER, 1997; THOMAS, 2004; WONG, 2013).

O sistema quadrupolo (ICP-QMS) é o mais utilizado e consiste em quatro barras cilíndricas condutoras idênticas de aço ou molibdênio montadas de forma equidistantes entre si. Tipicamente apresentam diâmetro de 10 a $20 \mathrm{~mm}$ e comprimento de 15 a $25 \mathrm{~cm}$, operando em frequência de 1-4 Mhz (GROSS, 2004; WOLF, 2013).

Este tipo de analisador opera aplicando campos elétricos de corrente contínua e rádio frequência de sinais opostos entre as quatro barras, gerando campos de radiofrequência quadrupoloares oscilantes (JARVIS, 1992; THOMAS, 2004).

Aproveitando a estabilidade dependente da relação m/q dos íons nesses campos e escolhendo uma razão ideal entre as correntes, os íons de relação m/q iguais (ressonantes) são selecionados e passam pelo quadrupolo em direção ao detector, enquanto os outros íons de m/q diferentes são filtrados pelo quadrupolo (íons não ressonantes), conforme FIGURA 21 (THOMAS, 2004; SARKIS, 2005). 


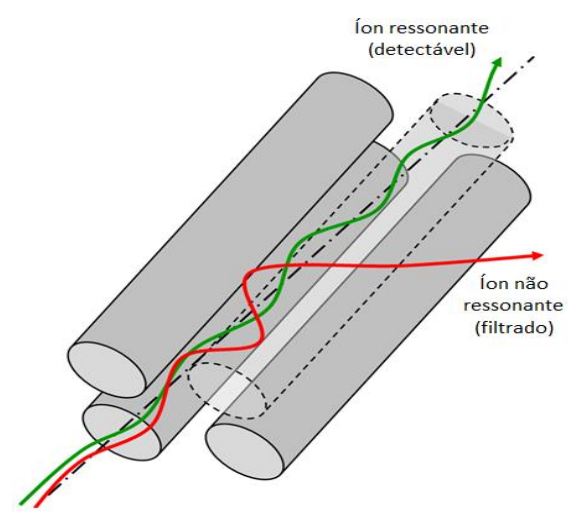

FIGURA 21: Filtro quadrupolar de massas

Desse modo, os íons ressonantes são capturados pelo detector que gera uma corrente iônica, que é proporcional a concentração do íon na amostra injetada pelo sistema de introdução.

\subsection{Estimativa das incertezas associadas aos procedimentos de medição}

A utilização de conceitos metrológicos é de suma importância quando se tem a intenção de obter dados metrologicamente rastreáveis e que possam ser, de alguma forma, comparáveis e avaliados.

A rastreabilidade reside na capacidade de relacionar o resultado de uma medição experimental (utilizando o sistema internacional de unidades - SI) com as referências estabelecidas, levando em conta as incertezas da medição (OLIVERIA JUNIOR, 2006).

Uma das características das incertezas de medição é representar a qualidade do resultado, medindo assim o grau de desconhecimento da medida obtido por uma técnica analítica qualquer.

$\mathrm{Na}$ área nuclear, principalmente nos processos de enriquecimento isotópico de urânio e fabricação do combustível, a qualidade dos resultados de razão isotópica e de concentração das impurezas, respetivamente, é extremamente importante para se obter resultados bem próximos ao real e verificar se estão de acordo com as especificações necessárias para uso como combustível.

Da mesma forma, no âmbito de salvaguardas, algumas decisões importantes são baseadas em resultados analíticos gerados durante e após as inspeções, sendo necessário ter alguma informação quanto à qualidade e a confiabilidade destes resultados, papel que é desempenhado pelas incertezas da medição. 
Nesse contexto, toda medição realizada está sujeita a um grau de dispersão. A incerteza de medição é o parâmetro associado ao resultado, que caracteriza esta dispersão dos valores atribuídos a um mensurando qualquer, desse modo um resultado de medição somente é completo quando está acompanhado por sua respectiva incerteza (BUCHMANN, 2000; OLIVEIRA JUNIOR, 2006; ISO-GUM, 2008; VIM 2012).

Esta variabilidade pode ser atribuída a diferentes fontes, tais como o equipamento de ensaio, o item que está sendo medido, operador, a amostragem etc.

A definição do guia ISO-GUM, 2008 para incerteza de medição traz vários pontos a destacar. Primeiramente, ressalta-se que a incerteza está relacionada a um valor de medição, que é o resultado da medição, e não ao valor verdadeiro do mensurando, o qual na prática não é conhecido. O resultado da medição é apenas a melhor estimativa de tal valor verdadeiro e, na ausência de efeitos sistemáticos, geralmente é obtido pela média aritmética de $\mathrm{N}$ medições repetidas do mesmo mensurando na mesma amostra (JORNADA, 2009).

O segundo ponto relevante é que a incerteza caracteriza uma faixa de dispersão ou intervalo, e não um valor pontual. Nesse sentido, a incerteza não deve ser confundida com “erro", pois esse último é um valor pontual e não uma faixa e usualmente pode ser corrigido, quando aplicado um fator de correção adequado. Já a incerteza é a dúvida remanescente associada ao resultado da medição (JORNADA, 2009).

A incerteza mede o grau de desconhecimento sobre aquilo que está sendo medido, sendo assim, um parâmetro fundamental que indica a qualidade da medição.

Segundo sugere o guia ISO-GUM, 2008, existem cinco etapas para a estimativa da incerteza de uma medição, são elas:

1. Especificação do mensurando - Modelo matemático

2. Identificação das fontes de incerteza - Diagrama de Ishikawa

3. Quantificação das incertezas padrões $\left(\mathrm{u}_{\mathrm{xi}}\right)$ - Tipo A ou B

4. Cálculo da incerteza combinada $\left(\mathrm{u}_{\mathrm{c}}\right)$

5. Cálculo da incerteza expandida ou global (U)

O processo para estimativa da incerteza de medição é iniciado pelo estabelecimento do mensurando, que pode ser entendido como "'grandeza específica submetida à medição" e da relação entre o mensurando e os parâmetros dos quais ele depende, sendo apresentado na forma de um modelo matemático (VIM, 2012) 
O guia ISO-GUM está baseada na "lei da propagação de incertezas". Assim após o conhecimento do mensurando e do modelo matemático, define-se uma estratégia para identificar as fontes de incertezas que contribuem para a incerteza final das medições.

Normalmente, este objetivo pode ser alcançado e, principalmente, melhor visualizado, através da utilização do diagrama de Ishikawa, conhecido como diagrama de causa e efeito, ou anda espinha de peixe, FIGURA 22 (BUCHMANN, 2000).

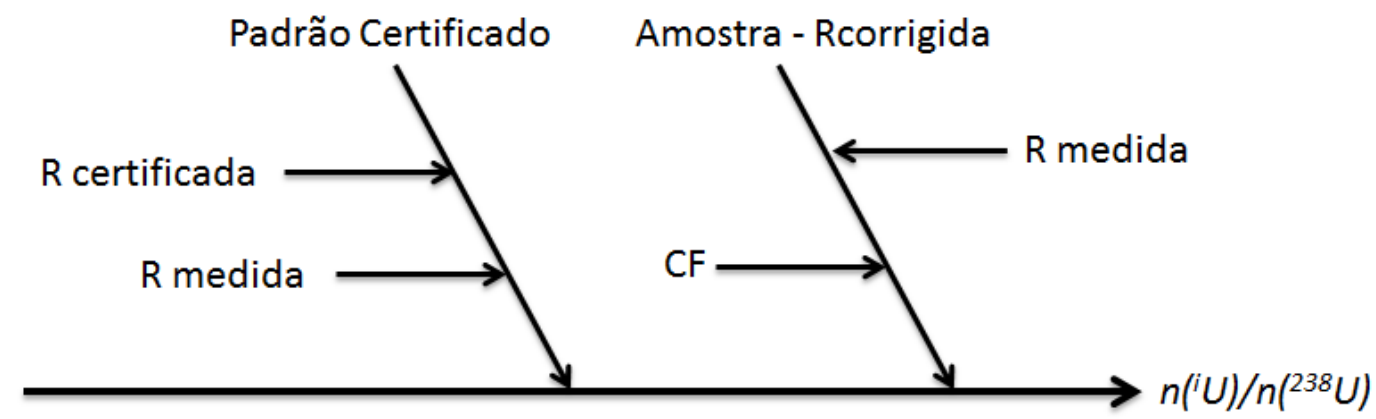

FIGURA 22: Diagrama de causa e efeito (Ishikawa): Fontes das incertezas associadas na determinação das razões isotópicas de urânio. Detalhamento na sessão de 5.1. Tratamento dos dados.

Identificadas às fontes das incertezas, então cada uma delas é calculada separadamente como incerteza padrão $\left(\mathrm{u}_{\mathrm{xi}}\right)$, tratadas como desvios padrão, obtendo a contribuição de cada componente para a incerteza expandida.

As incertezas padrão podem ser divididas em:

$\checkmark$ Tipo A - proveniente de efeitos aleatórios, estimada a partir de experimentos do tipo repetitivo sendo sua estimativa quantificada em termos de desvio padrão dos valores medidos (ULRICH, 2001). Assim, é uma avaliação de uma componente da incerteza de medição por uma análise estatística dos valores medidos, obtidos sob condições definidas de medição (VIM, 2012).

$\checkmark$ Tipo B - realizada através de um julgamento científico, baseado em todas as informações possíveis sobre a variabilidade da grandeza medida (ULRICH, 2001), podendo ser uma avaliação de uma componente da incerteza de medição determinada por meios diferentes daquele dotado para a avaliação 
do Tipo A. Exemplo: Avaliação baseada na informação associada a valores publicados por autoridade competente, associada ao valor de um material de referência certificado, obtida a partir de um certificado de calibração, etc. (VIM, 2012).

Em posse das incertezas padrão $\left(\mathrm{u}_{\mathrm{xi}}\right)$, a incerteza combinada $\left(\mathrm{u}_{\mathrm{c}}\right)$ é calculada através da relação 1 .

$$
u_{c}=\sqrt{\sum_{i=1}^{n} u(x i)^{2}}
$$

O resultado final de uma medição é expresso de forma a permitir um fator de abrangência associado ao nível de confiança escolhido. Isto se dá multiplicando a incerteza combinada $\left(u_{c}\right)$ por uma constante, que depende do intervalo de confiança, chamada de fator de abrangência (k), obtendo-se a incerteza expandida (U) representada na relação 2.

$$
U=u_{c} x k
$$

Portanto, os resultados nesse trabalho serão expressos por y $\pm \mathrm{U}$, onde y é o resultado médio, de $\mathrm{N}$ repetições obtido experimentalmente, sendo $\mathrm{U}$ a incerteza expandida com nível de $95,45 \%$ de confiança $(\mathrm{k}=2)$.

Os valores das incertezas deste trabalho foram calculados pelo software GUM Workbench $^{18}$. No ANEXO 1 está descrito os cálculos para a estimativa das incertezas associadas às determinações de razões isotópicas de urânio, por ICP-QMS, utilizados nesse trabalho.

No contexto desse trabalho, foram utilizados conceitos metrológicos por julgarmos ser importante para obter dados rastreáveis, confiáveis, que mostrem a qualidade da medida e que possam ser comparáveis.

\footnotetext{
${ }^{18}$ GUM Workbench. The tool for the expression of uncertainty in measurement. Education Version 2.3. Metrodata Gmbh.
} 


\section{DESENVOLVIMENTO EXPERIMENTAL}

Este trabalho foi desenvolvido no Laboratório de Caracterização Química e Isotópica do Centro de Química e Meio Ambiente LCQ/CQMA - IPEN. A metodologia utilizada para a análise das amostras de esfregaço seguiu procedimentos sugerido pela AIEA. Decidiu-se também incluir a caracterização morfológica das partículas de urânio presentes nas amostras de esfregaço com o intuito de se extrair informações complementares à caracterização isotópica. A caracterização morfológica e química foi realizada com o auxílio das técnicas de MEV-EDS; enquanto a caracterização isotópica foi realizada por meio da técnica de ICP-QMS.

\subsection{Tratamento dos dados}

\subsubsection{Atividade radioativa}

O urânio emite principalmente partículas alfa e a relação que foi utilizada para fornecer a atividade medida $(\mathrm{Bq})$ das amostras analisadas nesse estudo depende de parâmetros de construção do instrumento utilizado para a medição, da taxa de decaimento e é dado pela seguinte relação:

$$
A_{\text {medida }}=\frac{N-N o}{E i . E s . F .60}
$$

Onde:

$\mathrm{N}=$ Contagens por minuto da amostra;

No $=$ Contagens por minuto do branco do processo;

$\mathrm{Ei}=$ Eficiência da sonda;

Es = Eficiência de emissão da fonte;

$\mathrm{F}=$ Fator de transferência do esfregaço;

60 = Conversão de minutos para segundos

Segundo Rucker, 1998, a partir de dados empíricos e interpolações matemáticas é possível ajustar uma função que forneça a atividade empírica $(\mathrm{Bq} / \mathrm{g})$ em relação à massa de urânio em razão das emissões alfa, partindo do nível de enriquecimento isotópico em ${ }^{235} \mathrm{U}$ (fração atômica molar), conforme a relação 4 


$$
A_{\text {empírica }}=37000 \cdot\left(0,19192+0,64333\left(\% 235_{U}\right)-0,00025\left(\% 235_{U}\right)^{2}\right)
$$

Onde $\%{ }^{235} \mathrm{U}$ é a fração atômica molar relativa ao isotópico ${ }^{235} \mathrm{U}$.

Ao relacionar a atividade medida $(\mathrm{Bq})$, relação 3 , com a atividade empírica $(\mathrm{Bq} / \mathrm{g})$, relação 4, é possível estimar a massa de urânio existente em cada amostra.

Esta metodologia foi comprovada por Marin, 2013, onde o autor depositou pequenas quantidades $\mathrm{UF}_{4}$ e $\mathrm{U}_{3} \mathrm{Si}_{2}$ com diferentes enriquecimentos $\left(\mathrm{UF}_{4}-0,789 \%{ }^{235} \mathrm{U}\right.$; $\mathrm{U}_{3} \mathrm{Si}_{2}-19,85 \%{ }^{235} \mathrm{U}$ e $0,795 \%{ }^{235} \mathrm{U}$ ) sobre amostras de esfregaço. Utilizando os valores empíricos fornecidos pela relação 4 e tendo conhecimento da massa de urânio contida em cada amostra simulada, pôde-se estimar a atividade em becquerel para que se pudesse comparar com os valores de atividade medida obtidos pelo contador.

Marin, 2013 verificou que a expressão empírica para estimativa da atividade total de urânio é válida, pois a diferença relativa entre as atividades empírica (calculada, relação 4) e medida (relação 3 ) foram de $-0,21 \%$ a $6,9 \%$ para as amostras de $\mathrm{UF}_{4}$ e $\mathrm{U}_{3} \mathrm{Si}_{2}$.

\subsubsection{Razões isotópicas de urânio}

Na determinação das razões isotópicas de urânio foi utilizada a relação 5 a seguir:

$$
\frac{n\left(i_{U}\right)}{n\left(238_{U}\right)}=\frac{I i_{U}}{I 238_{U}}=\frac{i_{U}}{238_{U}}
$$

Onde:

$n\left({ }^{i} U\right)$ é número de átomos do isótopo i do urânio. Onde i pode ser os isótopos ${ }^{234} \mathrm{U},{ }^{235} \mathrm{U}$ ou ${ }^{236} \mathrm{U}$;

$n\left({ }^{238} U\right)$ é o número de átomos do isótopo ${ }^{238} \mathrm{U}$;

$\mathrm{I}^{\mathrm{i} U}$ é corrente iônica relativa ao isótopo ${ }^{\mathrm{i}} \mathrm{U}$;

$\mathrm{I}^{238} \mathrm{U}$ é corrente iônica relativa ao isótopo ${ }^{238} \mathrm{U}$.

\subsubsection{Fração atômica molar dos isótopos de urânio}

Na determinação da fração atômica do isótopos de urânio foi utilizada a relação 6 a seguir: 


$$
\text { Fração Atômica }_{i}=\frac{i_{U} / 238_{U}}{1+\sum i_{U} / 238_{U}} \times 100
$$

Onde:

Fração atômica é a abundância isotópica referente ao isótopo i do urânio. Onde i pode ser os isótopos ${ }^{234} \mathrm{U},{ }^{235} \mathrm{U}$ ou ${ }^{236} \mathrm{U}$;

${ }^{\mathrm{i}} \mathrm{U} /{ }^{238} \mathrm{U}$ é a razão isotópica do isótopo i em relação ao ${ }^{238} \mathrm{U}$. Onde ${ }^{\mathrm{i}} \mathrm{U} /{ }^{238} \mathrm{U}$ pode ser ${ }^{234} \mathrm{U} /{ }^{238} \mathrm{U} ;{ }^{236} \mathrm{U} /{ }^{238} \mathrm{U}$ e ${ }^{236} \mathrm{U} /{ }^{238} \mathrm{U}$.

\subsubsection{Fração mássica dos isótopos de urânio}

Na determinação da fração mássica do isótopos de urânio foi utilizada a relação 7 a seguir:

$$
\text { Fração Mássica } a_{i}=\frac{\left(i_{U} / 238_{U}\right) \times A i}{\sum\left(i_{U} / 238_{U}\right) \times A i} \times 100
$$

Onde:

Fração mássica é a fração em massa referente ao isótopo i do urânio. Onde i pode ser os isótopos ${ }^{234} \mathrm{U},{ }^{235} \mathrm{U},{ }^{236} \mathrm{U}$ e ${ }^{238} \mathrm{U}$.

Ai é a massa atômica do isótopo i. Onde i pode ser os isótopos ${ }^{234} \mathrm{U},{ }^{235} \mathrm{U},{ }^{236} \mathrm{U}$ e ${ }^{238} \mathrm{U}$. Conforme TABELA 1.

\subsubsection{Discriminação de massa}

A corrente iônica relativa a cada isótopo medida no ICP-MS deveria ser equivalente à sua abundância atômica se não existissem erros de discriminação de massa - mass bias (BUCHMANN, 2000).

A discriminação de massa é um fenômeno físico que acarreta uma diferença entre o valor verdadeiro da razão isotópica de uma amostra e o valor medido experimentalmente. Ele está associado ao transporte preferencial dos íons mais pesados nas etapas de amostragem, vaporização, ionização, transmissão ou detecção dos íons no interior do espectrômetro de massas (OLIVEIRA JUNIOR, 2000).

O fenômeno ocorre devido aos íons mais leves serem mais defletidos que os pesados, tornando a força repulsiva Coulombiana dependente da diferença de massas entre os isótopos (BECKER, 2002; MARIN, 2013). 
Geralmente a discriminação de massas pode ser corrigida através da análise de um padrão externo de composição isotópica conhecida (material de referência certificado MRC).

Para tal, existe um fator de correção para cada razão isotópica, que pode ser calculado por leis lineares, exponenciais ou potências. Nesse estudo foi utilizada a lei linear propostas por KERL, 1997 e FURUSAWA, 1999 seguindo as relações 8 a10.

$$
f m d=\frac{\frac{n\left(i_{U}\right)}{n\left(238_{U}\right)} \operatorname{cert}}{\frac{n\left(i_{U}\right)}{n\left(238_{U}\right)} m e d}
$$

Onde:

fmd é o fator de discriminação de massa;

$n\left({ }^{i} U\right) / n\left({ }^{238} U\right)$ cert é o valor da razão isotópica encontrada no certificado do MRC, onde i pode ser os isótopos ${ }^{234} \mathrm{U},{ }^{235} \mathrm{U}$ ou ${ }^{236} \mathrm{U}$; $n\left({ }^{i} U\right) / n\left({ }^{238} U\right)$ med é o valor da razão isotópica medida experimentalmente para o MRC.

O fmd é utilizado para calcular o valor de discriminação de massa por unidade de massa atômica - CF, segundo a relação 9:

$$
C F=\frac{(f m d-1)}{\Delta m}
$$

Onde:

$\Delta \mathrm{m}$ é a diferença entre as massas dos isótopos utilizados na razão isotópica. Exemplo: Para a razão $n\left({ }^{234} U\right) / n\left({ }^{238} U\right)$ o $\Delta \mathrm{m}=(238-234)=4$.

Por fim, a razão isotópica corrigida é obtida seguindo a relação 10:

$$
\frac{n\left(i_{U}\right)}{n\left(238_{U}\right)} \operatorname{corr}=\frac{n\left(i_{U}\right)}{n\left(238_{U}\right)} \operatorname{med} x(1+C F)^{\Delta m}
$$

Onde:

$n\left({ }^{i} U\right) / n\left({ }^{238} U\right)$ corr é o valor da razão isotópica corrigida pelo fator de discriminação de massas para a razão $n\left({ }^{i} U\right) / n\left({ }^{238} U\right)$; 
$n\left({ }^{i} U\right) / n\left({ }^{238} U\right)$ med é o valor da razão isotópica medida na amostra para a razão $n\left({ }^{i} U\right) / n\left({ }^{238} U\right)$.

\subsection{Equipamentos}

Para as medições de atividade radioativa dos esfregaços (emissões alfa), foi utilizado um contador Ludlum 2929 em conjunto com o módulo 43-10-01 (Sweetwater, TX - USA). Esse equipamento conta com um cintilador $\mathrm{ZnS}(\mathrm{Ag})$, janela de $0,4 \mathrm{mg} / \mathrm{cm}^{2} \mathrm{e}$ eficiência de $49 \%$ para ${ }^{238}$ U. Equipamento localizado no Centro do Combustível Nuclear do Instituto de Pesquisas Energéticas e Nucleares (IPEN/CNEN).

Nas análises morfológicas das partículas individuais, foram utilizados dois microscópios eletrônicos de varredura (MEV), localizados no Centro de Ciência e Tecnologia dos Materiais (CCTM) do IPEN-CNEN, a saber:

$>\quad$ Hitachi Tabletop TM3000 com aceleração de $15 \mathrm{kV}$, magnificações de 15x a 30.000x, resolução de 30nm, detector de elétrons retroespalhados - BSE. A caracterização química foi realizada através da técnica de espectroscopia de energia dispersiva de raios-x - EDS, que utiliza um detector Silicon-Drift Detector - SDD de $30 \mathrm{~mm}^{2}$ e possui resolução de $135 \mathrm{eV}$, por um sistema Quantax 70.

$>\quad$ Philips XL30 equipado com Microssonda de Energia Dispersiva (EDS), de fabricação EDAX (Ametek). Utiliza dois detectores sendo um de elétrons retroespalhados (BSE) e outro de elétrons secundários (SE). Apresenta aceleração que pode variar de 0,5 a $30 \mathrm{kV}$ e ampliação de 10x a 100.000x.

As medições de razão isotópica de urânio foram realizadas utilizando um ICP-MS quadrupolo, Agilent 7500ce (Hachioji-shi, Tokio, Japão) com sistema de reação octapolo e nebulizador micromist. Instrumento localizado no Centro de Energia Nuclear na Agricultura (CENA), Universidade de São Paulo (USP), Piracicaba-SP.

Dente outros equipamentos, utilizaram-se ainda:

○ Balança semi-analítica modelo BG 400 da Gehaka ${ }^{\circledR}$;

○ $\quad$ Forno Mufla Quimis ${ }^{\circledR}$ Q-318M24, 3720 W, 220 V;

○ $\quad$ Micropipetas LABMATE+ ${ }^{\circledR}$; 
- Chapa de aquecimento;

○ $\quad$ Sistema de ultrassom Ultrasonic Cleaner Thornton T14;

○ Centrífuga Excelsa® II modelo 206 BL.

\subsection{Materiais de laboratório}

○ Béquer de teflon e polipropileno;

○ $\quad$ Colunas BioRad ${ }^{\circledR}$ poly-prep ;

○ Tubos de poliestireno de 15 e $50 \mathrm{~mL}$ com tampa, tipo Falcon;

- Cadinho de porcelana de $150 \mathrm{~mL}$;

○ Pipetas Pasteur, com capacidade para $3 \mathrm{~mL}$;

○ Dessecador de vidro borosilicato com cloreto de cálcio anidro;

○ Pinça de alumínio;

○ Esfregaço - discos de falso tecido (viscose), $50 \mathrm{~mm}$ de diâmetro, gramatura de 80 $\mathrm{g} / \mathrm{m}^{2}$ (fornecido pela empresa Montair Serviços e Cortes Ltda, São Bernardo do Campo, Brasil);

○ Embalagens plásticas vedáveis.

\subsection{Reagentes, padrões e materiais de referência}

○ $\quad$ Ácido Clorídrico P.A. Destilado (HCl);

○ $\quad$ Ácido Nítrico P.A. Destilado $\left(\mathrm{HNO}_{3}\right)$;

○ $\quad$ Ácido Fluorídrico P.A. (HF);

○ $\quad$ Ácido Iodícrico (HI);

○ $\quad$ Ácido Perclórico P.A. $\left(\mathrm{HClO}_{4}\right)$;

○ $\quad$ Água obtida por sistema de purificação Milli-Q®, com resistividade de 18,2M $\Omega . c m$ a $25^{\circ} \mathrm{C}$;

○ Resina Aniônica Forte - Dowex® AG 1x8 - 200 mesh, forma clorídrica (SigmaAldrich, USA);

○ Detergente Extran ${ }^{\circledR}$;

○ Padrão Isotópico de Urânio CRM NBL U200, fornecido pelo NBL - New Brunswick Laboratory. Com valores de porcentagem atômica dos isótopos ${ }^{234} \mathrm{U},{ }^{235} \mathrm{U},{ }^{236} \mathrm{U}$ e ${ }^{238} \mathrm{U}$ de $0.1246 \pm 0.0003 ; 20.013 \pm 0.020 ; 0.2116 \pm 0.0006 ; 79.651 \pm 0.021$, respectivamente. Uma cópia do certificado está disposto no ANEXO 2; 
○ $\quad \mathrm{UF}_{4}$ fornecido pela CEA - Commissariat a L'Énergie Atomique, França;

$\circ \quad \mathrm{U}_{3} \mathrm{O}_{8}$ proveniente do NBL United States Atomic Energy Commission, 1969.

\subsection{Descontaminação dos materiais de laboratório}

Todos os materiais utilizados nesse trabalho passaram por processos de descontaminação antes de serem utilizados, seguindo as etapas descritas a seguir.

○ Lavou-se o material com bucha e detergente neutro;

- Deixou-se o material por um dia em banho com detergente Extran 5\% (v/v);

○ Enxaguou-se o material com água desmineralizada;

○ Deixou-se o material imerso em $\mathrm{HNO}_{3} 35 \%$ (v/v) em chapa de aquecimento em $60^{\circ} \mathrm{C}$ durante a noite;

○ Enxaguou-se o material com água desmineralizada;

- Deixou-se o material imerso em $\mathrm{HNO}_{3} 10 \%$ (v/v) durante um dia;

○ Enxaguou-se o material com água Milli-Q;

○ Secou-se em estufa a $40^{\circ} \mathrm{C}$.

\section{6. Área de amostragem}

No Instituto de Pesquisas Energéticas e Nucleares, IPEN-CNEN, o Centro do Combustível Nuclear é o departamento responsável pela produção do elemento combustível tipo placa à base de dispersão de $\mathrm{U}_{3} \mathrm{Si}_{2}-\mathrm{Al}$ (enriquecido á 19,75 \pm 0,20\% no isótopo ${ }^{235} \mathrm{U}$, com densidade de $3,1 \mathrm{gU} / \mathrm{cm}^{3}$ ) necessário para operação do reator de pesquisa, IEA-R1, tipo piscina conhecido como MTR - Materials Testing Reactor (SILVA, 1988; IPEN, 2013).

O Centro do Combustível Nuclear é composto por três centros que exercem a função da produção do combustível, sendo eles o Centro do Combustível e Recuperação (CCR), Centro do Combustível de Ligas (CCL) e o Centro do Combustível de Pós (CCP).

A instalação do CCR é responsável pela conversão do $\mathrm{UF}_{6}$ a $\mathrm{UF}_{4}$, intermediário necessário para fabricação da liga de $\mathrm{U}_{3} \mathrm{Si}_{2}-\mathrm{Al}$, e pela recuperação de $\mathrm{UF}_{4}$ do processo. A FIGURA 23 apresenta uma das rotas de produção da liga de $\mathrm{U}_{3} \mathrm{Si}_{2}$-Al utilizada pelo Centro do Combustível Nuclear. 


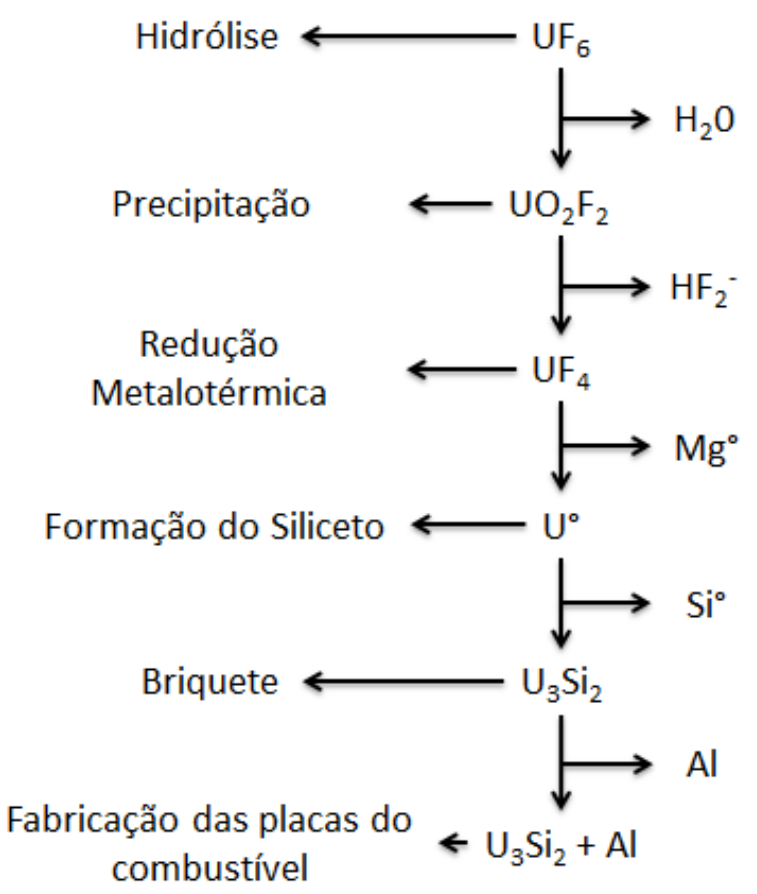

FIGURA 23: Fluxograma de uma das rotas de produção do combustível nuclear utilizado no reator IEA-R1 formado pela liga metálica de siliceto de urânio e alumínio.

As amostras foram coletadas utilizando a técnica de esfregaço em pontos externos e internos da instalação do CCR segundo FIGURA 24.

Cada esfregaço foi aplicado em uma área de aproximadamente $100 \mathrm{~cm}^{2}$, posteriormente armazenados em embalagens plásticas vedáveis, evitando contaminações externas, devidamente identificadas (FIGURA 25). 


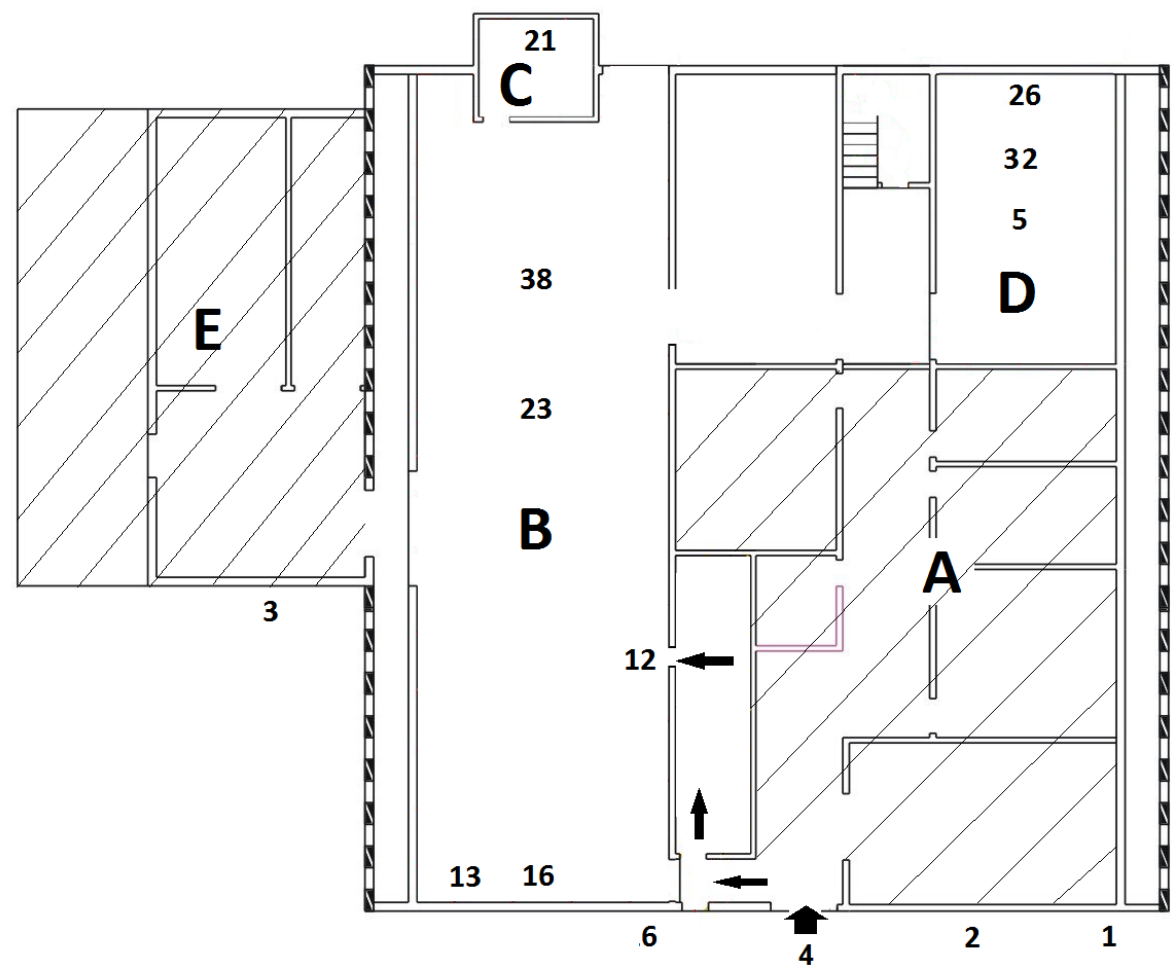

FIGURA 24: Mapa dos pontos de coleta dos esfregaços nas dependências da instalação de reconversão de urânio do CCR utilizada como estudo de caso. Onde A: Escritórios; B:

Usina de Produção do $\mathrm{UF}_{4}$; C: Sala de transferência do UF6; D: Laboratório de recuperação do $\mathrm{UF}_{4}$; E: Depósito.

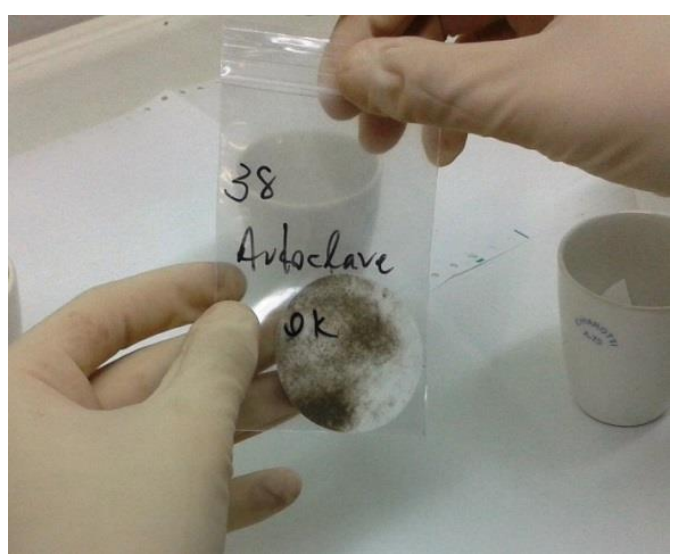

FIGURA 25: Amostra real de esfregaço coletada na planta de reconversão do CCR.

\subsection{Estratégia analítica}

Os esfregaços foram submetidos a uma sequência de ensaios a fim de obter informações (assinaturas) quanto ao nível de atividade radioativa $\alpha$, características das 
partículas individuais assim como o enriquecimento isotópico, que possam levar a identificação de atividade nuclear desenvolvida na área inspecionada.

Para tal, foi proposta uma estratégia analítica, onde, inicialmente, são realizadas medidas de atividade radioativa $\alpha$, análise composicional microscópica e morfológica bem como análise isotópica como desfecho final da avaliação, conforme FIGURA 26.

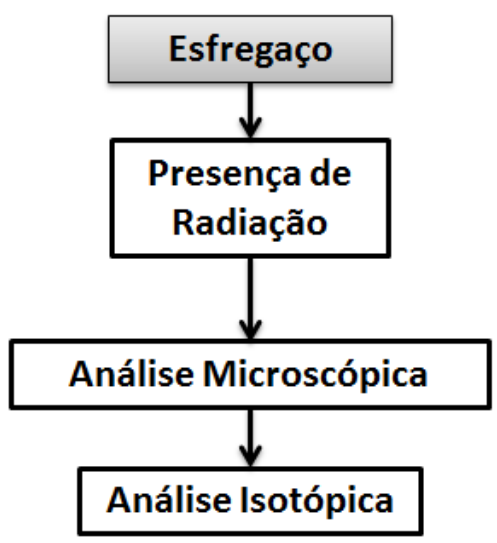

FIGURA 26: Estratégia analítica aplicada nos esfregaços para Sequência de ensaios realizados para caracterização das amostras de esfregaço.

\subsubsection{Análise microscópica}

Em posse dos esfregaços, com a ajuda de uma fita dupla face de carbono, foram recuperadas algumas partículas da amostra e a fita colada em um suporte de alumínio apropriado para a análise no MEV.

Para a análise de EDS o equipamento foi programado para um tempo de 200 segundos para aquisição dos dados.

As partículas analisadas foram comparadas com as amostras de urânio que o laboratório possui: tetrafluoreto de urânio, $\mathrm{CEA} \mathrm{UF}_{4}-0,789 \pm 0,074 \%{ }^{235} \mathrm{U}$, siliceto de urânio, $\mathrm{U}_{3} \mathrm{Si}_{2}-19,85 \%{ }^{235} \mathrm{U}$ e $0,795 \pm 0,071 \%{ }^{235} \mathrm{U}$ produzido nas instalações do Centro do Combustível Nuclear do IPEN e que é caracterizado isotopicamente pelo LCQ/CQMA.

\subsubsection{Análise isotópica}

A fim de verificar a eficiência e aplicabilidade do método de lixiviação assistida por ultrassom (Lix/Us), foram selecionados esfregaços com baixa e alta atividade radioativa e foram submetidos ao método de Lix/Us assim como o de digestão total (DT). 
Cada esfregaço foi cortado ao meio e cada metade submetida a um método conforme FIGURA 27.

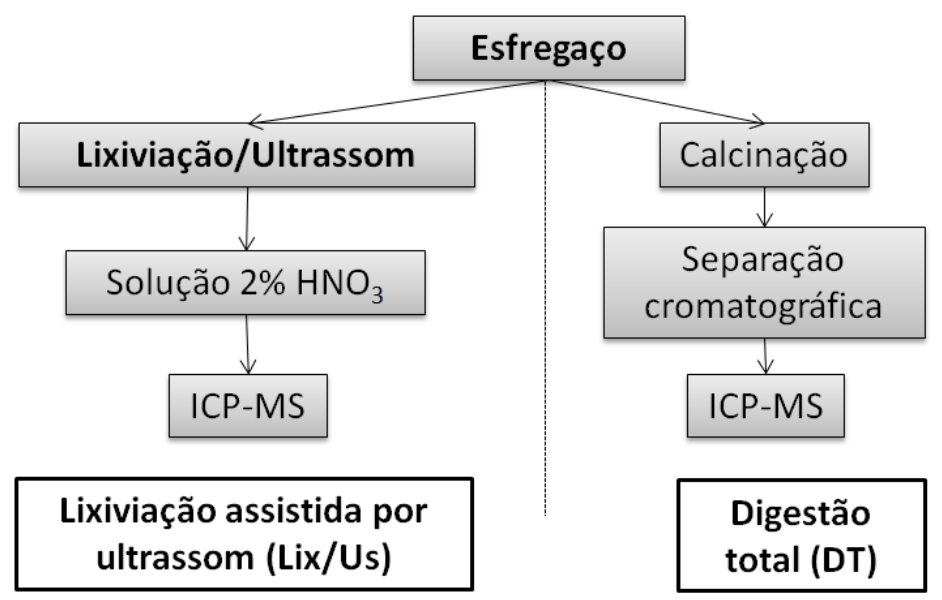

FIGURA 27: Diferentes métodos aplicados nas amostras para verificar a eficiência do método de Lix/Us como forma de extração de urânio dos esfregaços.

\subsubsection{Lixiviação assistida por ultrassom (Lix/Us)}

O processo Lix/Us aplicado em amostras de esfregaços foi proposta por PESTANA, 2013 e será utilizado nesse trabalho.

Para o processo de Lix/Us dos esfregaços, procedeu-se da seguinte forma:

$\checkmark$ Colocou-se separadamente cada esfregaço no interior de tubos de poliestireno, com capacidade para $50 \mathrm{~mL}$, contendo $20 \mathrm{~g}$ de solução de 0.29 mol. $\mathrm{Kg}^{-1} \mathrm{HNO}_{3}$.

$\checkmark$ Deixou-se o esfregaço imerso no ácido no ultrassom por 15 minutos.

$\checkmark$ Retirou-se o esfregaço do interior tubo, procedendo a centrifugação da solução por 3 minutos a $3000 \mathrm{rpm}$.

$\checkmark$ Com pipetas descartáveis transferiu-se o sobrenadante para tubos de poliestireno novos para serem analisados isotopicamente por ICP-QMS.

\subsubsection{Digestão total (DT)}

Usualmente os métodos de preparação de amostras utilizados em esfregaços são baseados no processo de DT em que o esfregaço é totalmente digerido, utilizando sistema de microondas ou forno mufla, seguida de uma separação cromatográfica. 
Sendo assim, no presente trabalho foi aplicado o método de DT baseado no trabalho de WILLIAMS, 2005 e VOGT, 2006. Onde:

$\checkmark$ Os esfregaços foram submetidos ao processo de calcinação em cadinhos de porcelana, previamente descontaminados, em forno mufla seguindo o programa de aquecimento de 2 horas em $450^{\circ} \mathrm{C}$ e 2 horas em $600^{\circ} \mathrm{C}$.

$\checkmark$ O resíduo remanescente foi dissolvido com $\mathrm{HNO}_{3} 8$ mol. $\mathrm{L}^{-1}$ e seguiu-se as etapas apresentados na FIGURA 28.

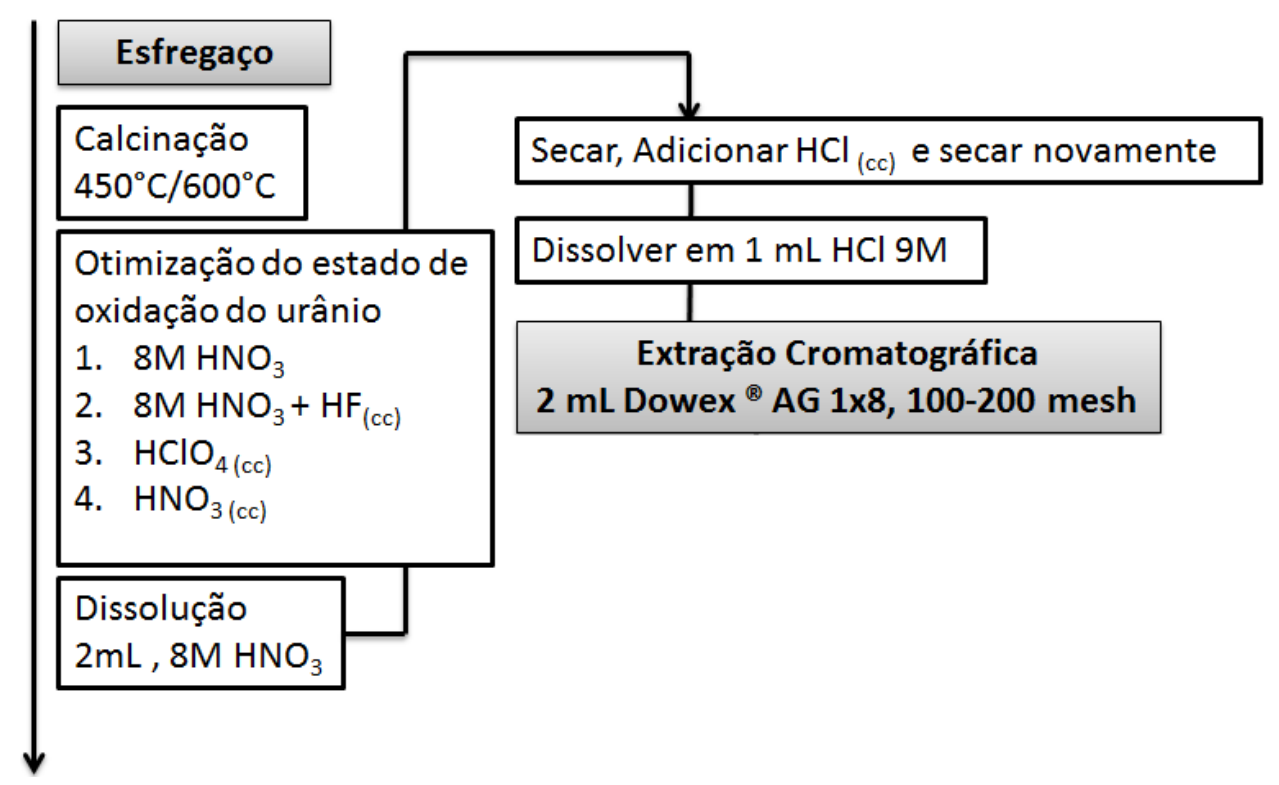

FIGURA 28: Sequência utilizada no procedimento de DT

Quando se faz a coleta dos esfregaços, além do possível urânio, o tecido carrega quantidades significativas de materiais indesejados, como grande quantidade de ferro, óxidos metálicos, material orgânico, que são prejudiciais e indesejados à estabilidade e funcionamento em um ICP-MS.

A utilização de resinas de troca iônica têm-se mostrado um método eficiente na separação de actinídeos em solução. O urânio no seu estado de oxidação +6 é retido em resina aniônica forte na forma de seus complexos. Em soluções de ácido nítrico o $\mathrm{U}^{6+}$ é fracamente adsorvido em resina aniônica forte, sua maior retenção está na faixa entre 6 a 8 mol $\mathrm{L}^{-1}$ de ácido nítrico $\left(\mathrm{Kd}^{19} \sim 12\right.$ a 16 ), sendo absorvido na forma de complexos $\mathrm{UO}_{2}\left(\mathrm{NO}_{3}\right)_{4}{ }^{2-}$ e $\mathrm{UO}_{2}\left(\mathrm{NO}_{3}\right)_{3}{ }^{-}$. Desse modo a retenção em meio clorídrico, na forma de

${ }^{19} \mathrm{Kd}=$ Coeficiente de distribuição 
$\mathrm{UO}_{2} \mathrm{Cl}_{3}{ }^{-}$, é preferível onde o $\mathrm{Kd}$ do $\mathrm{U}^{6+}$ é igual a 1000 na faixa de concentração de 8 a 12 mol L ${ }^{-1}$ de ácido clorídrico (KORKISCH, 1989).

O processo de separação do urânio utilizado está descrito na FIGURA 29 e parte do princípio que o urânio hexavalente $\left(\mathrm{U}^{+6}\right)$, em sua forma complexada, é separado por resina de troca iônica forte em meio clorídrico.

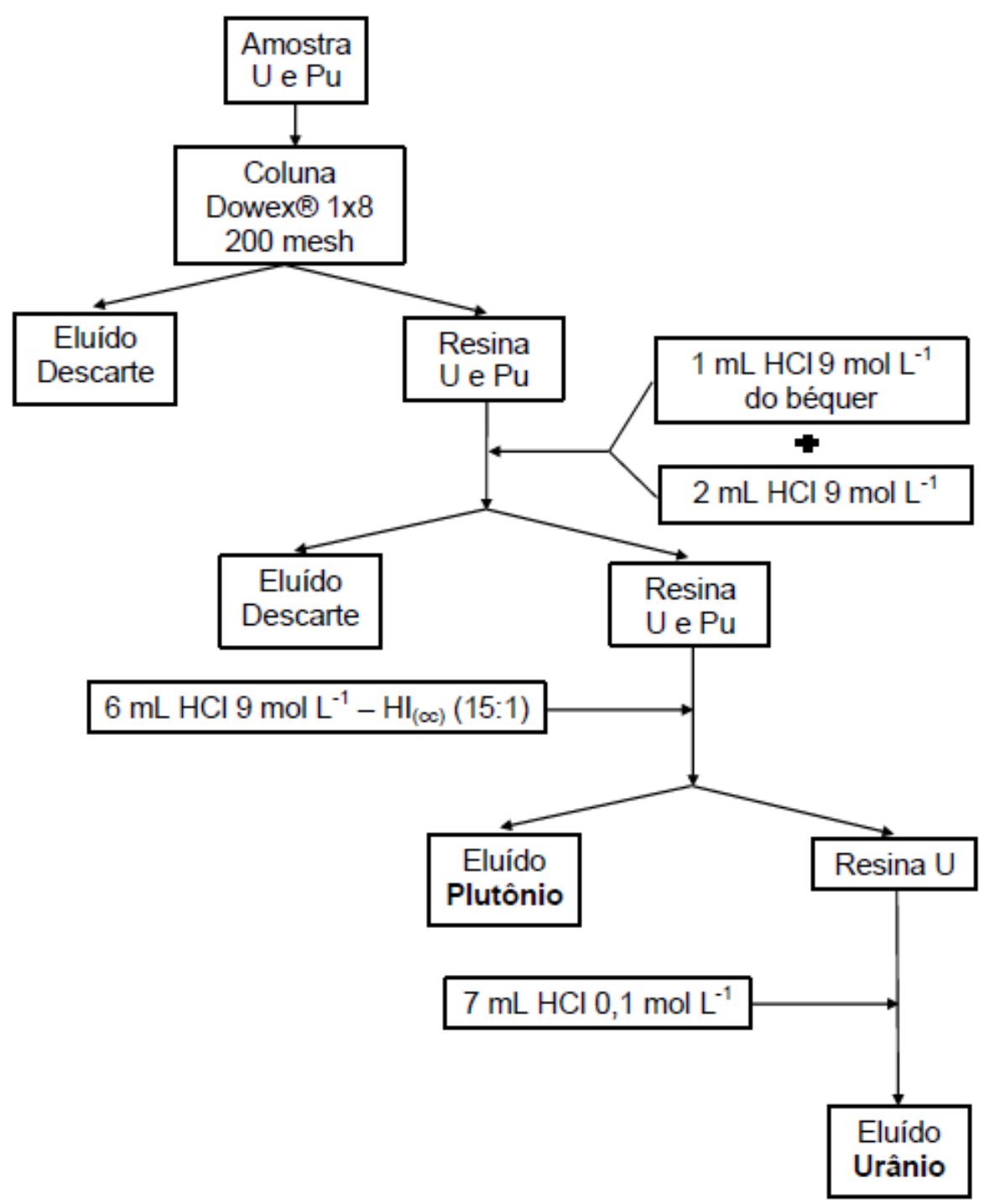

FIGURA 29: Fluxograma do processo envolvido na separação cromatográfica do urânio em meio clorídrico em resina aniônica forte. 


\section{RESULTADOS E DISCUSSÃO}

Conforme descrito anteriormente o Programa $93+2$ preconiza o uso de amostras ambientais dentro e nas vizinhanças das instalações nucleares. Dessa forma, no âmbito desse trabalho foram coletadas amostras no interior $(5,12,13,16,21,23,26,32$ e 38) assim como nas vizinhanças da instalação (1, 2, 3, 4 e 6).

\subsection{Atividade}

As amostras de esfregaços coletadas foram inicialmente analisadas em um contador de radiação alfa, com a finalidade de se constatar a presença de material radiativo e selecionar as melhores amostras in loco, conduzindo-as para as análises posteriores.

A partir da contagem das emissões alfa, pode-se obter a atividade medida bem como a massa estimada de urânio presente em cada esfregaço.

Os resultados obtidos da atividade medida, atividade empírica (calculada matematicamente pela relação 3) e massa estimada de urânio em cada amostra de esfregaço estão apresentados na

TABELA 6, com suas respectivas incertezas expandidas. 
TABELA 6: Valores de atividade medida, atividade empírica e quantidade estimada de urânio presente em cada amostra com suas respectivas incertezas expandidas com nível de confiança de $95,45 \%$.

\begin{tabular}{c|ccc}
\hline Amostra & $\begin{array}{c}\text { Atividade medida } \\
{[\mathbf{B q}]}\end{array}$ & $\begin{array}{c}\text { Atividade empírica } \\
{\left[\mathbf{x} \mathbf{1}^{\mathbf{+ 2}} \mathbf{B q} / \mathbf{g}\right]}\end{array}$ & $\begin{array}{c}\text { Massa de urânio } \\
{[\mathbf{m g}]}\end{array}$ \\
\hline $\mathbf{1}$ & $<\mathbf{L D}^{\mathbf{a}}$ & - & - \\
$\mathbf{2}$ & $<\mathbf{L D}^{\mathbf{a}}$ & - & - \\
$\mathbf{3}$ & $<\mathbf{L D}^{\mathbf{a}}$ & - & - \\
$\mathbf{4}$ & $\mathbf{1 1} \pm \mathbf{5}$ & $\mathbf{1 5 7 0} \pm \mathbf{2 4}$ & $\mathbf{0 , 0 7} \pm \mathbf{0 , 0 3}$ \\
$\mathbf{6}$ & $<\mathbf{L D}^{\mathbf{a}}$ & - & - \\
5 & $108 \pm 6$ & $3190 \pm 27$ & $0,34 \pm 0,02$ \\
12 & $<\mathrm{LD}^{\mathrm{a}}$ & - & - \\
13 & $2240 \pm 77$ & $3430 \pm 73$ & $6,5 \pm 0,3$ \\
16 & $8870 \pm 183$ & $3310 \pm 49$ & $26,8 \pm 0,7$ \\
21 & $3193 \pm 121$ & $1110 \pm 26$ & $28,7 \pm 1,3$ \\
23 & $134 \pm 12$ & $2650 \pm 45$ & $0,50 \pm 0,05$ \\
26 & $2067 \pm 71$ & $3750 \pm 70$ & $5,5 \pm 0,2$ \\
32 & $379 \pm 61$ & $4260 \pm 94$ & $0,9 \pm 0,1$ \\
38 & $891 \pm 18$ & $3500 \pm 33$ & $2,5 \pm 0,1$ \\
\hline
\end{tabular}

${ }^{a}$ Valor não detectado pelo equipamento utilizado, possivelmente valor está abaixo do limite de detecção (LD) do contador alfa.

OBS: Os resultados de atividade medida são para média de 5 leituras independentes de 1 minuto cada. O branco para o processo de medição foi de 2,1 $\pm 1,3$ contagens por minuto e descontado no valor das amostras antes do cálculo de atividade medida. As amostras em negrito são esfregaços coletados em áreas externas a instalação do CCR.

Conforme apresentado na

TABELA 6, foi possível identificar a presença de radiação em apenas uma das amostras externas (amostra 4, coletada em frente a porta de entrada, com $11 \pm 5 \mathrm{~Bq}$ ) assim como a massa estimada de urânio presente, que foi de $0,007 \pm 0,003 \mathrm{mg}$.

Dentro da instalação a amostra com maior atividade medida foi a amostra 16 (coletada no interior de uma capela, com $8870 \pm 183 \mathrm{~Bq}$ ) e que apresentou a segunda maior massa de urânio dentre os esfregaço $(26,8 \pm 0,7 \mathrm{mg})$ devido a sua maior fração atômica no isótopo ${ }^{235} \mathrm{U}(10,231 \pm 0,081 \%)$ em comparação com a amostra 21 (coletada 
no chão da sala de transferência de $\left.\mathrm{UF}_{6}\right)$ que apresentou a maior massa $(28,7 \pm 1,3 \mathrm{mg})$ devido a sua menor fração atômica molar no isótopo ${ }^{235} \mathrm{U}(4,426 \pm 0,036 \%)$.

Os resultados obtidos nessa análise prévia foram utilizados para selecionar as melhores amostras de esfregaço para as análises de microscopia eletrônica de varredura assim como para a comparação entres os métodos de DT e Lix/Us, conforme TABELA 7.

TABELA 7: Métodos que serão aplicados nas amostras coletadas no CCR.

\begin{tabular}{|c|c|c|}
\hline Amostra & Local & Método/Técnica \\
\hline 1 & & Lix/Us'- ICP-QMS \\
\hline 2 & & Lix/Us'- ICP-QMS \\
\hline 3 & Área externa ao CCR & MEV-EDS \\
\hline 4 & & Lix/Us'- ICP-QMS \\
\hline 6 & & MEV-EDS \\
\hline 5 & Área interna do CCR & Lix/Us e DT²-ICP-QMS \\
\hline 12 & & Lix/Us e DT²- ICP-QMS \\
\hline 13 & & Lix/Us'- ICP-QMS \\
\hline 16 & & MEV-EDS e Lix/Us ${ }^{1-}$ ICP-QMS \\
\hline 21 & & Lix/Us ${ }^{1}-\mathrm{ICP}-\mathrm{QMS}$ \\
\hline 23 & & Lix/Us e DT²- ICP-QMS \\
\hline 26 & & Lix/Us' ${ }^{1}$ ICP-QMS \\
\hline 32 & & Lix/Us e DT²- ICP-QMS \\
\hline 38 & & Lix/Us e DT²- ICP-QMS \\
\hline
\end{tabular}

1 - Lix/Us - Análise de razão isotópica utilizando método de lixiviação assistida por ultrassom

2 - DT - Análise de razão isotópica utilizando método de digestão total

OBS: as amostras em negrito são esfregaços coletados em áreas externas a instalação do CCR.

\subsection{Análise microscópica por MEV-EDS}

Para o estudo microscópico foram selecionados esfregaços de modo a identificar partículas de urânio em amostras com alta atividade (16), assim como amostra com atividade não detectada ( 3 e 6), verificando a robustez da técnica nesse tipo de análise.

O uso da técnica de MEV, em uma amostra real de esfregaço, exige um trabalho laborioso em encontrar partículas de interesse, frente à grande quantidade de partículas encontradas nesse tipo de amostra, conforme pode ser visualizado na FIGURA 30. 


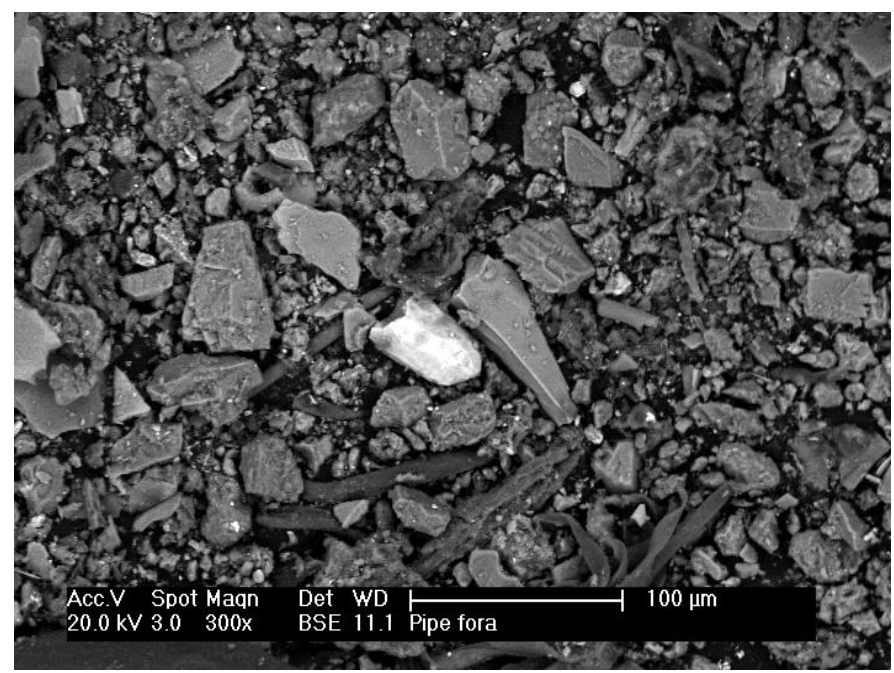

FIGURA 30: Micrografia obtida pela técnica de MEV para a amostra 3 utilizando uma magnificação de 300X. A partícula em destaque no centro da imagem é uma partícula de zircônio.

Com o uso do detector de elétrons retroespalhados - BSE, partículas com número atômico médio elevado brilham com mais intensidade do que as com menor número atômico médio. Sendo assim, uma ferramenta útil na identificação de partículas de urânio, uma vez que o urânio apresenta número atômico de 92.

A FIGURA 31, apresenta o efeito do uso de detector de elétrons secundários - SE, amostras (a) e (c), frente ao uso do detector de elétrons retroespalhados - BSE, amostras (b) e (d). 
(a)
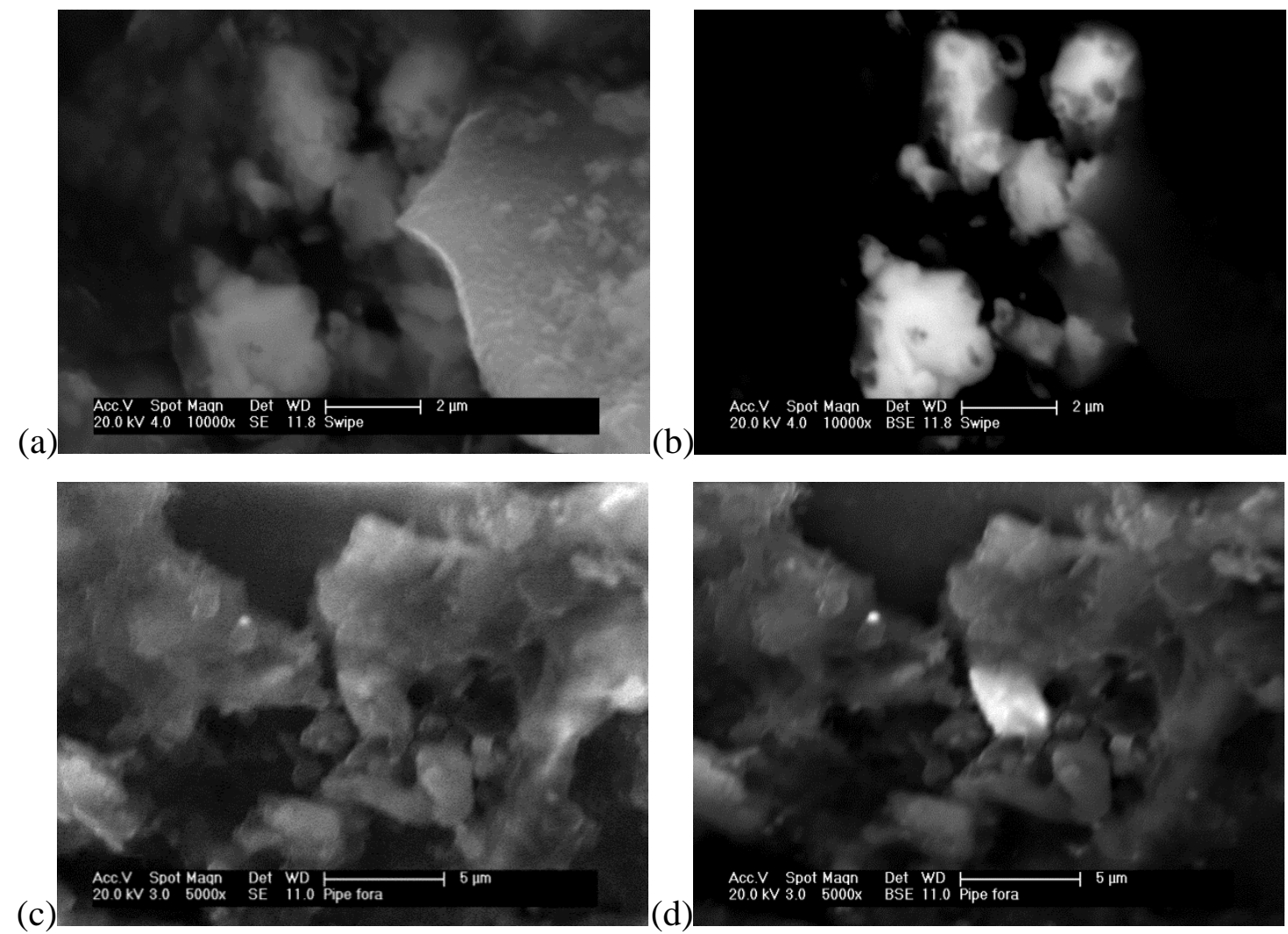

FIGURA 31: Micrografias obtidas de partículas de urânio encontradas nos esfregaços:

Diferenças do uso do detector SE (a) e (c) e BSE (b) e (d). Partículas (a) e (b) são

provenientes da amostra 6 (externa), sendo as (c) e (d) amostras coletadas em uma tubulação de saída de ar, localizada externamente a instalação (amostra 3). Imagens obtidas pelo equipamento Philips XL-30.

Através da FIGURA 31, pode-se observar uma nítida diferença nas partículas de urânio, sendo elas destacadas das demais pelo fato do número atômico elevado. Desse modo, todas as varreduras foram realizadas com detector no modo BSE a fim de facilitar a identificação de partículas de urânio. Em todas as partículas encontradas nos esfregaços pela técnica de MEV a presença de urânio, como elemento majoritário, foi confirmada pela técnica de EDS.

\subsubsection{Análise morfológica por MEV}

Foram identificadas uma grande quantidade de partículas de urânio na amostra 16, sendo quatro delas apresentadas na FIGURA 32. 

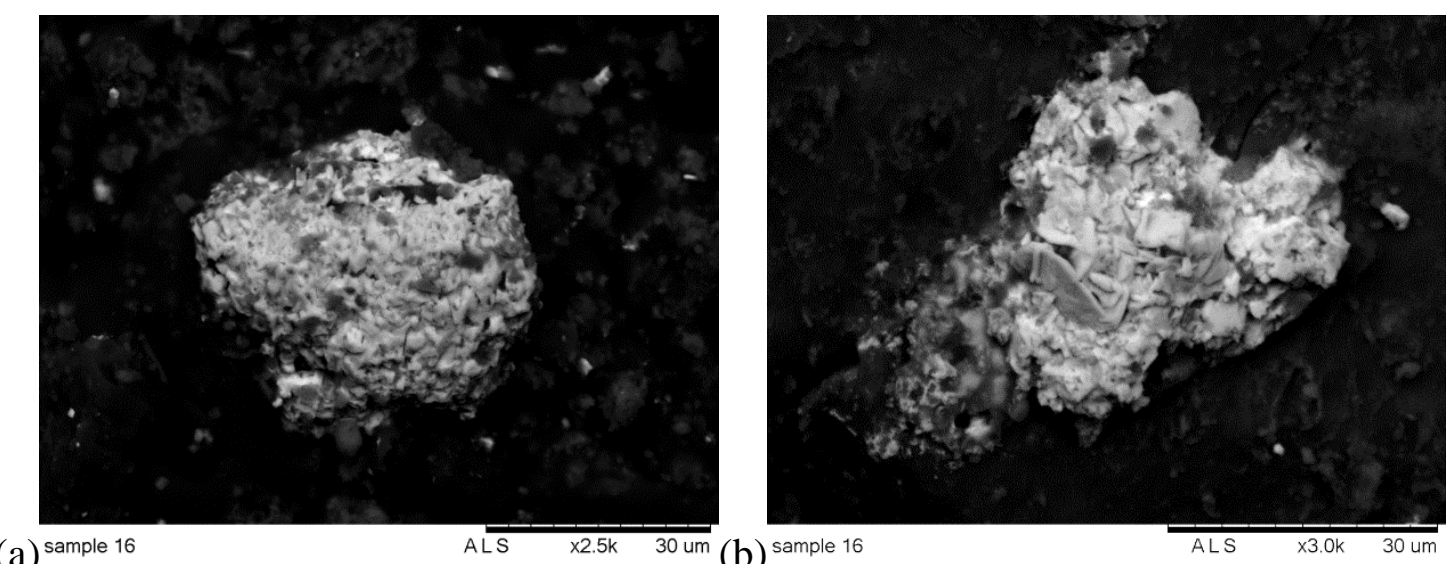

(a) sample $16^{2}$

$$
\text { ALs } \quad x 2.5 \mathrm{k} \quad 30 \mathrm{um}(\mathrm{b})^{\text {sample } 16}
$$
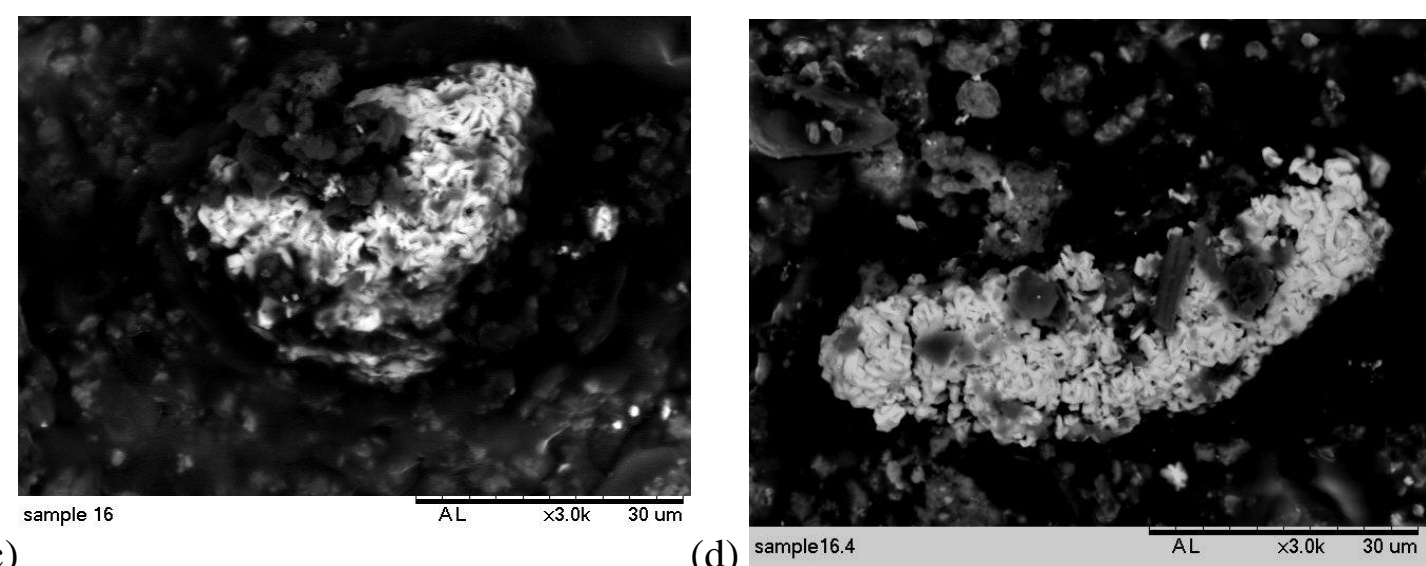

(c)

(d) sample 16.4

FIGURA 32: Micrografias de partículas de urânio encontradas na amostra 16.

As quatro partículas apresentadas na FIGURA 32 apresentaram área média de 1173 $\mu \mathrm{m}^{2}$, sendo as áreas individuais apresentadas na

TABELA 8.

TABELA 8: Área aproximada das partículas de urânio encontradas na amostra 16 referentes a FIGURA 32.

\begin{tabular}{c|c}
\hline Amostra 16-Partícula & Área $\left[\boldsymbol{\mu m}^{2}\right]$ \\
\hline (a) & 1394 \\
(b) & 1460 \\
(c) & 754 \\
(d) & 1082 \\
\hline
\end{tabular}

Segundo SALIBA-SILVA, 2011, a produção de $\mathrm{UF}_{4}$ via $\mathrm{HF}_{2}{ }^{-}$a partícula apresenta características morfológicas mais porosas, conforme FIGURA 33 (a). Pode-se verificar 
uma semelhança com a partícula encontrada na amostra 16, trazendo indícios de produção de $\mathrm{UF}_{4}$ produzido pela rota $\mathrm{HF}_{2}{ }^{-}$.
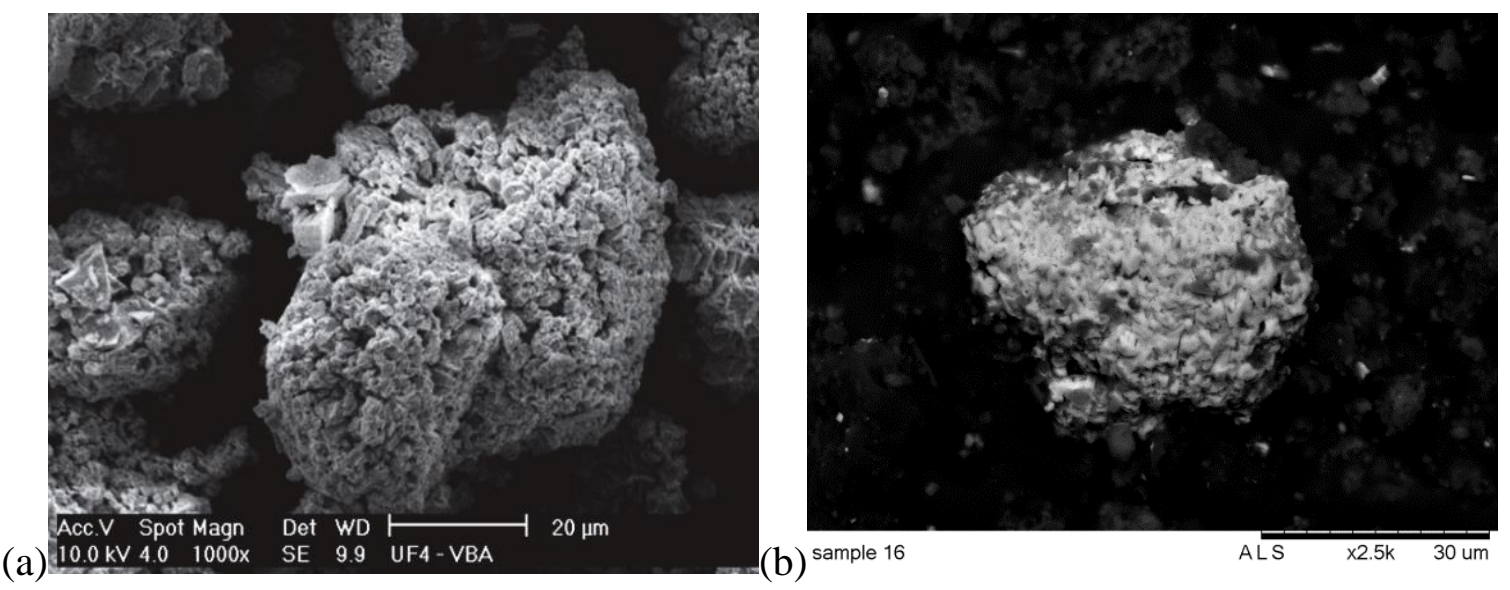

FIGURA 33: Características morfológicas de $\mathrm{UF}_{4}$ produzido (a) via $\mathrm{HF}_{2}^{-}$e (b) possível partícula de $\mathrm{UF}_{4}$ produzido pela mesma rota.

$\mathrm{Na}$ amostra 3, coletada externamente (FIGURA 34) foi encontrada uma partícula esférica que, segundo, STEBELKOV, 2010, pode ser $\mathrm{UO}_{2} \mathrm{~F}_{2}$ e são formadas pela reação de hidrólise do $\mathrm{UF}_{6}$ segundo a reação 1 .
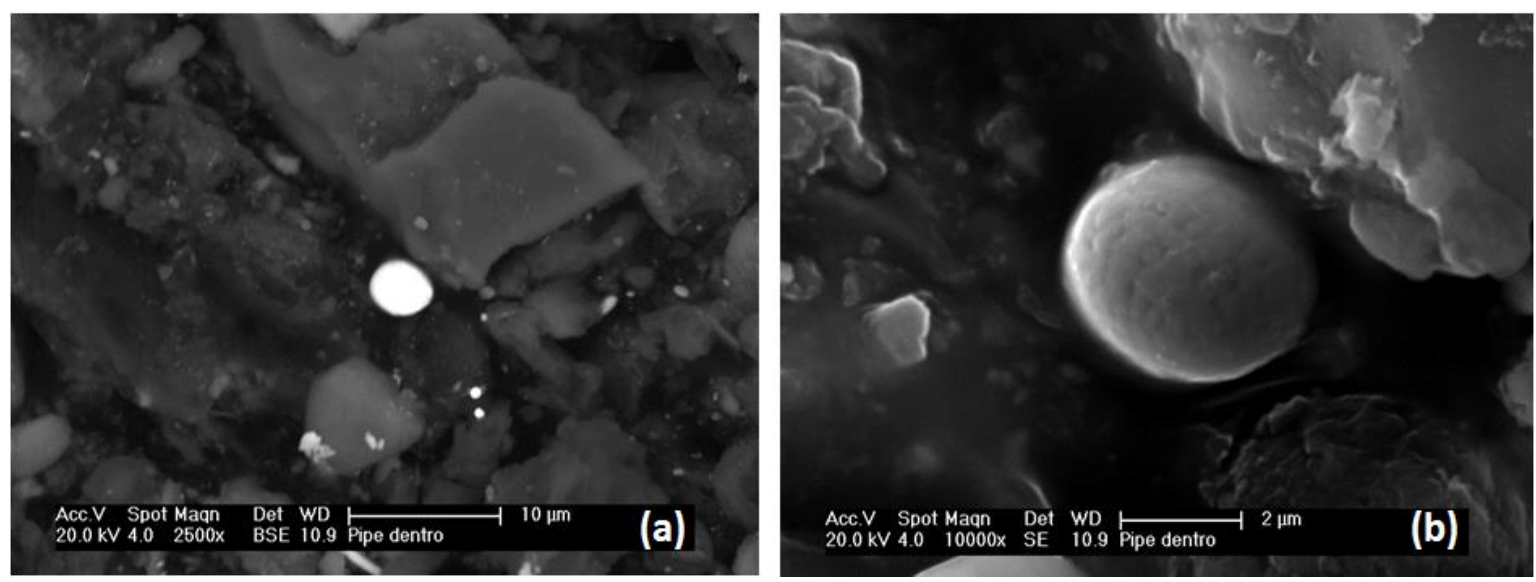

FIGURA 34: Partícula esférica de $\mathrm{UO}_{2} \mathrm{~F}_{2}$ (área de $13 \mu \mathrm{m}^{2}$ ) encontrada na amostra 3. Uso do detector BSE, com uma magnificação de 2500x (a), onde facilita encontrar partículas de urânio e (b) com o uso de detector SE e magnificação de 10000x, onde privilegia as características superficiais do material.

A identificação desse tipo de partícula $\left(\mathrm{UO}_{2} \mathrm{~F}_{2}\right)$ está de acordo com os materiais manipulados pela instalação estudada, visto que uma planta de reconversão manuseia 
cilindros de $\mathrm{UF}_{6}$, assim como realiza a hidrólise do mesmo para a posterior conversão a $\mathrm{UF}_{4}$ durante o processo de produção do combustível nuclear a base de $\mathrm{U}_{3} \mathrm{Si}_{2}-\mathrm{Al}$.

Para atribuir uma fórmula química às partículas de urânio encontradas nos esfregaços se faz necessário ter uma base de dados completa com os principais compostos de urânio utilizados no $\mathrm{CCN}$, assim como suas respectivas rotas de produção.

O ANEXO 3 apresenta uma base de dados de micrografias de diferentes compostos de urânio que podem ser encontrados nos diferentes processos dentro do $\mathrm{CCN}$.

A seguir, FIGURA 35, são apresentadas micrografias de partículas de urânio presentes nas amostras de esfregaços coletadas externamente (amostra 3 - (a) e (b) e amostra 6 - (c) e (d)) a instalação de reconversão.

(a)
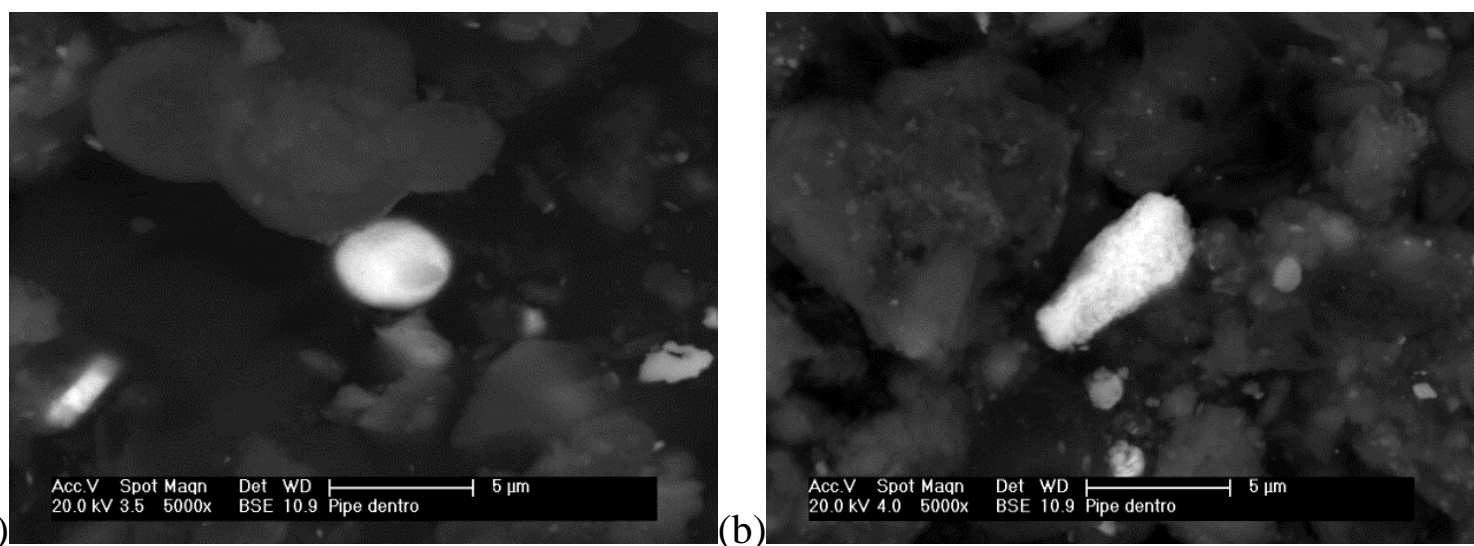

(c)
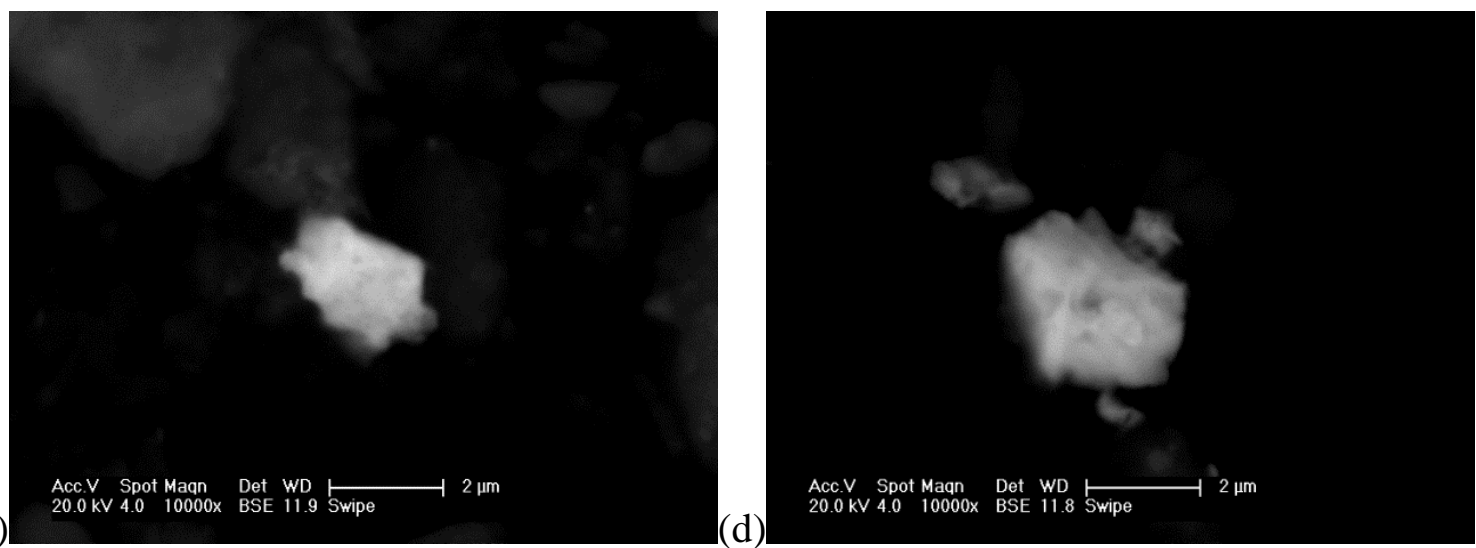

FIGURA 35: Micrografias das amostras de esfregaços coletadas externamente (amostra 3 - (a) e (b) e amostra 6 - (c) e (d)) a instalação de reconversão.

Como pode ser observado, as quatro partículas centrais apresentadas na FIGURA 35 apresentaram área média em torno de $10 \mu \mathrm{m}^{2}$, sendo as áreas individuais apresentadas na TABELA 9. 
TABELA 9: Área aproximada das partículas de urânio encontradas nas amostras 3 e 6 referentes a FIGURA 35.

\begin{tabular}{c|c}
\hline Amostra 3 - Partícula & Área $\left[\boldsymbol{\mu m}^{2}\right]$ \\
\hline (a) & 4,4 \\
(b) & 8,2 \\
Amostra 6 - Partícula & \\
(c) & 11 \\
(d) & 16 \\
\hline
\end{tabular}

Como pode ser observado a diferença do tamanho médio das partículas internas e externas está na ordem de 100 vezes. Essa diferença pode ser atribuída por um desgaste natural que as partículas sofrem num processo de transporte de dentro para fora da instalação.

É importante notar a flexibilidade e robustez da técnica de MEV na identificação de partículas de urânio presentes no ambiente.

\subsubsection{Análise química pela técnica de EDS}

O passo seguinte é analisar semi-quantitativamente, através da técnica de EDS, as partículas de urânio presentes nos esfregaços na tentativa de trazer informações químicas a respeito das mesmas.

A FIGURA 36 apresenta o espectro da partícula (a) da FIGURA 32 encontrada na amostra 16. 


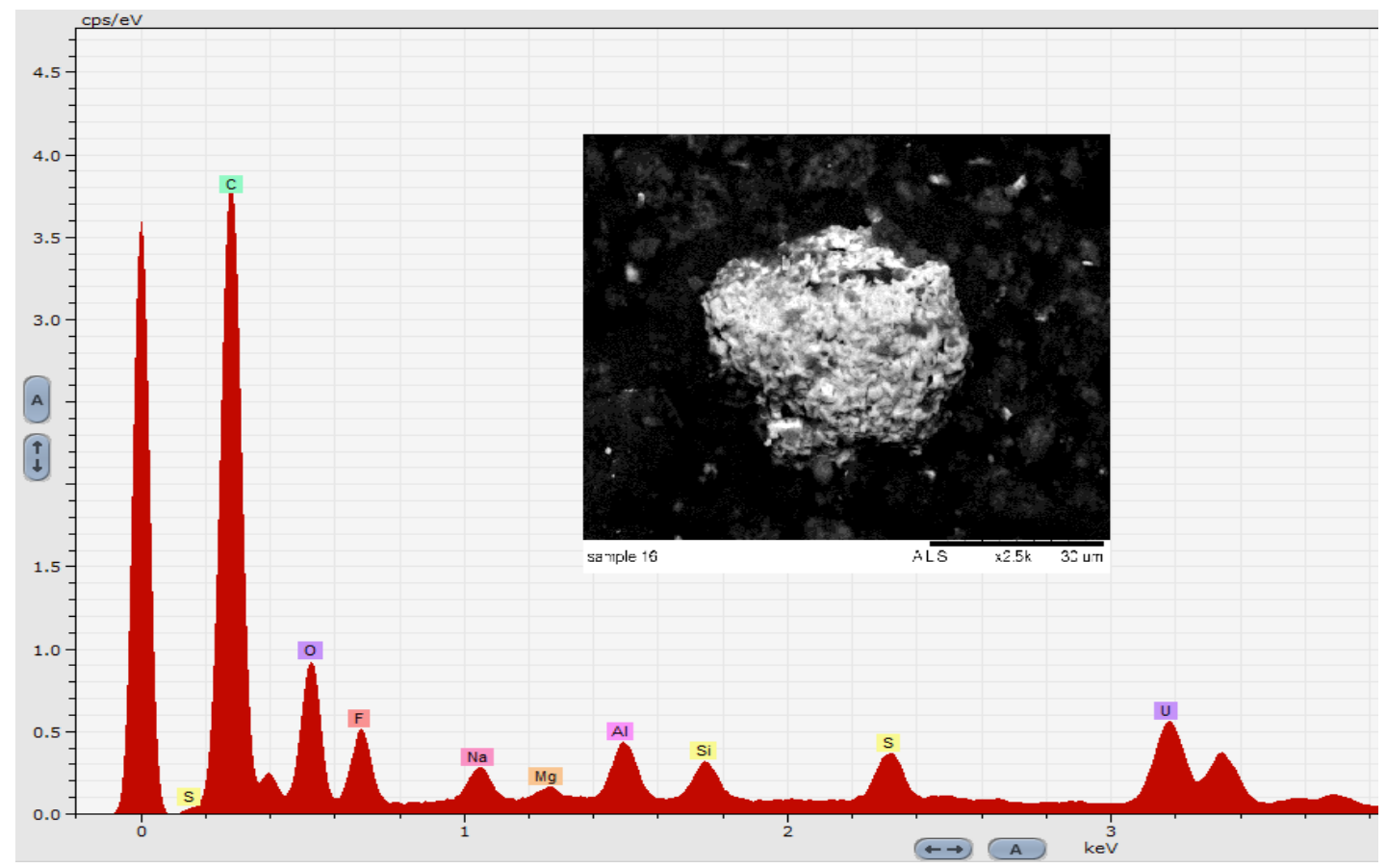

FIGURA 36: Espectro de EDS da partícula de urânio encontrada na amostra 16 - FIGURA 32 (a).

Em uma análise dos espectros obtidos, pode-se perceber a presença de elementos como $\mathrm{Si}, \mathrm{Al}, \mathrm{C}, \mathrm{O}$, os quais podem estar relacionados como artefatos (Si proveniente do detector, $\mathrm{Al}$ do porta amostra, $\mathrm{C}$ proveniente do recobrimento da amostra) e pelo ambiente da câmara do microscópio $\left(\mathrm{O}-\mathrm{O}_{2}\right)$.

A presença de elementos como $\mathrm{Fe}, \mathrm{Na}, \mathrm{S}, \mathrm{Mg}, \mathrm{Ca}$, podem ser justificadas por ser tratar de amostras ambientais coletadas sobre diferentes superficies.

A fim de verificar a distribuição dos elementos nas partículas, a técnica de EDS permite realizar um mapeamento químico de uma área desejada.

Esse mapeamento pode ser observado na FIGURA 37 onde apresenta o mapa químico de uma outra partícula de urânio encontrada na amostra 16. Foram selecionados apenas os elementos F, U e S para a análise. Pode-se observar a área roxa formada por urânio (azul) e flúor (vermelho), assim como partículas agregadas de enxofre (amarelo) e flúor. 


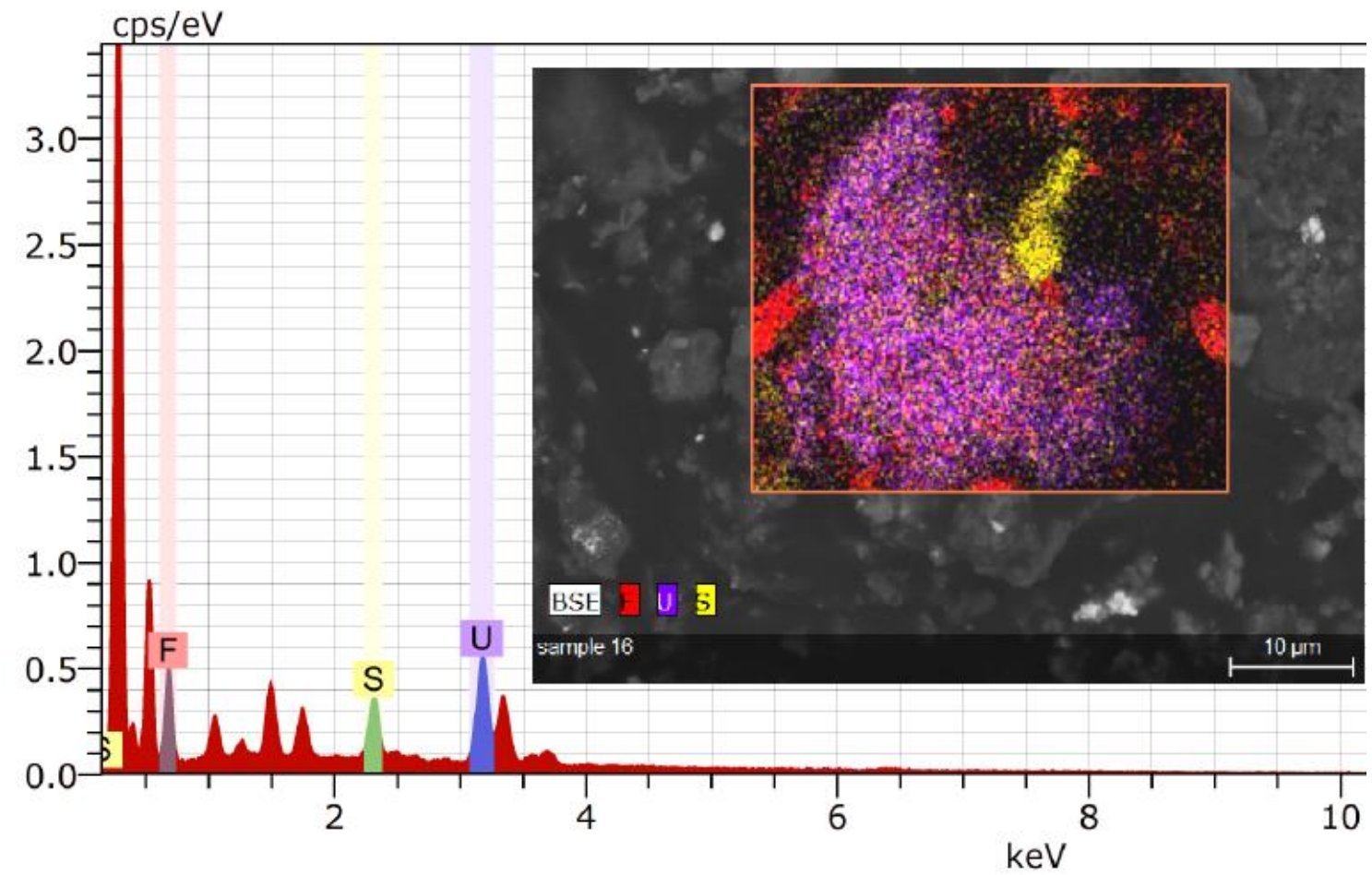

FIGURA 37: Mapa químico de uma partícula de urânio encontrada na amostra 16.

Além disso, foi realizado um estudo de modo a verificar a composição química do $\mathrm{UF}_{4}$ pela técnica de EDS. Para tanto foram realizadas análises pontuais em partículas encontradas nos padrões de $\mathrm{UF}_{4} \mathrm{CEA}$ e $\mathrm{U}_{3} \mathrm{Si}_{2}$ IPEN com o objetivo de comprar estes valores de \% atômica gerados pelo equipamento com os valores teóricos. Os resultados obtidos estão dispostos na TABELA 10.

TABELA 10: Resultados de \% atômica obtidos pela análise semi-quantitativa por EDS para os padrões $\mathrm{UF}_{4} \mathrm{CEA}$ e $\mathrm{U}_{3} \mathrm{Si}_{2} \mathrm{IPEN}$.

\begin{tabular}{l|ccc}
\hline & Valor obtido & Valor Teórico & Erro relativo (\%) \\
\hline \multirow{2}{*}{ \% atômica U } & UF4 CEA & & \\
\% atômica F & 19,6 & 20 & 2,0 \\
& 80,4 & 80 & 0,5 \\
\% atômica U & $\mathbf{U}_{3} \mathbf{S i}_{2}$ IPEN & & \\
\% atômica $\mathrm{Si}$ & 60,2 & 60 & 0,4 \\
\end{tabular}

OBS: Valores médios obtidos por 5 leituras independentes, no mesmo ponto, com tempo de aquisição de 200 segundos cada. 
Os valores presentes na TABELA 10, apresentaram erros relativos inferiores a $2 \%$. Portanto pode-se, como uma boa aproximação, obter dados semi-quantitativos para a identificação de alguns compostos de urânio em amostras de esfregaços.

O mesmo procedimento foi aplicado nas partículas (a) e (b) encontradas na amostra 16 (FIGURA 32). Os resultados estão dispostos na TABELA 11.

TABELA 11: Resultados de \% atômica obtidos pela análise semi-quantitativa de EDS para duas partículas (a) e (b) (FIGURA 32) encontradas na amostra 16, assim como para o padrão de $\mathrm{UF}_{4} \mathrm{CEA}$.

\begin{tabular}{l|ccccc}
\hline & \multicolumn{5}{|c}{ Amostra 16 } \\
\hline & UF4 CEA & Partícula (a) & Erro Relativo \% & Partícula (b) & Erro Relativo \% \\
\% Atômica U & 19,6 & 18,7 & 4,6 & 20,6 & 5,0 \\
\% Atômica F & 80,4 & 81,3 & 1,1 & 79,4 & 1,2 \\
\hline
\end{tabular}

OBS: Valores médios obtidos por 5 leituras independentes, no mesmo ponto, com tempo de aquisição de 200 segundos cada.

Conforme pode ser observado, a composição química das partículas estão de acordo com aquela encontra para o padrão UF4 CEA apresentando erros relativos na mesma ordem de magnitude.

A técnica de EDS fica limitada quando se trata de identificar a composição química de compostos oxigenados do urânio como $\mathrm{UO}_{2}, \mathrm{U}_{3} \mathrm{O}_{8}, \mathrm{UO}_{3}, \mathrm{UO}_{2} \mathrm{~F}_{2}$ dentre outros que apresentam oxigênio em sua composição, pelo fato do ambiente de análise não estar em vácuo extremo, contendo assim, $\mathrm{O}_{2}$ na câmara. Para realizar análises de composição química de compostos desse tipo, a técnica de espectroscopia micro Raman é aconselhada.

Sendo assim, até esse ponto do trabalho, foi possível identificar atividade radioativa, a quantidade estimada de urânio presentes nos esfregaços, o composto de urânio manipulado assim como sua possível rota de produção.

\subsection{Análise Isotópica}

Até o momento foi identificado assinaturas químicas $\left(\mathrm{UF}_{4}\right.$ e $\left.\mathrm{UO}_{2} \mathrm{~F}_{2}\right)$ e físicas (morfologias das partículas), sendo necessária a caracterização das assinaturas isotópicas para apresentar um quadro completo das informações geradas pelas amostras de esfregaços. 
Desse modo, inicialmente, o ICP-QMS foi otimizado utilizando o material de referência certificado (MRC) NBL U200. A TABELA 12 apresenta os principais parâmetros otimizados.

TABELA 12: Condições otimizadas de operação e parâmetros de aquisição para análises isotópicas no ICP-QMS.

\begin{tabular}{l|c}
\hline \multicolumn{2}{c}{ Parâmetros otimizados utilizados no ICP-QMS para } \\
medições de razão isotópica \\
\hline Sample e Skimmer cones & Nickel \\
RF-power $(\mathrm{W})$ & 1500 \\
$\mathrm{X}, \mathrm{Y}, \mathrm{Z}$ torch position & Daily \\
Nebulizer gas flow rate $(\mathrm{L} / \mathrm{mim})$ & 0,95 \\
Plasma gas flow rate $(\mathrm{L} / \mathrm{mim})$ & 15 \\
Auxiliary gas flow rate $(\mathrm{L} / \mathrm{mim})$ & 0.8 \\
Octopole RF $(\mathrm{V})$ & 170 \\
Octopole bias voltage $(\mathrm{V})$ & -6 \\
Number of repeats & 6 \\
Stabilization time $(\mathrm{s})$ & 25 \\
Integration time ${ }^{234} \mathrm{U},{ }^{235} \mathrm{U}$ and ${ }^{236} \mathrm{U}(\mathrm{s})$ & 3 \\
Integration time ${ }^{238} \mathrm{U}(\mathrm{s})$ & 0,3 \\
Dwell time $(\mu \mathrm{s})$ & 10 \\
Nebulization chamber temperature & $4{ }^{\circ} \mathrm{C}$ \\
\hline
\end{tabular}

O NBL U200 também foi utilizado para a obtenção do fator de discriminação de massas - fmd, necessário para os cálculos de correção do valor da razão isotópica nas amostras. Os dados obtidos para o padrão estão apresentados na TABELA 13.

TABELA 13: Erro relativo e porcentagem das incertezas expandidas para razões isotópicas do MRC NBL U200. Dados para solução de concentração de $10 \mu \mathrm{g} / \mathrm{kg}$ de urânio. Valores de incertezas expandidas com nível de confiança de 95,45\%.

\begin{tabular}{l|cccc}
\hline \multicolumn{5}{c}{ NBL U200 } \\
\hline & Certificado & Medido & Erro relativo* (\%) & $\% \mathrm{U}^{* *}$ \\
$n\left({ }^{234} U\right) / n\left({ }^{238} U\right)$ & $0,0015643 \pm 0,0000038$ & $0,001563 \pm 0,000069$ & 0,08 & 4,42 \\
$n\left({ }^{235} U\right) / n\left({ }^{238} U\right)$ & $0,25126 \pm 0,00026$ & $0,2509 \pm 0,0019$ & 0,15 & 0,75 \\
$n\left({ }^{236} U\right) / n\left({ }^{238} U\right)$ & $0,0026566 \pm 0,0000076$ & $0,00270 \pm 0,00010$ & 1,76 & 3,77 \\
\hline
\end{tabular}

*Erro relativo ao valor absoluto encontrado para as razões (média das $\mathrm{N}$ medições) com os valores apresentados no certificado, não levando em consideração as incertezas da medição.

$* * \% \mathrm{U}=$ porcentagem da incerteza expandida 
Com os dados obtidos para o MRC NBL U200 foi calculado o fmd para cada razão isotópica segundo a relação 8, obtendo os valores apresentados na TABELA 14.

TABELA 14: Valores do fator de discriminação de massas obtidos para razões isotópicas de urânio para o MRC NBL U200. Incertezas apresentadas como incertezas padrão.

${ }^{a}$ Erro relativo a unidade.

\begin{tabular}{|c|c|c|}
\hline Razão & fmd & Erro relativo \%a \\
\hline$n\left({ }^{234} U\right) / n\left({ }^{238} U\right)$ & $1,001 \pm 0,022$ & 0,10 \\
\hline$n\left({ }^{235} U\right) / n\left({ }^{238} U\right)$ & $1,0015 \pm 0,0039$ & 0,15 \\
\hline$n\left({ }^{236} U\right) / n\left({ }^{238} U\right)$ & $0,983 \pm 0,019$ & 1,70 \\
\hline
\end{tabular}

O erro relativo encontrado para o fmd é o erro referente ao valor 1 , que é o valor que seria esperado se não houvesse transporte preferencial dos íons de massas mais elevadas no interior do ICP-QMS. Na FIGURA 38 está melhor visualizado os valores dispostos na TABELA 14

\section{Fmd}

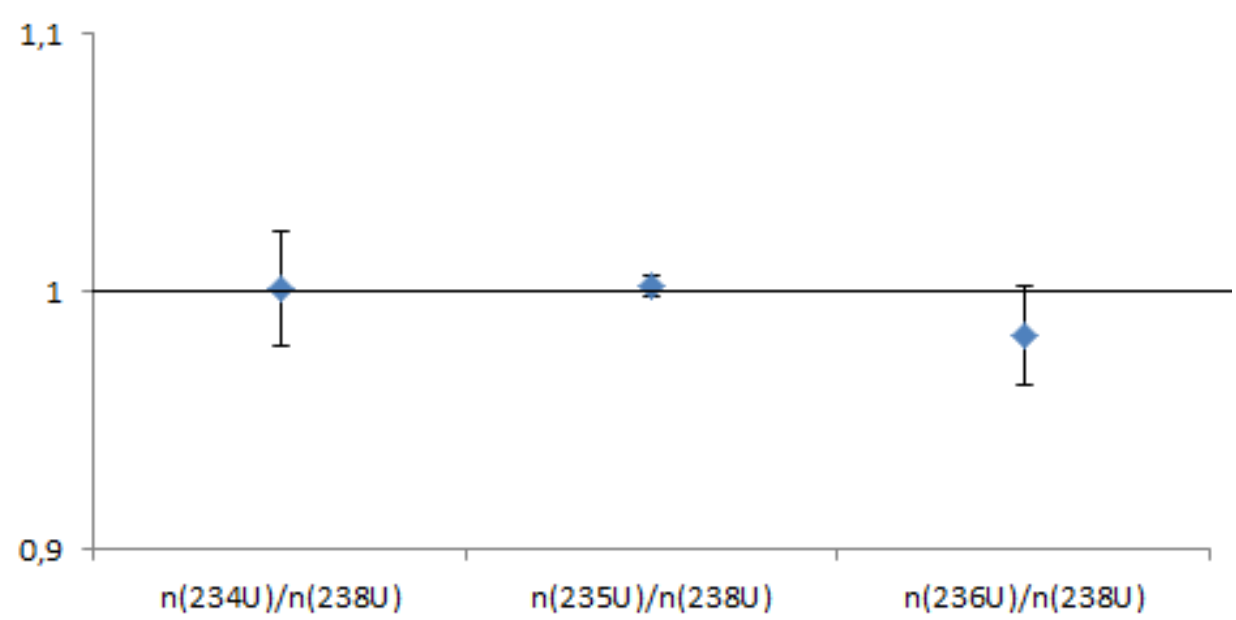

FIGURA 38: Valores do fmd para as razões isotópicas de urânio para MRC NBL U200.

\subsubsection{Desenvolvimento do método de Lix/Us}

Com o ICP-QMS otimizado, primeiramente, foi realizado um ensaio piloto, com um esfregaço simulado com pó de $\mathrm{U}_{3} \mathrm{Si}_{2}$ enriquecido, para verificar o uso do método de Lix/Us em amostras desse tipo. Os dados obtidos foram comparados com resultados de 
amostras de combustível nuclear, a base de $\mathrm{U}_{3} \mathrm{Si}_{2}$ utilizado no reator IEA-R1 e analisados por HR-ICP-MS ${ }^{20}$, assim como o valor especificado pelo Centro do Combustível Nuclear do IPEN (SILVA, 1988). Os resultados obtidos estão dispostos na TABELA 15.

TABELA 15: Comparação de resultados de fração mássica referente ao isótopo ${ }^{235} U$ para amostra simulada de esfregaço, amostra de combustível nuclear e valor especificado. Valores de incertezas expandidas com nível de confiança de 95,45\%.

\begin{tabular}{ccc}
\hline Amostra & Fração mássica ${ }^{235} \boldsymbol{U}$ & \% U* \\
\hline Especificação & $19,75 \pm 0,20$ & 1,01 \\
Análise do combustível $^{\mathrm{A}}$ & $19,826 \pm 0,040$ & 0,20 \\
Esfregaço simulado $^{\mathrm{B}}$ & $19,81 \pm 0,17$ & 0,85 \\
\hline
\end{tabular}

$* \% \mathrm{U}=$ porcentagem da incerteza expandida

A - Analisado por HR-ICP-MS

B - Analisado por ICP-QMS

Os dados de fração mássica no isótopo ${ }^{235} \mathrm{U}$ das amostras da TABELA 15 estão representados na forma de gráfico de barras na FIGURA 39.

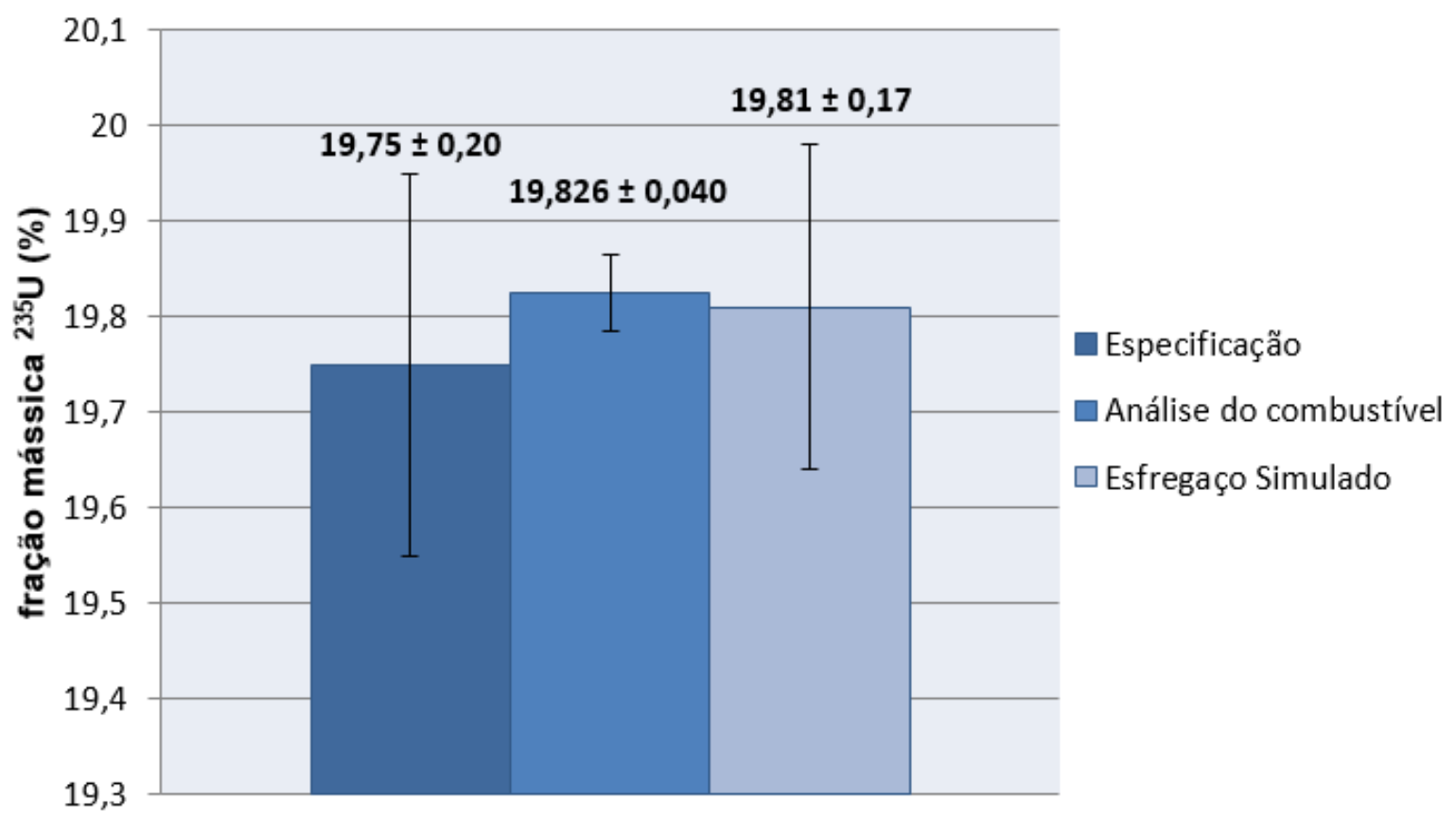

FIGURA 39: Resultados de fração mássica no isótopo ${ }^{235} \mathrm{U}$ para amostra de esfregaço simulada, amostra de combustível nuclear e valores alvos.

\footnotetext{
${ }^{20}$ HR-ICP-MS - Espectrometria de massas com fonte de plasma indutivamente acoplado de alta resolução
} 
Como pode ser observado na FIGURA 39, a análise do combustível nuclear do IPEN realizada por um HR-ICP-MS forneceu uma incerteza de 4,25 vezes menor que a incerteza obtida para a amostras simulada analisada com um ICP-MS quadrupolar, porém a obtida pela amostra simulada está na mesma ordem de magnitude da incerteza requerida pelo Centro do Combustível Nuclear - IPEN.

$\mathrm{Na}$ continuação do processo de verificar a eficiência do método de Lix/Us, as amostras 5, 12, 23, 32 e 38 foram selecionadas para a comparação entre os métodos de Lix/Us e DT.

Os valores das razões isotópicas, corrigidas pelo fator de discriminação de massa, obtidas para as amostras de comparação de método estão apresentados na TABELA 16 com suas respectivas incertezas expandidas.

TABELA 16: Valores das razões isotópicas de urânio para as amostras utilizadas para comparação entre os métodos de digestão total (DT) e método da lixiviação assistida por ultrassom (Lix/Us). Valores de incertezas expandidas com nível de confiança de 95,45\%.

\begin{tabular}{c|ccc}
\hline Amostra & $\boldsymbol{n}\left({ }^{234} \boldsymbol{U}\right) / \boldsymbol{n}\left({ }^{238} \boldsymbol{U}\right)$ & $\boldsymbol{n}\left({ }^{235} \boldsymbol{U}\right) / \boldsymbol{n}\left({ }^{238} \boldsymbol{U}\right)$ & $\boldsymbol{n}\left({ }^{236} \boldsymbol{U}\right) / \boldsymbol{n}\left({ }^{(338} \boldsymbol{U}\right)$ \\
\hline 5 DT & $0,001413 \pm 0,000014$ & $0,1415 \pm 0,0011$ & $*$ \\
$5 \mathrm{Lix} / \mathrm{Us}$ & $0,001390 \pm 0,000013$ & $0,1354 \pm 0,0013$ & $*$ \\
$12 \mathrm{DT}$ & $0,0010148 \pm 0,000011$ & $0,10796 \pm 0,00091$ & $0,000920 \pm 0,000029$ \\
$12 \mathrm{Lix} / \mathrm{Us}$ & $0,0009274 \pm 0,0000084$ & $0,09950 \pm 0,00040$ & $0,000799 \pm 0,000014$ \\
$23 \mathrm{DT}$ & $0,000995 \pm 0,000030$ & $0,1090 \pm 0,0013$ & $0,000851 \pm 0,000034$ \\
$23 \mathrm{Lix} / \mathrm{Us}$ & $0,001012 \pm 0,000010$ & $0,1235 \pm 0,0011$ & $0,000852 \pm 0,000012$ \\
$32 \mathrm{DT}$ & $0,001762 \pm 0,000019$ & $0,2239 \pm 0,0019$ & $0,001437 \pm 0,000016$ \\
$32 \mathrm{Lix} / \mathrm{Us}$ & $0,001779 \pm 0,000014$ & $0,2176 \pm 0,0017$ & $0,001326 \pm 0,000016$ \\
$38 \mathrm{DT}$ & $0,001255 \pm 0,000012$ & $0,1636 \pm 0,0020$ & $*$ \\
$38 \mathrm{Lix} / \mathrm{Us}$ & $0,001160 \pm 0,000010$ & $0,1720 \pm 0,0014$ & $*$ \\
\hline
\end{tabular}

*Não determinado devido à baixa contagem do isótopo ${ }^{236} \mathrm{U}$

Dispondo os valores das razões isotópicas $n\left({ }^{235} U\right) / n\left({ }^{238} U\right)$ das amostras da TABELA 16 em um gráfico de barras obtemos a FIGURA 40. 


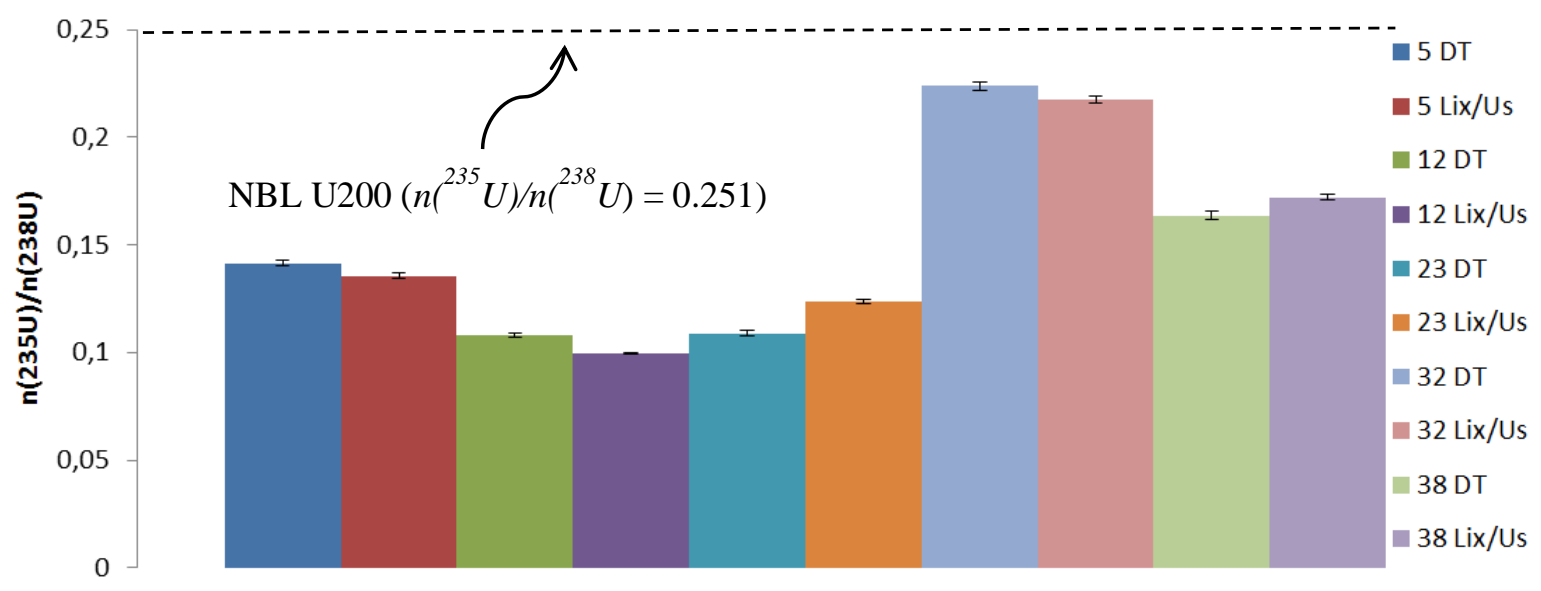

FIGURA 40: Valores da razão isotópica $n\left({ }^{235} U\right) / n\left({ }^{238} U\right)$ para as amostras submetidas aos dois diferentes métodos a fim de verificar suas equivalências. A linha tracejada é o valor da razão $n\left({ }^{235} U\right) / n\left({ }^{238} U\right)$ para o MRC NBL U200.

Através da FIGURA 40, pode-se observar diferenças nos valores das razões isotópicas para as mesmas amostras, porém é preciso levar em consideração que as amostras analisadas foram amostras de esfregaços reais, onde não existe uma homogeneidade em cada metade analisada.

A TABELA 17 apresenta uma comparação dos valores das incertezas expandidas encontradas para razão $n\left({ }^{235} U\right) / n\left({ }^{238} U\right)$ em diferentes trabalhos na literatura envolvendo análises de esfregaços.

TABELA 17: Comparação das incertezas expandidas percentuais (\%U) obtidas para razão $n\left({ }^{235} U\right) / n\left({ }^{238} U\right)$ em diferentes estudos em esfregaços.

\begin{tabular}{c|c}
\hline Estudo & \% $\boldsymbol{U}^{*}$ \\
\hline Godoy, 2009 & 0,2 a 1,9 \\
Szeles, 2010 & 3,8 a 6,2 \\
Este estudo - Lix/Us & 0,40 a $0,86^{\mathrm{a}}$ \\
Este estudo - DT & 0,78 a 1,22 \\
\hline
\end{tabular}

$* \% \mathrm{U}=$ porcentagem da incerteza expandida, com nível de confiança de 95,45\%.

${ }^{a}$ Valores obtidos para amostras internas. O maior valor de \% $\mathrm{U}$ obtida entre todas as amostras, para o método de Lix/Us, foi de $1,63 \%$ para a amostra 2.

Podemos verificar que as incertezas expandidas estão em boa concordância com outros trabalhos encontrados na literatura. Importante considerar que no trabalho de 
Godoy, 2009 foram utilizadas amostras de esfregaços simulados e de Szeles, 2010 foram amostras reais, assim como as do presente trabalho.

Após os estudos anteriores, segundo sugerido pelo INMETRO, 2010, calculou-se os valores de Limite de Detecção (LD) e de Quantificação (LQ) para o método de Lix/Us. Os valores encontrados, assim como o valor do branco para o método de Lix/Us estão dispostos na TABELA 18.

TABELA 18: Valores obtidos de Branco, Limite de Detecção (LD) e de Quantificação (LQ) encontrados para o método de Lix/Us.

\begin{tabular}{c|cl}
\hline & Valor & Unidade $^{*}$ \\
\hline Branco & $0,0070 \pm 0,0015$ & $\mu \mathrm{gU} \mathrm{L}^{-1}$ \\
LD & 0,01 & $\mu \mathrm{gU} \mathrm{L}^{-1}$ \\
LQ & 0,02 & $\mu \mathrm{gU} \mathrm{L}^{-1}$ \\
\hline
\end{tabular}

* micro gramas de urânio por litro de solução.

OBS: O valor encontrado para o branco é uma média de 7 brancos independentes, submetida ao processo de Lix/Us. A incerteza associada ao valor do branco está apresentada como desvio padrão.

Com a confirmação da eficiência da Lix/Us em extrair urânio presente nos esfregaço, foi aplicado o método para as amostras 1, 2, 4, 13, 16, 21 e 26. Os resultados obtidos e suas respectivas incertezas expandidas estão apresentados na TABELA 19.

TABELA 19: Valores das razões isotópicas e incertezas expandidas para amostras submetidas ao processo de Lix/Us. Valores de incertezas expandidas com nível de confiança de $95,45 \%$.

\begin{tabular}{c|ccc}
\hline Amostra & $\boldsymbol{n}\left({ }^{234} \boldsymbol{U}\right) / \boldsymbol{n}\left({ }^{238} \boldsymbol{U}\right)$ & $\boldsymbol{n}\left({ }^{235} \boldsymbol{U}\right) / \boldsymbol{n}\left({ }^{238} \boldsymbol{U}\right)$ & $\boldsymbol{n}\left({ }^{236} \boldsymbol{U}\right) / \boldsymbol{n}\left({ }^{238} \boldsymbol{U}\right)$ \\
\hline 2 & $0,000137 \pm 0,000061$ & $0,01475 \pm 0,00024$ & $0,0000656 \pm 0,0000021$ \\
1 & $*$ & $0,04086 \pm 0,00038$ & $0,000116 \pm 0,000021$ \\
4 & $0,000636 \pm 0,000012$ & $0,06791 \pm 0,00058$ & $0,000484 \pm 0,00033$ \\
13 & $0,00151 \pm 0,00012$ & $0,1675 \pm 0,00012$ & $0,001414 \pm 0,000013$ \\
16 & $0,0011172 \pm 0,0000092$ & $0,11421 \pm 0,00089$ & $0,0010000 \pm 0,0000078$ \\
21 & $0,0003043 \pm 0,0000038$ & $0,04633 \pm 0,00038$ & $0,0001128 \pm 0,0000011$ \\
26 & $0,001621 \pm 0,000014$ & $0,1866 \pm 0,0016$ & $0,001436 \pm 0,000012$ \\
\hline
\end{tabular}

*Não determinado devido à baixa contagem do isótopo ${ }^{234} \mathrm{U}$ 
Como pode ser observado na TABELA 19, a identificação da razão $n\left({ }^{236} U\right) / n\left({ }^{238} U\right)$ é um indicativo de material reprocessado e também que os valores estão na mesma ordem de grandeza da razão $n\left({ }^{234} U\right) / n\left({ }^{238} U\right)$.

Com o intuito de visualizar melhor os enriquecimentos da amostras analisadas, a

TABELA 20 apresenta a fração atômica molar em relação ao isótopo ${ }^{235} \mathrm{U}$ para todas as amostras de esfregaços utilizadas nesse trabalho.

TABELA 20: Valores de fração atômica molar em relação ao isótopo ${ }^{235} \mathrm{U}$ para as amostras utilizadas no trabalho. Valores de incertezas expandidas com nível de confiança de $95,45 \%$.

\begin{tabular}{c|cc}
\hline Amostra & Fração atômica molar ${ }^{235} \boldsymbol{U}$ & $\mathbf{\% U}^{*}$ \\
\hline 1 & $3,923 \pm 0,036$ & 0,92 \\
2 & $\mathbf{1 , 4 5 3} \pm \mathbf{0 , 0 2 3}$ & $\mathbf{1 , 6}$ \\
4 & $6,353 \pm 0,054$ & 0,85 \\
5 & $12,37 \pm 0,10$ & 0,81 \\
12 & $9,035 \pm 0,073$ & 0,81 \\
13 & $14,31 \pm 0,12$ & 0,84 \\
16 & $10,231 \pm 0,081$ & 0,79 \\
21 & $4,426 \pm 0,036$ & 0,81 \\
23 & $10,970 \pm 0,094$ & 0,86 \\
26 & $15,68 \pm 0,13$ & 0,83 \\
$\mathbf{3 2}$ & $\mathbf{1 8 , 2 4} \pm \mathbf{0 , 1 5}$ & $\mathbf{0 , 8 2}$ \\
38 & $14,66 \pm 0,12$ & 0,82 \\
\hline
\end{tabular}

*\% $\mathrm{U}=$ porcentagem da incerteza expandida

OBS: Amostra 5 e 32 são resultados obtidos pelo método de DT. Em negrito as amostras com maior e menor valor de fração atômica molar e em itálico as amostras coletadas na área externa ao CCR.

Desse modo, conforme a

TABELA 20, todos os esfregaços coletados na instalação do CCR apresentaram níveis de enriquecimentos inferiores ao valor máximo de operação declarado pela instalação que é de $20 \%$ no isótopo ${ }^{235} \mathrm{U}$ (fração atômica molar).

Essa diferença pode ser atribuída à presença de urânio natural, também manipulado pela instalação, que faz com que a razão isotópica $n\left({ }^{235} U\right) / n\left({ }^{238} U\right)$ caia nos pontos de amostragem. 
Através das coletas realizadas externamente (amostras 1, 2, 4), uma forma não intrusiva de amostragem, foi possível à identificação de atividades de manuseio de material enriquecido com medidas de urânio enriquecido, em fração atômica molar, de 1,453 \pm $0,023 \%$ a $6,331 \pm 0,055 \%$ no isótopo ${ }^{235} \mathrm{U}$.

Com as análises das amostras internas foi possível identificar níveis de enriquecimento, em fração atômica molar, variando de 4,426 \pm 0,036\% até 18,24 $\pm 0,15 \%$ no isótopo ${ }^{235} \mathrm{U}$.

Há de se notar ainda, a presença do isótopo artificial ${ }^{236} \mathrm{U}$ nas amostras coletadas. Tal fato recai que as amostras são oriundas de reprocessamento, uma vez que, o isótopo ${ }^{236} \mathrm{U}$ é produzido por reações de transmutação no reator. Evidenciando que a instalação utilizada como estudo de caso manipula material reprocessado, sendo, o $\mathrm{UF}_{6}$ reprocessado o material mais provável em uma instalação de reconversão. 


\section{CONCLUSÕES}

Hoje em dia, o sistema de salvaguardas desempenha um papel importante no regime de não proliferação nuclear. Assim, muitas amostragens ambientais estão sendo realizadas, como parte integrante do Protocolo Adicional (INFCIRC/540), exigindo grandes esforços dos laboratórios de salvaguardas no desenvolvimento de novas metodologias para suas análises.

A estratégia analítica proposta nesse trabalho mostrou ter um grande potencial, podendo vir a ser utilizada no atendimento da demanda internacional nas análises de esfregaços para fins de salvaguardas.

Primeiramente, com as contagens alfa tem-se atividade da amostra podendo, em situações reais aumentar probabilidade de obter uma amostra mais representativa, com uma imagem mais completa das atividades desenvolvidas na instalação.

Além disso, a estimativa da quantidade de urânio presente, através da atividade alfa, pode vir a ser útil na utilização de métodos como diluição isotópica, assim como na adequação nos fatores de diluição para análise isotópica.

O uso da técnica de MEV-EDS permitiu a identificação do composto de urânio, informações sobre a morfologia das partículas, indícios quanto à sua rota química, sendo uma importante ferramenta na obtenção de informações adicionais sobre a instalação. Nesse caso, importante frisar, que o seu uso será mais eficaz se dispusermos de um banco de dados contendo a características morfológicas dos principais compostos utilizados no ciclo do combustível nuclear.

O método tradicional de bulk analysis é um método demorado, que envolve a digestão total da amostra, carregando uma grande quantidade de material indesejado, exigindo laboriosos procedimentos químicos de separação.

A Lix/Us vem como uma alternativa para a preparação da amostra, sendo um método simples, rápido e eficiente. O tempo necessário para extrair o urânio do esfregaço, cerca de 15 minutos, é bastante reduzido e de grande ajuda principalmente quando há um elevado número de amostras. Sem perda de qualidade dos resultados finais, o método proporciona uma considerável redução dos passos de preparação, em comparação ao método tradicional de digestão total (bulk analysis), o que reduz os esforços laboratoriais e o risco de contaminação.

No estudo de caso utilizado nesse trabalho as assinaturas encontradas nas partículas de urânio, provenientes do esfregaço, trouxeram informações relevantes sobre as atividades 
desenvolvidas na instalação. Informações como: enriquecimento da amostra, origem de material reprocessado, bem como a identificação de compostos e sua possível rota química.

Desse modo, o trabalho mostrou a importância do uso de técnicas analíticas complementares, trazendo importantes subsídios para a interpretação das informações trazidas pelas amostras de esfregaço no controle de atividades nucleares desenvolvidas em Estados sob salvaguardas. 
ANEXO 1: Cálculos para a estimativa das incertezas associadas às determinações de razões isotópicas de urânio

Para a estimativa da incerteza expandida da razão isotópica foram consideradas as seguintes componentes individuais:

$\checkmark$ Incerteza padrão dos valores obtidos para as razões isotópicas na amostra analisada - Tipo A

$\checkmark$ Incerteza padrão relacionada à correção pelo fator de discriminação de massa - Tipo A

$\checkmark$ Incerteza padrão dos valores obtidos para as razões isotópicas no MRC NBL U200 - Tipo A

$\checkmark$ Incerteza padrão apresentada no certificado do MRC NBL U200 - Tipo B

A seguir serão demonstradas as equações para o cálculo das incertezas padrão $\left(\mathrm{u}_{\mathrm{xi}}\right)$ de cada componente considerada para o cálculo final da incerteza expandida (U). Para simplificar a notação será utilizado Rmed para denotarmos uma razão isotópica genérica, obtida experimentalmente, $n\left({ }^{i} U\right) / n\left({ }^{238} U\right)$, onde i é o isótopo de urânio de interesse.

$\checkmark$ Incerteza Padrão da Rmed na amostra analisada por ICP-MS:

$$
u_{\text {Rmed }}=\frac{S D}{\sqrt{N}}
$$

Onde:

SD é o valor do desvio padrão relativo à média das Rmed;

$\mathrm{N}$ é o número de repetições independentes realizadas na análise da Rmed. Nesse trabalho foi utilizado $\mathrm{N}=6$.

$\checkmark$ Incerteza Padrão do fator de discriminação de massa:

$$
u_{f m d}=f m d x \sqrt{\left(\frac{u M R C_{R m e d}}{M R C \text { Rmed }}\right)^{2}+\left(\frac{u M R C_{\text {Rcert }}}{M R C \text { Rcert }}\right)^{2}}
$$

Onde:

fmd é valor do fator de discriminação de massa obtido pela relação 8; 
u MRC Rmed é a incerteza da razão isotópica de interesse medida para o MRC;

MRC Rmed é o valor da razão isotópica de interesse medida para o MRC;

uMRC Rcert é a incerteza para a razão isotópica de interesse disponível no certificado para o MRC;

MRC Rcert é o valor da razão isotópica de interesse disponível no certificado para o MRC.

$\checkmark$ Incerteza Padrão da discriminação de massa por unidade de massa atômica - CF:

$$
u_{C F}=\frac{u_{f m d}}{\Delta m}
$$

Onde:

$\Delta \mathrm{m}$ é a diferença entre as massas dos isótopos utilizados na razão isotópica de interesse.

$\checkmark$ Incerteza Padrão da razão isotópica corrigida da amostra (Rcorr):

$$
u_{R c o r r}=\sqrt{\left[(1+C F)^{\Delta m} \times u_{R m e d}\right]^{2}+\left[\Delta m \times R_{\text {med }} \times(1+C F)^{\Delta m-1} \times u_{C F}\right]^{2}}
$$

Onde:

CF é o valor de discriminação de massa por unidade de massa atômica obtido pela relação 9 .

Definidas as incertezas padrão, que contribuem para a incerteza final, a incerteza combinada é somente o valor da incerteza da razão corrigida, $\mathrm{u}_{\text {rcorr}}$, pois as outras incertezas já estão sendo contabilizadas no fmd, portanto:

$$
u_{c}=u_{R c o r r}
$$

O resultado final de uma medição é expresso de forma a permitir um fator de abrangência associado ao nível de confiança escolhido. Isto se dá multiplicando a incerteza combinada $\left(\mathrm{u}_{\mathrm{c}}\right)$ por uma constante, que depende do intervalo de confiança, chamada de fator de abrangência (k), obtendo-se a incerteza expandida (U) representada na relação 16. 


$$
U=u_{c} x k
$$

Portanto, os resultados nesse trabalho serão expressos por y $\pm \mathrm{U}$, onde y é o resultado médio, de $\mathrm{N}$ repetições obtido experimentalmente, sendo $\mathrm{U}$ a incerteza expandida com nível de 95,45\% de confiança $(\mathrm{k}=2)$. Na FIGURA 41 está representado um fluxograma das fontes das incertezas associadas ao processo de medição e correção das razões isotópicas de urânio utilizadas nesse trabalho.

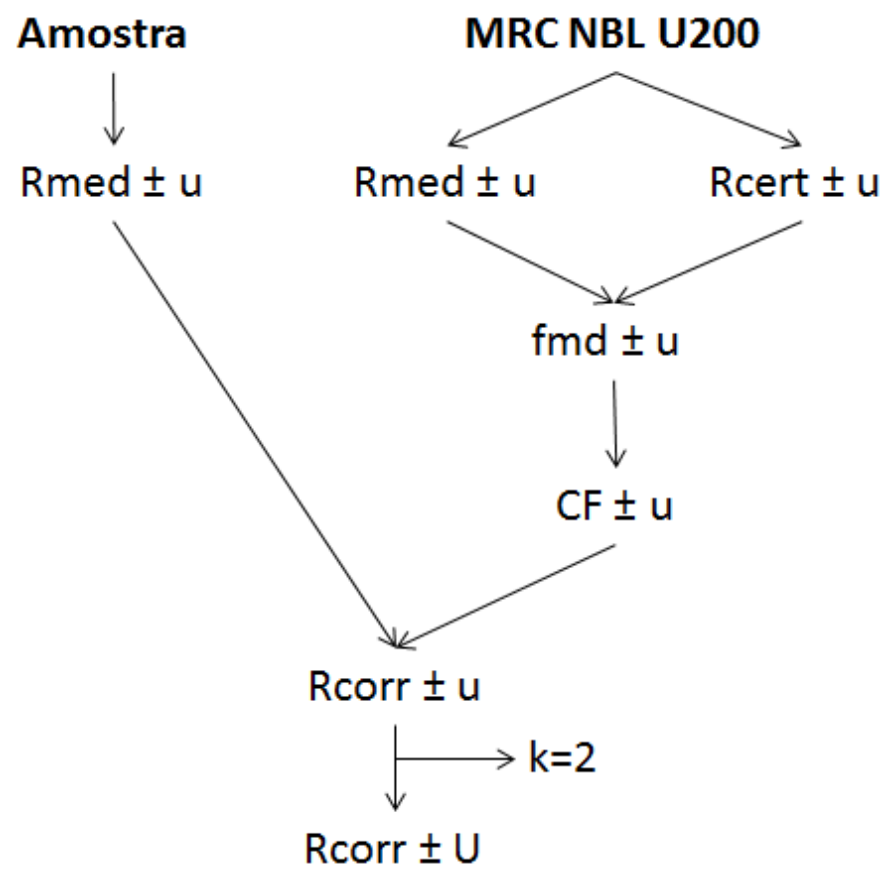

FIGURA 41: Fluxograma das incertezas associadas ao processo de medição e correção das razões isotópicas de urânio. 


\section{New Brunswick Laboratory U.S. Department of Energy}

\section{Certificate of Analysis CRM U200 \\ Uranium Isotopic Standard $10 \mathrm{mg}$ Uranium as $\mathrm{U}_{3} \mathrm{O}_{8}$}

$\begin{array}{rcccc} & { }^{234} \mathrm{U} & { }^{235} \mathrm{U} & { }^{236} \mathrm{U} & { }^{238} \mathrm{U} \\ \text { Atom Percent: } & 0.1246 & 20.013 & 0.2116 & 79.651 \\ \text { Uncertainty: } & \pm 0.0003 & \pm 0.020 & \pm 0.0006 & \pm 0.021 \\ \text { Weight Percent: } & 0.1229 & 19.811 & 0.2103 & 79.856\end{array}$

This Certified Reference Material (CRM) is primarily intended for the calibration of mass spectrometers used to perform uranium isotopic measurements. The specific purpose of this isotopic standard is for the determination of mass discrimination effects for uranium isotopes being measured under similar analytical conditions. Each unit of CRM U200 consists of approximately 10 milligrams of uranium, in the form of highly purified $\mathrm{U}_{3} \mathrm{O}_{8}$, contained in a glass bottle.

The indicated uncertainties for the isotopic composition of the CRM are $95 \%$ confidence intervals for a single determination. This term can be defined as an approximate two-sigma limit, where sigma is the standard deviation of the measurements data obtained from the material. The uncertainties include allowances for inhomogeneity of the material as well as analytical error.

This CRM was originally issued in 1970 by the National Bureau of Standards (NBS) as Standard Reference Materia: (SRM) U-200. The measurements made at NBS leading to the certification were performed by E. L. Garner, L. A. Machlan, M.S. Richmond and W. R. Shields. In 1987, the technical and administrative transfer of NBS Special Nuclear SRMs into the NBL CRM Program was coordinated by the NBS Office of Standard Reference Materials and N. M. Trahey, NBL.

The ${ }^{235} \mathrm{U}$ and ${ }^{238} \mathrm{U}$ abundance values were determined at NBS, Union Carbide Nuclear Company, Oak Ridge, Tennessee, and Goodyear Corporation, Portsmouth, Ohio; all values were given equal weight in the calculation of the certified value. NBS performed ${ }^{235} \mathrm{U} /{ }^{238} \mathrm{U}$ measurements using a solid-sample thermal ionization mass spectrometer equipped with a Faraday cup detection system. The isotope ratios were corrected for mass discrimination effects by intercomparison with $10 \%$ and $50 \%{ }^{235} \mathrm{U}$ level SRMs. The ${ }^{235} \mathrm{U}^{238} \mathrm{U}$ value for this standard, 0.25126 , is known to at least $0.1 \%$.

The ${ }^{234} \mathrm{U}$ and ${ }^{236} \mathrm{U}$ abundances were determined at NBS by isotope dilution mass spectrometry using high-purity ${ }^{233} \mathrm{C}$ as the spike. The ${ }^{235} \mathrm{U}$ values obtained from Union Carbide and Goodyear Atomic are based upon direct ${ }^{235} \mathrm{U}$ concentration determination by oxide dilution and $\mathrm{UF}_{6}$ analysis. The minor isotopes were calculated using the NBS values and the ${ }^{238} \mathrm{U}$ value obtained by difference.

NOTE: NBS Special Publication 260-27 presents further details of the measurements made at NBS which provided the basis for the certification, and is available from the NBS Office of Standard Reference Materials

March 30, 2008

Argonne, Illinois www.nbl.doe.gov

Page 1 of 1
Jon Neuhoff, Director New Brunswick Laboratory

(Editorial revision of Certificate dated October 1, 1987) 
ANEXO 3: Base de dados: Micrografias de diferentes compostos de urânio.
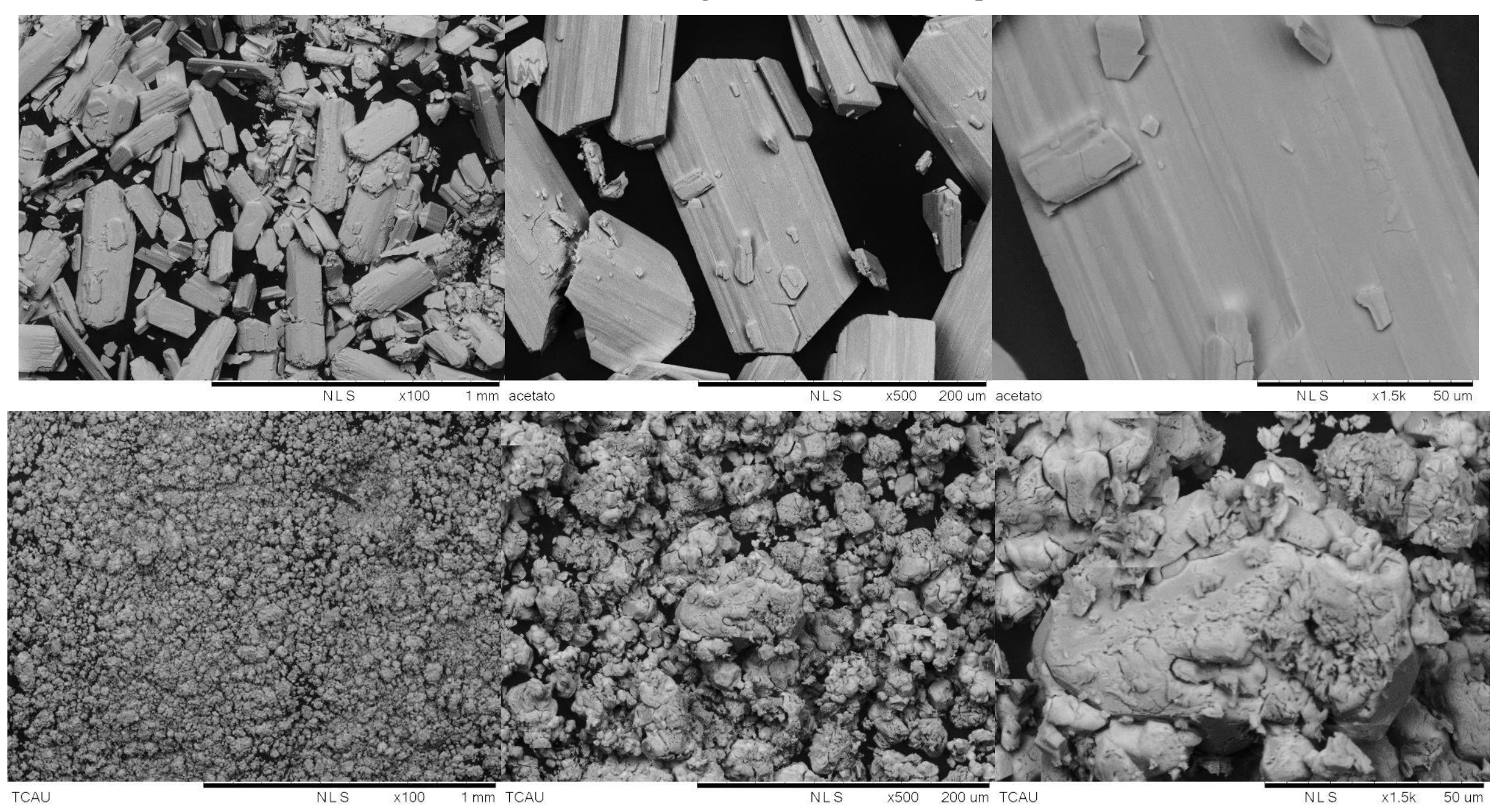

FIGURA 42: Micrografias de compostos de urânio. Superior: Acetato de uranila $\left(\mathrm{CH}_{3} \mathrm{COO}\right)_{2} \mathrm{UO}_{2}$; Inferior: Tricarbonato de amônio e uranila $\mathrm{UO}_{2}\left(\mathrm{CO}_{3}\right)_{3}\left(\mathrm{NH}_{4}\right)_{4}$. Sequências com magnificações de 100x, 500x e 1500x. 

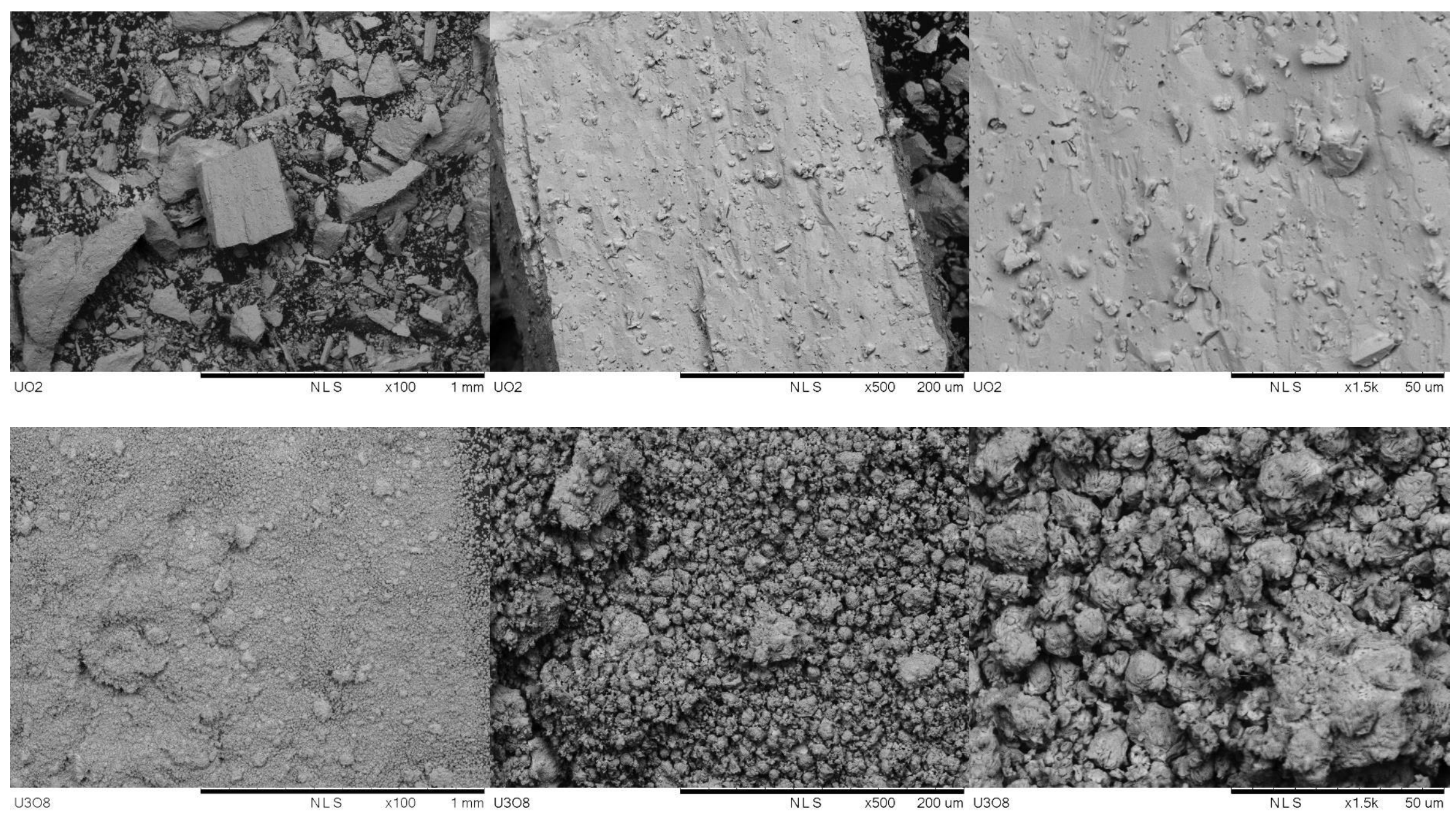

FIGURA 43: Micrografias de compostos de urânio. Superior: Dióxido de urânio $\mathrm{UO}_{2}$; Inferior: Octóxido de triurânio $\mathrm{U}_{3} \mathrm{O}_{8}$. Sequências com magnificações de 100x, 500x e 1500x. 

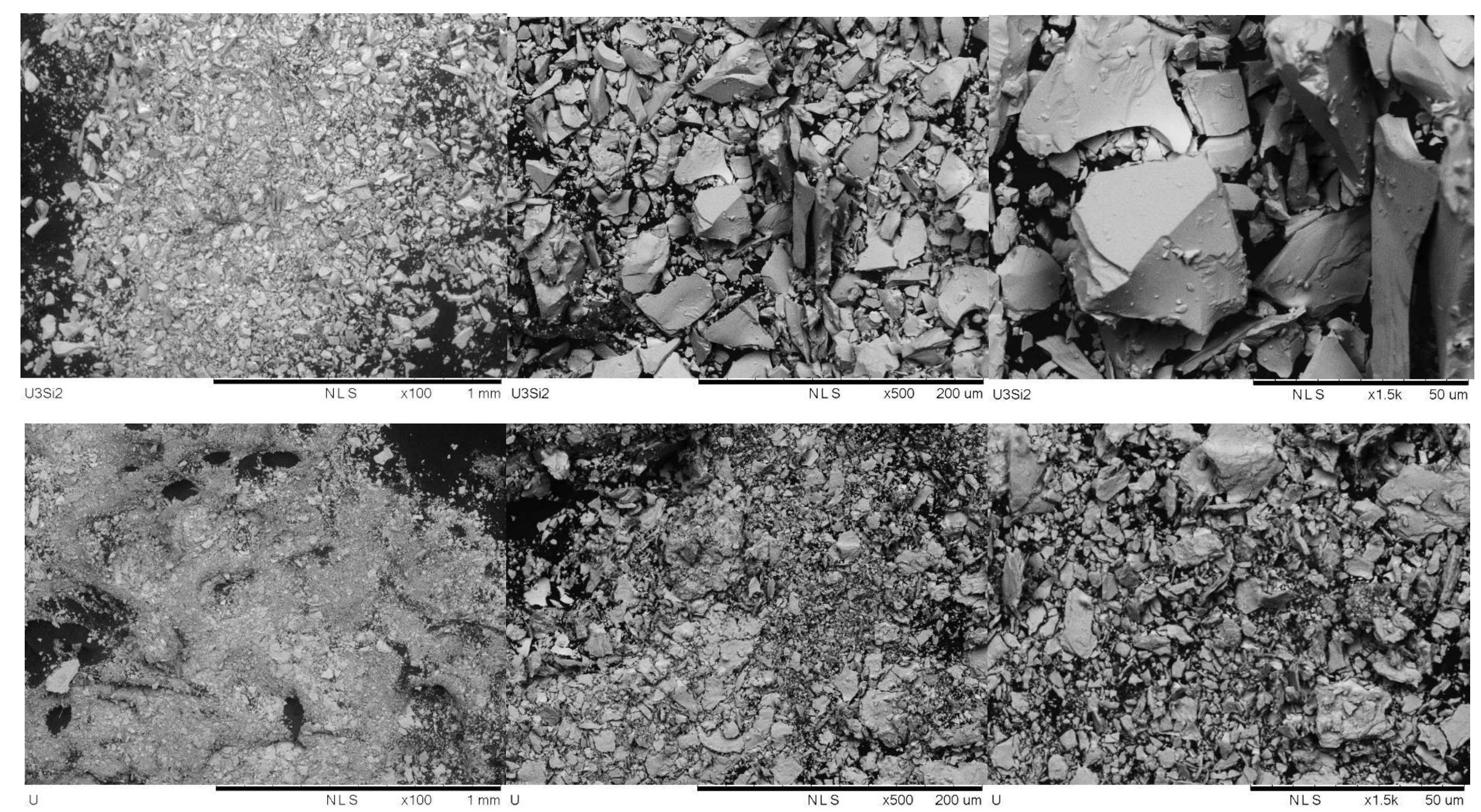

FIGURA 44: Micrografias de compostos de urânio. Superior: Siliceto de urânio $\mathrm{U}_{3} \mathrm{Si}_{2}$; Inferior: Urânio metálico $\mathrm{U}^{\circ}$. Sequências com magnificações de 100x, 500x e 1500x. 

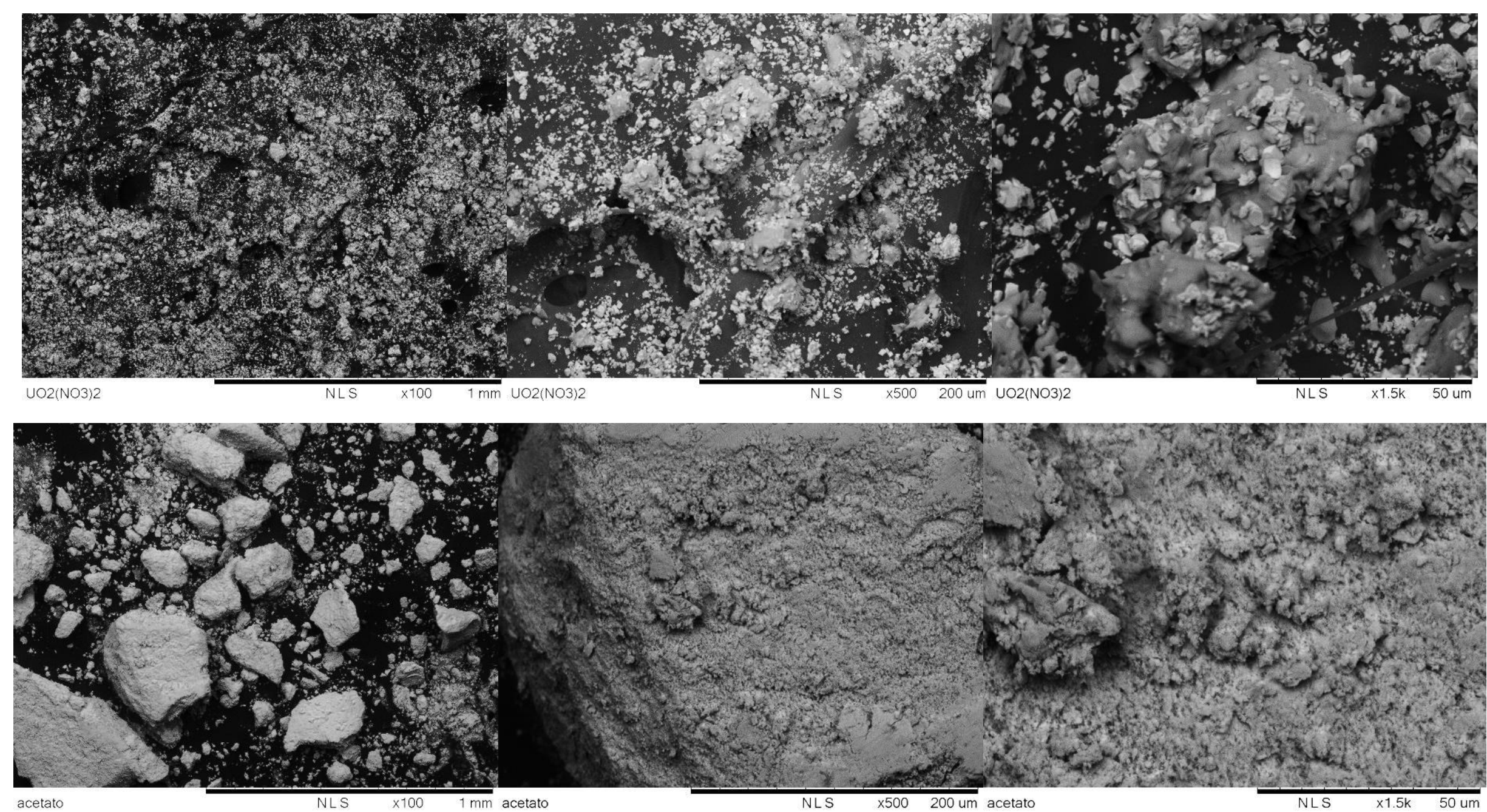

FIGURA 45: Micrografias de compostos de urânio. Superior: Nitrato de uranila $\mathrm{UO}_{2}\left(\mathrm{NO}_{3}\right)_{2}$; Inferior: Diuranato de amônio $\mathrm{NH}_{4} \mathrm{U}_{2} \mathrm{O}_{7}$. Sequências com magnificações de 100x, 500x e 1500x. 


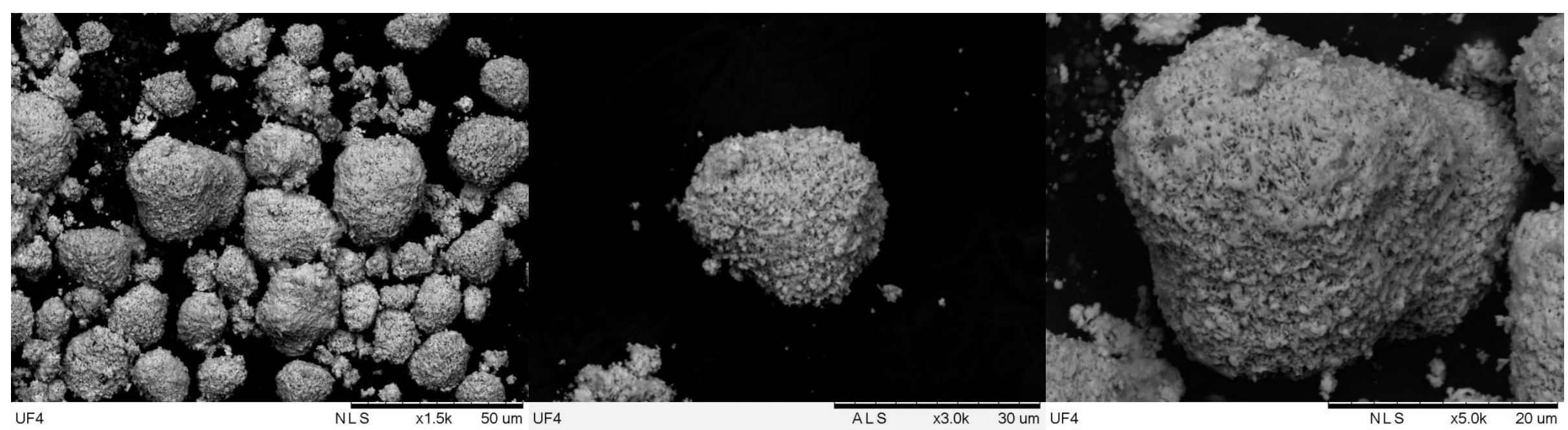

FIGURA 46: Micrografias de compostos de urânio. Superior: UF 4 Sequências com magnificações de 1500x, 3000x e 5000x. 


\section{REFERÊNCIAS BIBLIOGRÁFICAS}

ABACC. Agência Brasileiro-Argentina de Contabilidade e Controle de Materiais Nucleares. Disponível em: <http://www.abacc.org/port/abacc_aiea/abacc_aiea.htm>. Acesso em: 11/05/2011.

ABACCa, Agência Brasileiro-Argentina de Contabilidade e Controle de Materiais Nucleares. Disponível em: <http://www.abacc.org.br/?page_id=16>. Acesso em: 22/01/2013.

ABACCb, Agência Brasileiro-Argentina de Contabilidade e Controle de Materiais Nucleares. Disponível em: < http://www.abacc.org.br/?page_id=9>. Acesso em: 22/01/13.

ACA. Arms Control Association. Threat Assessment Brief. Analyssis on effective policy responses to weapons-related security threats. The naval nuclear reactor threat to the NPT. 2013.

AGILENT, Technologies. Disponível em: <http://www.chem.agilent.com/enUS/search/library/Pages/LibrarySearchResult.aspx $? \mathrm{k}=\mathrm{icp} \& \mathrm{v}=$ relevance \&so=desc \&start=3 01>. Acesso em: 29/08/2013.

AHF. Atomic Heritage Foudation. Remembering the Trinity Test. Disponível em: <http://www.atomicheritage.org/index.php/ahf-updates-mainmenu-153/702-rememberingthe-trinity-test.html>. Acesso em: 03/09/2013.

AIEA. Agência Internacional de Energia Atômica. The Structure and Content of Agreements Between the Agency and States Required in Connection with the Treaty on the Non-Proliferation of Nuclear Weapons. INFCIRC/153 (Corrected), 1972.

AIEA. Agência Internacional de Energia Atômica. Agreement of 13 December 1991 between the republic of Argentina, the federative republic of Brazil, the Brazilian Argentine Agency for Accounting and Control of nuclear materials and the International Atomic Energy Agency for the application of safeguards. INFCIRC/435, 1994. 
AIEA. Agência Internacional de Energia Atômica. International Atomic Energy Agency Board of Governors, Model Protocol Additional to the Agreement(s) between State(s) and the International Atomic Energy Agency for the Application of Safeguards. INFCIRC/540 - Corrected. IAEA, Vienna, September, 1997.

AIEA. Agência Internacional de Energia Atômica. Safeguards Glossary 2001 edition. International Nuclear Verification. Series, n.3, 2002.

AIEA. Agência Internacional de Energia Atômica. Radiation, people and the environment. A broad overview of ionizing radiation, its effects and uses, as well as the measures in place to use it safely. IAEA. Vienna, 2004.

AIEA. Agência Internacional de Energia Atômica - International Atomic Energy Agency, Nuclear Foresic Support, Technical Guidance - Reference Manual. IAEA Nuclear Security Series, n.2, 2006.

AIEA. Agência Internacional de Energia Atômica . International Atomic Energy Agency. IAEA Safeguards: Staying Ahead of the Game, 2007.

AIEA, Agência Internacional de Energia Atômica. Annual Report, 2012.

AIEA. Agência Internacional de Energia Atômica Agencia. The Members of the Agency. INFCIRC/2/Rev.73. 2012

AIEAa, Agência Internacional de Energia Atômica. Disponível em: <http://www.iaea.org/About/statute.html>. Acesso em: 17/01/2013.

AIEAb. The Safeguards System of the International Atomic Energy Agency. Disponível em: <http://www.iaea.org/safeguards/documents/safeg_system.pdf >. Acesso em: $14 / 06 / 2013$.

AIEAc. Agência Internacional de Energia Atômica. Disponível em: 
<AIEAd. Agência Internacional de Energia Atômica. http://www.iaea.org/pris/>. Acesso em: 30/08/2013.

ALDAVE, L. et al. Characterization of environmental radioactive particles. ITU-JRC Radioprotection - Colloques, v.37, Cl. 2002.

AQUINO, Afonso Rodrigues. Materiais e ciclo do combustível nuclear - TNM 5788. Fundamentos de Tecnologia Nuclear. IPEN/USP, 2008.

AREGBE, Y. et al. NUSIMEP-6: Uranium isotope amount ratios in uranium particles. Interlaboratory Comparison Report. IRMM-JRC, 2008.

AREGBE, Y. MAYER, K. HEDBERG, M. Destructive sample analysis for nuclear safeguards. Nuclear safeguards and non-proliferation. Course Syllabus. Esarda Bulletin, 2009.

ATSDR. Toxicological profile for uranium. U.S. department of health and human services. Agency for Toxic Substances and Disease Registry. 2013. Disponível em: <http://www.atsdr.cdc.gov/toxprofiles/tp150.pdf>. Acesso em 13/08/2013.

AUDI, G. The history of nuclidic masses and of their evaluation. International Journal of Mass Spectrometry. v. 251 p. 85-94. 2006.

AXELSSON. A. FISCHER.D. M. Penkin. M. V. Use of data from environmental sampling for IAEA safeguards. Case study: uranium with near-natural 235U abundance. Journal of Radioanalytical and Nuclear Chemistry, v. 282, p.725-729, 2009.

BALDWIN, G. T. International Nuclear Safeguards. INMM Tutorial. SAND 2006-4071P. 2006.

BECKER, J. S. State-of-the-art and progress in precise and accurate isotope ratio measurements by ICP-MS and LA-ICP-MS. Journal of Analytical Atomic Spectrometry. v.17, p. 1172-1185. 2002 
BECKER, J. S. Inorganic Mass Spectrometry. Principles and applications. Wiley, 2007.

BERRIMAN, A.; LESLIE, R.; CARLSON, J. Information analysis for IAEA safeguards. INMM symposium, USA. 2004.

BETTI, M. Civil use of depleted uranium. Journal of Environmental Radioactivity, v.64, p.113-119, 2003.

BUCHMANN, J. H. O uso da monitoração ambiental como técnica de identificação de atividades de enriquecimento isotópico. 2000. Tese (Doutorado) - Instituto de Pesquisas Energéticas e Nucleares, São Paulo.

BUCHMANN, J. H. et al. Environmental monitoring used to identify nuclear signatures. Journal of Radioanalytical and Nuclear Chemistry, v.258, n.1, p.139-142, 2003.

BUCHMANN, J. H. et al. Environmental monitoring as an important tool for safeguards of nuclear material and nuclear forensics. Journal of Radioanalytical and Nuclear Chemistry, v.270, n.2, p.291-298, 2006.

CARTER, C. Transmission Electrons Microscopy: a textbook for materials science. Springer. 2009.

CHARNYSH, V. A Brief History of Nuclear Proliferation. Nuclear Age Peace Foundation-NAPF. Disponível em:

$<$ http://www.wagingpeace.org/articles/pdfs/Proliferation_History.pdf $>$. Acesso em: 03/09/2013.

CNEN, ELETRONUCLEAR, SIPRON. Fifth National Report of Brazil - Nuclear Safety Convention, Rio de Janeiro, September 2010.

CNEN. Site da Comissão Nacional de Energia Nuclear. Disponível em: <http://www.cnen.gov.br/acnen/atividades.asp>. Acesso em: 04/05/2011. 
CNENa, Comissão Nacional de Energia Nuclear. Disponível em: <http://www.cnen.gov.br/seguranca/lfc/lic-fis-cont.asp\#>. Acesso em: 18/01/2013.

CNENb. Comissão Nacional de Energia Nuclear. Disponível em: <http://www.cnen.gov.br/ensino/apostilas/rad_ion.pdf>. Acesso em: 01/08/2013.

CONSTITUIÇÃO DA REPÚBLICA FEDERATIVA DO BRASIL. Senado federal secretaria especial de editoração e publicações. Subsecretaria de edições técnicas. Brasília, 2010 .

CTBTO. Comprehensive Nuclear-Test-Ban Treaty Organization. History of Nuclear testing - WORLD OVERVIEW. Disponível em: <http://www.ctbto.org/nucleartesting/history-of-nuclear-testing/world-overview/ >. Acesso em: 05/09/2013.

DD. Department of Defense. 50th Anniversary of World War II Commemorative Committee. Pearl Harbor: 50th Anniversary Commemorative Chronicle, "A Grateful Nation Remembers" 1941-1991. Washington: The Committee, 1991. Disponível em: <http://www.idaillinois.org/cdm/ref/collection/isl3/id/12313>. Acesso em: 03/09/2013.

DEGEO. Departamento de Geologia- UFOP. Disponível em <http://www.degeo.ufop.br/laboratorios/microlab/mev.htm>. Acesso em: 29/08/2013.

DE LAETER, J. R. et al. Atomic weights of the elements: review 2000 (IUPAC Technical Report). Pure Appl. Chem., v.75, n. 6, p. 683-800, 2003.

DOE. U. S. Department of Energy Office of Environmental Management Depleted Uranium Hexafluoride Management Program. Characteristics of Uranium and Its Compounds, 2001.

DONOHUE, D. Environmental Sample Analysis - Advances and Future Trends. AIEA-CN-184/159.

DONOHUE, D. Strengthening AIEA safeguards through environmental sampling and analysis. Journal of Alloys and Compounds, 271-273, p.11-18, 1998. 
DONOHUE, D. Environmental Sampling. Esarda Bulletin, 2002.

DONOHUE, D. Verifying the absence of evidence: the challenges of environmental sampling for safeguards. Esarda Bulletin, 2003.

DONOHUE, D. et al. Microscopic studies of spherical particles for nuclear safeguards. Applied Surface Science, 225. p.2561-2568, 2008.

DOUCET, F. R. et al. Determination of isotope ratios using laser-induced breakdown spectroscopy in ambient air at atmospheric pressure for nuclear forensics. Journal of Analytical Atomic Spectrometry, v. 26, 536, 2011.

DW, Deutsche Welle. Disponível em: <http://www.dw.de/1945-testada-a-primeirabomba-at\%C3\%B4mica/a-592473>. Acesso em: 13/08/2013.

EPA. A Performance-Based Approuch to the Use of Swipe Samples in Response to a Radiological or Nuclear Incident. United States Environmental Protection Agency. EPA 600/R-11/122, 2011.

ESAKA, F. et al. Isotope ratio analysis of individual sub-micrometer plutonium particles with inductively coupled plasma mass spectrometry. Talanta, v.83, p.569-573, 2010.

FEPC - The Federation of Eletric Power Companies of Japan. Peaceful Utilization of Nuclear Energy. v.15, 2002. Disponível em:

http://www.fepc.or.jp/english/library/power_line/detail/15/. Acesso em: 15/08/2013.

FISCHER, D. History of the International Atomic Energy Agency: the first forty years. IAEA. 1997.

FISCHER, W.; STEIN, G. Experiences from Nuclear Safeguarding. On-site Inspections: Common Problems, Different Solutions. Disarmament Forum, n.3, p. 45-54, 1999. 
FUNK, P. Containment, surveillance and monitoring of nuclear material. $10^{\text {th }}$ ESARDA Course - Nuclear Safeguards and Non Proliferation. Ispra - Italy. 2013.

FURUSAWA, H. A. et al. Uranium isotopic analyses by using a sector field inductively coupled plasma mass spectrometer. Journal of Radioalaytical and Nuclear Chemistry. v.242, n.3, p.647-651, 1999.

GODOY, M. L. D. P.; GODOY, J. M.; ROLDÃO, L. A. Application of ICP-QMS for te determination of plutonium in environmental samples for safeguards purposes. Journal of Environmental Radioactivity, v.97, p.124-136, 2007.

GODOY, M. L. D. P. et al. Determination of total content and isotopic compositions of plutonium and uranium in environmental samples for safeguards purposes by ICP-QMS. Journal of Environmental Radioactivity, v.100, p.613-625, 2009.

GLOBO. Jornal O Globo. Hiroshima 60 anos. Disponível em: <http://oglobo.globo.com/pais/noblat/arquivo05.asp>. Acesso em: 05/09/2013.

GROSS, H. J. Mass Spectrometry. A Textbook. Springer. 2004.

GROUEFF, S. Manhattan Project: the untold story of the making of the atomic bomb. Boston: Little Brown, 1967.

HANDLEY-SIDHU, S. et al. A review of the environmental corrosion, fate and bioavailability of munitions grade depleted uranium. Science of the Total Environment, 408, p.5690-5700, 2010.

HAMMOND, C. R; HAYNES, W. M. Handbook of Chemistry and Physics. The Elements. Oxford : CRC Press, v.93, p. 4-40, 2012.

HOOPER, R. The IAEA's Additional Protocol. On-site Inspections: common problems, different solutions. Disarmament Forum, n.3, p.7-16, 1999.

HOOPER, R. The changing nature of safeguards. IAEA Bulletin, 45/1, 2003. 
INMETRO. Orientação sobre validação de métodos analíticos. Coordenação Geral de Acreditação. DOQ-CGCRE-008, 2010.

INB, Indústrias Nucleares Brasileiras. Disponível em: <http://www.inb.gov.br/ptbr/WebForms/interna2.aspx?secao_id=48>. Acesso em: 08/01/2013.

IPEN. Instituto de Pesquisas Energéticas e Nucleares. Comissão Nacional de Energia Nuclear. Centro de combustível nuclear. Nosso Centro. Disponível em: <https://www.ipen.br/sitio/?idc=355>. Acesso em: 06/09/2013.

IRD, Instituto de Radioproteção e Dosimetria. Disponível em: $<$ http://www.ird.gov.br/index.php?option=com_content\&view=article\&id=52:olaboratorio-de-espectrometria-de-massa-do-ird-e-um-novo-membro-da-rede-nwal\&catid=1:latest-news\&Itemid=50>. Acesso em 06/03/2013.

ISO GUM. Guide to the expression of uncertainty in measurements. $2^{\text {nd }}$ edition. International Organization for Standardization, Geneva, 2008.

ITV - International Target Values 2010 for Measurement Uncertainties in Safeguarding Nuclear Materials. IAEA, Vienna 2010.

JARVIS, K. E.; GRAY, A. L.; HOUK, R. S. Handobook of inductively coupled plasma mass spectraometry. London: Blackie \& Son, 1992.

JONTER, T. Nuclear non-prolifereration - a brief historical background. Nuclear safeguards and non-proliferation. Course Syllabus. Esarda Bulletin, 2008.

JORNADA, D. H. Incerteza de medição: guia prático do avaliador de laboratórios. Procedimento do sistema de gestão da qualidade. Rede Metrológica RS. 2009.

KALINOWSKI, M. B. Environmental sample analysis. Nuclear safeguards and nonproliferation. Course Syllabus. Esarda Bulletin, 2009. 
KERL, W. et al. Isotopic and ultratrace analysis of uranium by double-focusing sector field ICP mass spectrometry. Journal of Analytical Chemistry, p.407-409, 1997.

KESTENBACK, H. J; BOTTA FILHO, W. J. Microscopia eletrônica transmissão e varredura. Associação Brasileira de Metais, ABM. São Paulo, 1989.

KHATER, A. E. M. Recent development in radiochemical analysis for safeguards purposes. A review article. Cairo: s.n. 2005.

KIPS, R. et al. Characterization of Uranium Particles Produced by Hydrolysis of UF6 Using SEM and SIMS. Microscopy and Microanalysis, 13, p.156-164, 2007.

KIPS, R. et al. Determination of fluorine in uranium oxyfluoride particles as an indicator of particle age. Spectrochimica Acta, Part B, 64, p.199-207, 2009.

KORKISCH, J. Handbook of Ion Exchange Resins: Their Application to Inorganic Analytical Chemistry. CRC Press, v.2, 1989.

KUHN, E.; FISCHER, D.; RYJINSKI, M. Environmental Sampling for IAEA Safeguards: A Five Year Review. IAEA-SM-367/10/01, 2001.

KRAIEM, M. Investigation of uranium isotopic signatures in real-life particles from a nuclear facility by thermal ionization mass spectrometry. Analytical Chemistry, 83, p.3011-3016, 2011.

KSHITIJ School - An Online Plataform for Boards. Applications Involving Charged Particles Moving in a Magnetic Field. Disponível em: <http://www.kshitijschool.com/Study-Material/Class-12/Physics/Magnetic-fields/Lorentz-force-and-massspectrometer.aspx>. Acesso em: 28/08/2013.

LEE, M. H. et al. Determination of Pu and $\mathrm{U}$ isotopes in safeguard swipe sample with extraction chromatographic techniques. Talanta, v.85, p.99-102, 2011. 
LIU, Z.; MORSY, S. Development of the physical model. IAEA-SM-367/13/07. 2007.

LLBL. Lawrence Berkeley National Laboratory. Nuclear Science - A Guide to the Nuclear Science Wall Chart. Chapter 8 The Search for "Heavy" Elements. Contemporary Physics Education Project (CPEP). 2003. Disponível em:

<http://www.lbl.gov/abc/wallchart/teachersguide/pdf/Chap08.pdf>. Acesso em: $07 / 09 / 2013$

LLOYD, N. S. et al. Precise and accurate isotopic analysis of microscopic uranium-oxide grains using LA-MC-ICP-MS. Journal of Analytical Atomic Spectrometry, 24, p.752$758,2009$.

MALISKA, A. M. Microscopia eletrônica de varredura e microanálise. Universidade Federal de Santa Catarina. Disponível em: <http://www.materiais.ufsc.br/lcm/webMEV/MEV_Apostila.pdf>. Acesso em: 02/09/2013.

MANNA, S. et al. Study of crystallization and morphology of ammonium diuranate and uranium oxide. Journal of Nuclear Materials, 424, p.94-100, 2012.

MARIN, R. C. Desenvolvimento de metodologias utilizadas na área de salvaguardas e forense nuclear baseadas na técnica LA-HR-ICP-MS. Dissertação (Mestrado) Instituto de Pesquisas Energéticas e Nucleares, São Paulo, 2013.

MAYER, K.; WALLENIUS, M. Nuclear Forensic Methods in Safeguards. Esarda Bulletin, n.38, June, 2008.

MCCLAIN, D. E. MILLER, A. C. KALINICH, J. F. Status of health concerns about military use of depleted uranium and surrogate metals in armor-penetrating munitions. NATO RTG-099, p. 21.01 - 21.20, 2005.

MEDALIA, J. Detection of nuclear weapons and materials: science, technologies, observations. Congressional Research Service, 2010.

MONTASER, A. Inductively coupled plasma mass spectrometry. Wiley. 1998. 
MORAES, B. T. F.; MOREIRA, W. C. A carta de Einstein de 1939 e o 'Projeto Manhattan'. IV congresso de Pesquisa e Inovação da Rede Norte e Nordeste de Educação Tecnológica. Belém, Pa, 2009.

MOYLAND, S. V. The IAEA's Programme '93+2'. Verification Matters. n.10, Vertic, London, 1997.

MPHPA. The Manhattan Project Heritage Preservation Association.Manhattan Project History - The Early Years (1900 - 1939) FISSION. Disponível em:

<http://www.mphpa.org/classic/HISTORY/H-02e.htm >. Acesso em: 03/09/2013.

NAU. Northern Arizona University. Disponível em:

<http://www4.nau.edu/microanalysis/Microprobe-SEM/Instrumentation.html> Acesso em: 02/09/2013.

NCRP - National Council on Radiation Protection and Measurements, Biological Effects and Exposure Limits for 'Hot Particles'. NCRP-Report 130, 1999.

NEA. Nuclear Energy Agency. Transition towards a sustainable nuclear fuel cycle. Nuclear Science, 2013.

NODE. Nederlands Onderzoeksplatform Duurzame Energievoorziening. History of Nuclear Fission. Disponível em:

<http://www.energyresearch.nl/energieopties/kernsplijting/achtergrond/historie/>. Acesso em: 03/09/2013.

OKUNO, E; YOSHIMURA, E. M. Física das radiações. Oficina de Textos. 2010.

OLIVEIRA JUNIOR, O. P. Análise multielementar e isotópica de compostos de urânio por espectrometria de massas com fonte de plasma induzido (ICPMS). Dissertação (Mestrado) - Instituto de Pesquisas Energéticas e Nucleares, São Paulo, 2000. 
OLIVEIRA JUNIOR, O. P. Preparação, caracterização e certificação de matérias de referência isotópica de urânio. Tese (Doutorado) - Instituto de Pesquisas Energéticas e Nucleares, São Paulo, 2006.

OPERAMUNDI. Hoje na história: EUA lançam o programa Átomos para a Paz. Disponível em:

<http://operamundi.uol.com.br/conteudo/noticias/2200/conteudo+opera.shtml>. Acesso em: 05/09/2013.

OUTREACHa. Positive Rays. Cavendish Laboratory. Department of Physics. University of Cambridge Disponível em http://wwwoutreach.phy.cam.ac.uk/camphy/positiverays/positiverays1_1.htm Acesso em 25/10/2013.

OUTREACHAb. Positive Rays. Cavendish Laboratory. Department of Physics, University of Cambridge Disponível em http://wwwoutreach.phy.cam.ac.uk/camphy/positiverays/positiverays7_1.htm Acesso em 25/10/2013.

PARRISHA, R. R. et al. Depleted uranium contamination by inhalation exposure and its detection after 20 years: implications for human health assessments. Science of the total environment, 390, p.58-68, 2008.

PESTANA, R. C. B. et al. New methodology for uranium analysis in swipe samples for nuclear safeguards purposes. Journal of Radioanalitical Nuclear Chemistry, DOI 10.1007/s10967-013-2467-1, v. 298. P.621-625. 2013.

POINTURIER, F. et al. Recent improvements of actinides trace analysis in environmental samples for nuclear activities detection. Symposium IAEA-CN-184/29, 2010.

RANEBO, Y. et al. Improved isotopic SIMS measurements of uranium particles for nuclear safeguard purposes. Journal of Analytical Atomic Spectroscopy, v.24, p.277$287,2009$. 
REDERMEIER, A. Fingerprinting of nuclear material for nuclear forensics. Esarda Bulletin, n.43, 2009.

RHODES, R. The making of the atomic bomb. Simon \& Schuster Paperbacks. New York: Simon \& Schuster Paperbacks, 1995.

RICHTER, B. Containment and Surveillance - Status and Perspectives. Nuclear safeguards and non-proliferation. Course Syllabus. Esarda Bulletin, 2008.

RODDEN, C. J. Analytical Chemistry of the Manhattan Project. McGraw-Hill Book Company, USA, 1950.

RODDEN, C. J. Analysis of essencial nuclear reactor material. New Brunswick Laboratory. U.S. Atomic Energy Commission. 1964.

ROSA, D, S. Caracterização química, física e isotópica de U3Si2 para fins forenses nucleares. Dissertação (Mestrado) - Instituto de Pesquisas Energéticas e Nucleares, São Paulo, 2011.

ROWLEY, L. K. Fundamental Studies of Interferences in ICP-MS. Tese (Doutorado) University of Plymounth. Inglaterra, 2000.

RUCKER, T. L.; JOHNSON JR. C. M. Relationship between isotopic uranium activities and total uranium at various uranium enrichments. Journal of Radioanalytical and Nuclear Chemistry, v. 235, n.1, p.47-52, 1998.

SALIBA-SILVA, A. M. et al. Fabrication of U3Si2 Powder for Fuels used in IEA-R1 Nuclear Research Reactor. Materials Science Forum. vol. 591-593. p. 194-199. 2008.

SALIBA-SILVA, A. M. et al. Research reactor fuel fabrication to produce radiosotopes. Radioisotopes - Application in Physical Sciences. Chapter 2. DOI: 10.5772/858. 2011. 
SARKIS, J. E. S. Espectrometria de massas. In: BRANCO, R. P. O. et al. Química forense sob olhares eletrônicos. Millennium Editora, 2005, p.43-72.

SCHMITZ, A. Introductory Chemistry. Nuclear Chemistry. Chapter 15. Book Archive v. 1.0. 2012. Disponível em: <http://2012books.lardbucket.org/books/general-chemistryprinciples-patterns-and-applications-v1.0/section_24_02.html>. Acesso em: 09/08/2013.

SCHRIEFER, D. New safeguards measures: initial implementation and experience. AIEA Bulletin, n.4, 1996.

SHARMA, K. S. Mass spectrometry-The early years. International Journal of Mass Spectrometry. p. 349-350. 2003.

SHEN, Y. et al. Study on analysis of isotopic ratio of uranium-bearing particle in swipe samples by FT-TIMS. Radiation Measurements, 43, p.S299-S302, 2008.

SKOOG, D. A. et al. Fundamentos de Química Analítica. Tradução da $8^{\text {a }}$ edição norteamericana. São Paulo: Ed. Thomson, 2006.

SILVA, J.E.R. Especificação do pó de U3Si2 para placa combustível do reator IEA-R1. ESPT 001.R01. 1998.

STEBELKOV, V. et. al. Occurrence of particles with morphology characteristics which are typical for certain kinds of nuclear activity. Symposium - IAEA-CN-184/82, 2010 .

STURM, M. Destructive analysis: effective analytical support to nuclear safeguards and non-proliferation. Esarda Bulletin, n.45, p.56-65, 2010.

SUZUKI, D. et al. A new method for isotope ratio measurement of uranium in trace amount by thermal ionization mass spectrometry: The continuous heating method. International Journal of Mass Spectrometry, 295, p.23-27, 2010. 
SZÉLES, E.; VARGA, Z.; STEFÁNKA, Z. Sample preparation method for analysis of swipe samples by inductively coupled plasma mass spectrometry. Journal of Analytical Atomic Spectrometry, v.25, p.1014-1018, 2010.

TAMBORINI, G. et al. Application of secondary ion mass spectrometry to the identification of single particles of uranium and their isotopic measurement. Spectrochimica Acta Part B, 53, p.1289-1302, 1998.

THINKQUEST. Oracle Education Foundation. Nuclear Fission. Disponível em: <http://library.thinkquest.org/3471/fission.html>. Acesso em: 03/09/2013.

THOMAS, R. Practical Guide to ICP-MS. Marcel Dekker, INC. New York, 2004.

TERREMOTO, L. A. A. Fundamentos de tecnologia nuclear reatores. Disciplina TNR5764. Divisão de Ensino - Secretaria de Pós-Graduação. Instituto de Pesquisas Energéticas e Nucleares IPEN/CNEN-SP, 2004.

UNSCEAR. The United Nations Scientific Committee on the Effects of Atomic Radiation. Report to the general Assembly, v.1 - Sources and Effects of Ionizing Radiation, 2000.

UFSM. Grupo de Ensino de Física da Universidade Federal de Santa Maria. Fissão Nuclear. Disponível em: <http://www.ufsm.br/gef/Nuclear/nuclear12.pdf>. Acesso em: 12/01/2013.

USNRC. United States Nuclear Regulatory Commission. Uranium Enrichment. Disponível em: <http://www.nrc.gov/materials/fuel-cycle-fac/ur-enrichment.html>. Acesso em: 06/02/2013.

ULRICH, J. C. Determinação de impurezas em compostos de urânio por meio da técnica de espectrometria de massas de alta resolução com fonte de plasma indutivo (HR-ICPMS). Dissertação (Mestrado) - Instituto de Pesquisas Energéticas e Nucleares, São Paulo, 2001. 
VEGA-BUSTILlOS, O. et al. A Espectrometria de Massas Quadrupolar. São Paulo. Editora Scor Tecci. 2003

VIM. Vocabulário Internacional de Metrologia: conceitos fundamentais e gerais e termos associados. INMETRO, 2012.

VOGT, S.; ZAHRADNIK, P.; KLOSE, D.; SWIETLY, H. Bulk analysis of environmental swipe samples. AIEA-SM-367/10/06. 2006.

WHO. Depleted uranium, sources, exposure and health effects, Department of protection of the human environment. Geneva: World Health Organization, 2001.

WILliamS, R. W. et al. Purification of $\mathbf{U}$ and Pu from Bulk Environmental Samples for Analysis by MC-ICPMS. Lawrence Livermore National Laboratory. UCRL-TR210135. 2005.

WILSON, P. D. The nuclear fuel cycle. From ore to wastes. Oxford University Press, 1996.

WOLF, R. E. What is ICP-MS?...and more importantly, what can it do? Crustal Geophysics and Geochemistry Science Center USGS, March 2005. Disponível em http://crustal.usgs.gov/laboratories/icpms/What_is_ICPMS.pdf Acesso em 24/10/2013

WONG, P. COOKS, R. G. Ion Trap Mass Spectrometry. Disponível em: http://www.currentseparations.com/issues/16-3/cs16-3c.pdf Acessado em 23/10/2013.

ZHANG, X. Z. et al. Application of inductively coupled plasma mass spectrometry to the determination of uranium isotope ratios in individual particles for nuclear safeguards. Spectrochimica Acta Part B, 62, p.1130-1134, 2007. 